

\section{Preventing intimate partner and sexual violence against women \\ Taking action and generating evidence}




\section{WHO Library Cataloguing-in-Publication Data:}

Preventing intimate partner and sexual violence against women: taking action and generating evidence / World Health Organization and London School of Hygiene and Tropical Medicine.

1.Spouse abuse - prevention and control. 2.Violence - prevention and control. 3.Sexual partners. 4.Risk assessment. 5.Battered women. 6.Sex offenses - prevention and control. I.World Health Organization.

ISBN 9789241564007

(NLM classification: HV 6625)

Suggested citation: World Health Organization/London School of Hygiene and Tropical Medicine. Preventing intimate partner and sexual violence against women: taking action and generating evidence. Geneva, World Health Organization, 2010.

\section{(c) World Health Organization 2010}

All rights reserved.

Publications of the World Health Organization can be obtained from WHO Press, World Health Organization, 20 Avenue Appia, 1211 Geneva 27, Switzerland (tel.: +41 22791 3264; fax: +41 22791 4857; e-mail: bookorders@who.int). Requests for permission to reproduce or translate WHO publications - whether for sale or for noncommercial distribution - should be addressed to WHO Press, at the above address (fax:+41227914806; e-mail: permissions@who.int).

The designations employed and the presentation of the material in this publication do not imply the expression of any opinion whatsoever on the part of the World Health Organization concerning the legal status of any country, territory, city or area or of its authorities, or concerning the delimitation of its frontiers or boundaries. Dotted lines on maps represent approximate border lines for which there may not yet be full agreement.

The mention of specific companies or of certain manufacturers' products does not imply that they are endorsed or recommended by the World Health Organization in preference to others of a similar nature that are not mentioned. Errors and omissions excepted, the names of proprietary products are distinguished by initial capital letters.

All reasonable precautions have been taken by the World Health Organization to verify the information contained in this publication. However, the published material is being distributed without warranty of any kind, either expressed or implied. The responsibility for the interpretation and use of the material lies with the reader. In no event shall the World Health Organization be liable for damages arising from its use.

The named authors alone are responsible for the views expressed in this publication.

Designed by minimum graphics.

Printed in Belgium 


\section{Contents}

Acknowledgements $\quad \mathrm{V}$

Executive summary

Foreword 3

Introduction $\quad \mathbf{5}$

The hidden costs of intimate partner and sexual violence 5

A public health approach to prevention $\quad 6$

A life-course perspective 8

What is the purpose of this document? 8

Who should use this document? 9

Key messages $\quad 10$

Chapter 1 The nature, magnitude and consequences of intimate partner
and sexual violence

1.1 What are intimate partner and sexual violence? 11

1.2 How prevalent are intimate partner and sexual violence? 12

1.3 What are the consequences of intimate partner and sexual violence? 15

$\begin{array}{ll}1.4 \text { Key messages } & 17\end{array}$

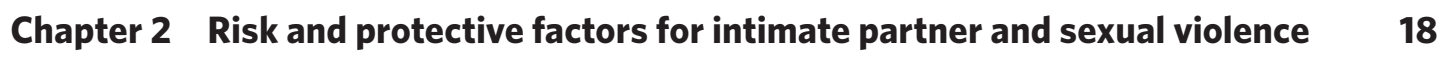

2.1 The ecological model of violence 18

2.2 Identifying risk factors 19

2.3 Risk factors associated with both intimate partner violence

2.4 Risk factors associated with intimate partner violence 26

2.5 Risk factors associated with sexual violence 29

2.6 Protective factors for intimate partner violence and sexual violence 31

$\begin{array}{ll}2.7 \text { Gender norms and inequality } & 31\end{array}$

2.8 Key messages $\quad 32$ 
Chapter 3 Primary prevention strategies - the evidence base

3.1 Introduction 34

3.2 Assessing the evidence for different prevention approaches 36

3.3 Summary tables of primary prevention strategies and programmes 38

3.4 During infancy, childhood and early adolescence 41

3.5 During adolescence and early adulthood 44

3.6 During adulthood 47

3.7 All life stages 51

$\begin{array}{ll}3.8 \text { Key messages } & 57\end{array}$

Chapter 4 Improving programme planning and evaluation 58

4.1 Step 1: Getting started 58

4.2 Step 2: Define and describe the nature of the problem 62

4.3 Step 3: Identify potentially effective programmes 66

4.4 Step 4: Develop policies and strategies 67

4.5 Step 5: Create an action plan to ensure delivery 68

4.6 Step 6: Evaluate and share learning $\quad 70$

$\begin{array}{ll}4.7 \text { Key messages } & 75\end{array}$

$\begin{array}{ll}\text { Future research priorities and conclusions } & \mathbf{7 6}\end{array}$

$\begin{array}{ll}\text { Future research priorities } & 76\end{array}$

$\begin{array}{ll}\text { Conclusions } & 77\end{array}$

$\begin{array}{ll}\text { References } & 79\end{array}$

Annexes

$\begin{array}{ll}\text { Annex A: Operational definitions } & 91\end{array}$

Annex B: Prevention activities that can be used for process

evaluation and potential sources of information on such activities 


\section{Acknowledgements}

This document was written by Alexander Butchart, Claudia Garcia-Moreno, and Christopher Mikton of the World Health Organization, and builds on an early draft produced by Joanna Nurse of the London School of Hygiene and Tropical Medicine and the United Kingdom Department of Health, and Damian Basher of the United Kingdom Department of Health. Natalia Diaz-Granados of McMaster University drafted Chapter 2: Risk and protective factors for intimate partner and sexual violence, while Joanne Klevens and Linda Anne Valle of the United States Centers for Disease Control and Prevention contributed to Chapter 4: Improving programme planning and evaluation. The document was edited by Tony Waddell.

The document has also benefited greatly from comments and suggestions provided by the following peer reviewers: Linda Dahlberg, Kathryn Graham, Rachel Jewkes, Holly Johnson, Julia Kim, Karen Lang, Charlotte Watts and Alys Willman.

The conceptual foundations for this document were outlined in a May 2007 expert consultation on the primary prevention of intimate partner and sexual violence and the background paper for the meeting prepared by Alison Harvey, Claudia Garcia-Moreno and Alexander Butchart. Consultation participants included: Mark Bellis, Pimpawun Boonmongkon, David Brown, Carme Clavel-Arcas, Jane Cottingham, Pamela Cox, Isabelle De Zoysa, Jane Ferguson, Vangie Foshee, Kathryn Graham, Henrica Jansen, Holly Johnson, Faith Kasiva, Jackson Katz, Karen Lang, Lori Michau, Adepeju Aderemi Olukoya, Judith Ann Polsky, Jamela Saleh Al-Raiby, Susan Blair Timberlake, Bernice Van Bronkhorst and Charlotte Watts.

The development and publication of this document has been made possible by the generous financial support of the Government of Belgium and the United States Centers for Disease Control and Prevention. 



\section{Executive summary}

Intimate partner and sexual violence affect a large proportion of the population - with the majority of those directly experiencing such violence being women and the majority perpetrating it being men. The harm they cause can last a lifetime and span generations, with serious adverse affects on health, education and employment. The primary prevention of these types of violence will therefore save lives and money - investments made now to stop intimate partner and sexual violence before they occur will protect the physical, mental and economic well-being and development of individuals, families, communities and whole societies.

This document aims to provide sufficient information for policy-makers and planners to develop data-driven and evidence-based programmes for preventing intimate partner and sexual violence against women and is divided into the following chapters:

- Chapter 1 outlines the nature, magnitude and consequences of intimate partner and sexual violence within the broader typology of violence.

- Chapter 2 identifies the risk and protective factors for such violence and the importance of addressing both risk and protective factors in prevention efforts.

- Chapter 3 summarizes the scientific evidence base for primary prevention strategies, and describes programmes of known effectiveness, those supported by emerging evidence and those that could potentially be effective but have yet to be sufficiently evaluated for their impact.

- Chapter 4 presents a six-step framework for taking action, generating evidence and sharing results.

In the closing section, several future research priorities are outlined and a number of key conclusions drawn.

The evidence-based prevention of intimate partner and sexual violence is still in its early days and much remains to be accomplished. At present, only one strategy has evidence supporting its effectiveness - and this only relates to intimate partner violence. The strategy in question is the use of school-based programmes to prevent violence within dating relationships. Evidence is, however, emerging of the effectiveness of a number of other strategies for preventing intimate partner and sexual violence, including microfinance programmes for women combined with gender-equality education; efforts to reduce access to and harmful use of alcohol; and changing social and cultural gender norms. Many more strategies appear to have potential, either on theoretical grounds or because they target known risk factors, but most of these have never been systematically implemented - let alone evaluated. 
The public health approach to prevention taken in this document is intended to complement criminal justice-based approaches. The approach relies upon the use of population-based data to describe the problem, its impact and associated risk and protective factors, while drawing upon the scientific evidence for effective, promising and theoretically indicated prevention strategies. Part of the approach is also to ensure that all policies and programmes include in-built monitoring and evaluation mechanisms. At the same time, taking a life-course perspective will help to identify early risk factors and the best times to disrupt the developmental trajectories towards violent behaviour using a primary prevention approach. For successful primary prevention, early intervention is required that focuses on younger age groups.

Although pressing, the need for evidence and further research in all these areas in no way precludes taking action now to prevent both intimate partner violence and sexual violence. Those programmes that have evidence supporting their effectiveness should be implemented and, where necessary, adapted. Those that have shown promise or appear to have potential can also play an immediate role - provided strenuous efforts are made to incorporate at the outset rigorous outcome evaluations. It is only by taking action and generating evidence that intimate partner and sexual violence will be prevented and the field of evidence-based primary prevention of such violence will successfully mature. 


\section{Foreword}

Intimate partner violence and sexual violence are serious and widespread problems worldwide. Apart from being violations of human rights, they profoundly damage the physical, sexual, reproductive, emotional, mental and social well-being of individuals and families. The immediate and long-term health outcomes that have been linked to these types of violence include physical injury, unwanted pregnancy, abortion, gynaecological complications, sexually transmitted infections (including HIV/AIDS), posttraumatic stress disorder and depression, among others. There are also a number of pregnancy-related complications such as miscarriage, premature labour and low birth weight associated with violence during pregnancy. In addition, high-risk behaviours such as smoking, harmful use of alcohol and drugs and unsafe sex are significantly more frequent among victims of intimate partner and sexual violence.

The overwhelming burden of intimate partner violence (physical, sexual and emotional) and of sexual violence is borne by women at the hands of men. In acknowledging the large scale and extensive consequences of the problem, scores of countries have passed laws to criminalize intimate partner and sexual violence, and many countries are increasingly providing legal, health and social services to abused women. At the same time, there have been remarkably few efforts to prevent intimate partner or sexual violence from occurring in the first place. Well-designed and properly implemented services for victims will continue to be vitally important. However the sheer magnitude of the problem means that preventing intimate partner and sexual violence before it occurs will be crucial not only in reducing the burden of suffering but also in reducing the long-term human, economic and public health costs of such violence. Both primary prevention efforts and responding services need to be well documented and evaluated for their effectiveness.

The current paucity of evidence-based prevention approaches is partly due to the separate development and implementation of research and advocacy activities in this area. It is also due in part to the complex array of factors that increase the likelihood of such violence occurring in the first place. These factors include gender inequality and social norms around masculinity, and other social determinants such as economic inequality; other problem behaviours (such as harmful use of alcohol); and other types of violence (such as child maltreatment). There is little coordination between programmes or research agendas on child maltreatment, alcohol and substance misuse, social determinants, and intimate partner and sexual violence. And yet all of these problems regularly affect families, predictably with greater frequency in economically disadvantaged communities where there is often also greater inequality between women and men. 
Preventing intimate partner and sexual violence against women: taking action and generating evidence aims to strengthen the field of intimate partner and sexual violence prevention so that prevention efforts can complement health, legal and other service-delivery programmes that respond to the problem. Primary prevention policies and programmes should be proactive, informed by the best available research evidence and focus on the root causes of the problem, including gender inequality, so that fewer women are affected by such violence in the first place.

This document is also built around a life-course perspective that recognizes how infant and early childhood experiences influence the likelihood of later becoming a perpetrator or victim of intimate partner and sexual violence. A review is provided of the latest available scientific findings on effective, promising and theoretically feasible prevention strategies, and a public health model used to highlight the steps needed to address the underlying determinants at the individual, family, community and societal level. Importantly, it is also strongly urged that future efforts to address intimate partner and sexual violence are designed and conducted with the explicit aim of expanding the scientific evidence base on the magnitude, consequences and preventability of these problems. This can be achieved for example by integrating outcome evaluations into prevention projects from the very start.

Reflecting the global importance of preventing intimate partner and sexual violence, this document is a joint publication of the World Health Organization and the London School of Hygiene and Tropical Medicine. Please join us in acting to increase the number, quality and effectiveness of intimate partner and sexual violence prevention programmes in all of the world's societies. This will contribute to a significant improvement in the personal safety, well-being and happiness of girls, boys, women and men everywhere.

\section{Etienne Krug}

Director, WHO Department of Violence and Injury Prevention and Disability

\section{Michael Mbizvo}

Director (ad interim), WHO Department of Reproductive Health and Research 


\section{Introduction}

\section{The hidden costs of intimate partner and sexual violence}

Because of their nature, the occurrence and impacts of intimate partner and sexual violence are frequently "hidden" resulting in a significant underestimation of the real level of harm caused. However, population-based surveys reveal that these forms of violence are common. For example, the WHO Multi-country study on women's health and domestic violence against women (Garcia-Moreno et al., 2005) indicated that $15-71 \%$ of women experience physical and/or sexual violence by an intimate partner at some point in their lives. Research also shows that intimate partner and sexual violence lead to a wide range of short- and long-term physical, mental and sexual health problems (Heise \& GarciaMoreno, 2002; Jewkes, Sen \& Garcia-Moreno, 2002). In fact, the magnitude of poor health outcomes due to intimate partner and sexual violence are comparable to (and in some cases exceed) those associated with many other better-known health risk factors. For example, a study using burden of disease methodology in Victoria, Australia estimated that among women 18-44 years of age, intimate partner violence was associated with $7 \%$ of the overall burden of disease. Such violence was a larger risk factor than others traditionally included, such as raised blood pressure, tobacco use and increased body weight (Vos et al., 2006).

Intimate partner violence also very often has severe negative impacts on the emotional and social well-being of the whole family, with adverse effects on parenting skills and on educational and employment outcomes. Some children from households where there is intimate partner violence may exhibit increased rates of behavioural and emotional problems that can result in increased difficulties with education and employment, often leading to early school drop out, youth offending and early pregnancy (Anda et al., 2001; Dube et al., 2002).

Intimate partner violence also has a significant adverse economic impact. For example, in the United Kingdom, one analysis estimated that its annual cost to the economy in England and Wales was approximately $£ 22.9$ billion (Walby, 2004). Another study in the United States of America (Arias \& Corso, 2005) looked at sex differences in the use of services to treat injuries caused by physical violence from a partner. Compared to men:

- women were more likely to report physical intimate partner violence and resulting injuries;

- a larger proportion of women reported seeking mental health services in response to experiencing physical intimate partner violence, and reported more visits on average; 
- women were more likely to report the use of emergency department, inpatient hospital and physician services; and

- women were more likely to take time off from work and from childcare or household duties because of their injuries.

In addition, the average cost per person for women experiencing at least one occurrence of physical intimate partner violence was more than twice that for men. When the costs of individuals not reaching their full productive potential are factored in, the overall costs to society will be even greater.

\section{A public health approach to prevention}

Different - but overlapping and largely complementary - approaches and perspectives have been adopted to understand intimate partner and sexual violence. For instance, the gender perspective emphasizes patriarchy, power relations and hierarchical constructions of masculinity and femininity as a predominant and pervasive driver of the problem. These are predicated on control of women and result in structural gender inequality.

The human rights approach is based on the obligations of states to respect, protect and fulfil human rights and therefore to prevent, eradicate and punish violence against women and girls. It recognizes violence against women as a violation of many human rights: the rights to life, liberty, autonomy and security of the person; the rights to equality and non-discrimination; the rights to be free from torture and cruel, inhuman and degrading treatment or punishment; the right to privacy; and the right to the highest attainable standard of health. These human rights are enshrined in international and regional treaties and national constitutions and laws, which stipulate the obligations of states, and include mechanisms to hold states accountable. The Convention on the Elimination of All Forms of Discrimination against Women (CEDAW), for example, requires that countries party to the Convention take all appropriate steps to end violence against women, as does the Inter-American Convention on the Prevention, Punishment and Eradication of Violence against Women (Convention of Belem do Para, 1994), the only regional convention to specifically address such violence.

The criminal justice approach sees its main task as responding to intimate partner and sexual violence after it has occurred by enforcing the law and ensuring that "justice is done". This involves properly identifying perpetrators of intimate partner and sexual violence, ascertaining their guilt and ensuring that they are appropriately sentenced. To prevent and respond to intimate partner and sexual violence the criminal justice approach relies primarily on deterrence, incarceration and the punishment and rehabilitation of perpetrators.

The public health approach ${ }^{1}$ adopted by this document draws on these other approaches and perspectives, particularly the gender perspective. As described in the World report on violence and health (Krug et al., 2002), the public health approach is a science-driven, population-based, interdisciplinary, intersectoral approach based on the ecological model which emphasizes primary prevention.

\footnotetext{
Public health is "the science and art of preventing disease, prolonging life and promoting health through the organized efforts and informed choices of society, organizations, public and private, communities and individuals" (Winslow, 1920).
} 
Rather than focusing on individuals, the public health approach aims to provide the maximum benefit for the largest number of people, and to extend better care and safety to entire populations. The public health approach is interdisciplinary, drawing upon knowledge from many disciplines including medicine, epidemiology, sociology, psychology, criminology, education and economics. Because intimate partner and sexual violence are multi-faceted problems, the public health approach to these forms of violence emphasizes a multi-sectoral response. It has been proved time and again that cooperative efforts from such diverse sectors as health, education, social welfare, and criminal justice are often necessary to solve what are usually assumed to be purely "criminal" or "medical" problems. The public health approach considers that violence, rather than being the result of any single factor, is the outcome of multiple risk factors and causes, interacting at four levels of a nested hierarchy (individual, close relationship/family, community and wider society).

From a public health perspective, prevention strategies can be classified into three types (Dahlberg \& Krug, 2002):

- Primary prevention - approaches that aim to prevent violence before it occurs.

- Secondary prevention - approaches that focus on the more immediate responses to violence, such as pre-hospital care, emergency services or treatment for sexually transmitted infections following a rape.

- Tertiary prevention - approaches that focus on long-term care in the wake of violence, such as rehabilitation and reintegration, and attempt to lessen trauma or reduce long-term disability associated with violence.

A public health approach emphasizes the primary prevention of intimate partner and sexual violence, i.e. stopping them from occurring in the first place. Until recently, this approach has been relatively neglected in the field, with the majority of resources directed towards secondary or tertiary prevention. Perhaps the most critical element of a public health approach to prevention is the ability to identify underlying causes rather than focusing upon more visible "symptoms". This allows for the development and testing of effective approaches to address the underlying causes and so improve health.

The public health approach is an evidence-based and systematic process involving the following four steps:

1. Defining the problem conceptually and numerically, using statistics that accurately describe the nature and scale of violence, the characteristics of those most affected, the geographical distribution of incidents, and the consequences of exposure to such violence (Chapter $\mathbf{1}$ ).

2. Investigating why the problem occurs by determining its causes and correlates, the factors that increase or decrease the risk of its occurrence (risk and protective factors) and the factors that might be modifiable through intervention (Chapter 2).

3. Exploring ways to prevent the problem by using the above information and designing, monitoring and rigorously assessing the effectiveness of programmes through outcome evaluations (Chapters 3, 4).

4. Disseminating information on the effectiveness of programmes and increasing the scale of proven effective programmes. Approaches to prevent intimate partner and sexual violence, whether targeted at individuals or entire communities, must be 
properly evaluated for their effectiveness and the results shared (section 4.6). This step also includes adapting programmes to local contexts and subjecting them to rigorous re-evaluation to ensure their effectiveness in the new setting.

\section{A life-course perspective}

This document views the causes, consequences and prevention of intimate partner and sexual violence within a life-course perspective based upon understanding how influences early in life can act as risk factors for health-related behaviours or health problems at later stages (Davey Smith, 2000). For the purpose of understanding and preventing intimate partner and sexual violence, the life course is divided into: infancy ( $0-4$ years), childhood and early adolescence (5-14 years); adolescence and young adulthood (15-25 years); adulthood (26 years and over); and all ages. Each of these life stages represents a special phase in the development of risk and a unique opportunity to target developmentally specific risk factors. Adopting such a life-course perspective therefore helps to both identify early risk factors and the best times to intervene using a primary prevention approach.

\section{What is the purpose of this document?}

This document provides a planning framework for developing policies and programmes for the prevention of intimate partner and sexual violence. Drawing upon sound public health principles, and supported by available evidence on risk factors for such violence and on the effectiveness of prevention programmes, it outlines how prevention strategies tailored to the needs, capacities and resources of particular settings can be developed. The document emphasizes the importance of integrating scientific evaluation procedures into all prevention initiatives to continuously monitor and improve their effectiveness, and to inform and expand the global evidence base in this area.

At present, the bulk of the limited human and financial resources expended in the area of intimate partner and sexual violence are devoted to the treatment, management and support of victims (who often do not seek out services until they are older) and the arrest and incarceration of perpetrators. Drawing lessons from a public health perspective means however that a similarly strong emphasis should now be placed upon the primary prevention of intimate partner and sexual violence. The principal focus of this document is therefore on the use of a public health approach to preventing intimate partner and sexual violence before it even occurs as this has the potential to:

- enhance the health, well-being and productivity of individuals, communities and societies;

- help reduce gender-based inequities, in so far as intimate partner and sexual violence - or the threat of them - contribute to maintaining such inequities;

- reduce the antisocial behaviour, offending and other forms of interpersonal violence that can result from witnessing intimate partner violence as a child; and

- reduce the direct and indirect economic and social costs and consequences associated with these forms of violence. 
Given - as indicated above - that the overwhelming burden of intimate partner and sexual violence is borne by women at the hands of men, this document focuses on intimate partner and sexual violence against women. Despite findings (mainly from the United States), based on self-reports, that men and women perpetrate intimate partner violence at approximately the same rate (Archer, 2000, 2006; Currie, 1998; Strauss, 1998, 2009), women are over-represented in terms of deaths and severe injuries due to intimate partner and sexual violence, and in emergency room and clinical populations (Anderson, 2005; Archer 2000, 2006; Straus 1999, 2009). The findings of sex symmetry primarily concern the less-severe forms of physical intimate partner violence and appear to apply mainly to high-income western countries (Archer, 2006). Furthermore, most of the currently available evidence on intimate partner and sexual violence comes from studies of how they affect women. Finally, the scope of this document does not include the significant differences that exist in the nature of, and risk factors and specific prevention strategies for, intimate partner and sexual violence perpetrated by women and male-to-male sexual violence.

Evidence on the nature of intimate partner and sexual violence and the effectiveness of prevention efforts has wherever possible been selected only from higher-quality studies - for example, from systematic reviews and large studies with good methodologies such as the use of randomized-controlled trials. However, most of the high-quality research studies come from the United States and the evidence of effectiveness may not always be directly transferable to a low-income setting. The evidence reviewed also includes examples of promising practice from low- and middle-income countries (LMIC).

\section{Who should use this document?}

This document is primarily aimed at policy-makers, programme developers and planners and funding bodies in public health and related sectors that aim to advance the prevention of intimate partner and sexual violence against women. Although public health practitioners are a key target audience, the document assumes no previous knowledge of public health principles. In addition to the principal audience, other interested parties will include:

- those working in other government sectors such as education, child welfare, social care, criminal justice and departments of women or gender equality;

- advocates for the prevention of intimate partner and sexual violence, for example, from nongovernmental organizations;

- local authorities;

- environmental and urban planners; and

- researchers.

It is intended that practitioners and other professionals working in these sectors will find this document a useful source of information on state-of-the-science efforts to enhance and strengthen multisectoral collaboration in the design, delivery and evaluation of programmes for the primary prevention of intimate partner and sexual violence. 


\section{Key messages}

Intimate partner and sexual violence may affect everyone - though there is a strong gender pattern with the majority of those experiencing it being women and the majority perpetrating it being men; everyone can help to prevent it and can work together to stop the continuation of violence across generations.

The harm caused by such violence can last a lifetime and span generations, with serious adverse affects on health, education, employment, crime and on the economic well-being of individuals, families, communities and societies.

The primary prevention of intimate partner and sexual violence is likely to save lives and money - investment to stop intimate partner and sexual violence before they occur is crucial as this will protect and promote the well-being and development of individuals, families, communities and societies.

This document takes a public health approach that draws on gender, human rights and criminal justice perspectives on prevention. The approach is based upon the use of population-based data to describe the problem, its impact, and its risk and protective factors, and draws upon the scientific evidence for proven, promising and theoretically indicated prevention strategies, while urging that all policies and programmes include in-built monitoring and evaluation mechanisms.

Taking a life-course perspective helps to identify early risk factors and the best times to intervene using a primary prevention approach. For successful primary prevention, early intervention is required that focuses on younger age groups.

Using evidence of what has already worked will increase the likelihood that prevention efforts are successful.

Incorporating outcome evaluations into primary prevention interventions is crucial in generating further evidence. 


\section{CHAPTER 1}

\section{The nature, magnitude and consequences of intimate partner and sexual violence}

\subsection{What are intimate partner and sexual violence?}

This document adopts the definitions of intimate partner violence and sexual violence from the World report on violence and health (Heise \& Garcia-Moreno, 2002; Jewkes, Sen \& Garcia-Moreno, 2002). These definitions (Box 1) are now widely used and provide a useful conceptual framework. However, they need to be operationalized for the purposes of monitoring progress and demonstrating how the magnitude of the problem changes in response to specific prevention efforts. For more information on the use of operational definitions see Annex A.

\section{BOX 1}

\section{Definition of terms}

- Intimate partner violence - behaviour within an intimate relationship that causes physical, sexual or psychological harm, including acts of physical aggression, sexual coercion, psychological abuse and controlling behaviours.

This definition covers violence by both current and former spouses and partners.

- Sexual violence - any sexual act, attempt to obtain a sexual act, unwanted sexual comments or advances, or acts to traffic, or otherwise directed against a person's sexuality using coercion, by any person regardless of their relationship to the victim, in any setting including but not limited to home and work.

This definition includes rape, defined as the physically forced or otherwise coerced penetration of the vulva or anus with a penis, other body part or object - however the legal definition of rape may vary in different countries.

Source: Heise \& Garcia-Moreno (2002); Jewkes, Sen \& Garcia-Moreno (2002)

Intimate partner violence occurs mainly from adolescence and early adulthood onwards, most often in the context of marriage or cohabitation, and usually includes physical, sexual and emotional abuse as well as controlling behaviours. Sexual violence can occur at any age - including during childhood - and can be perpetrated by parents, caregivers, acquaintances and strangers, as well as intimate partners. Both forms of violence are in the majority perpetrated by men against girls and women; however the sexual abuse of male children is also common. Intimate partner violence may also be perpetrated by women against men and can occur in the context of same-sex relationships. 
In preventing intimate partner and sexual violence from occurring in the first place, it is important to keep in mind how such violence is related to other forms of interpersonal, self-directed and collective violence. For example, experiencing child maltreatment ${ }^{1}-$ in particular physical, sexual and emotional abuse by parents and caregivers - increases the likelihood during adolescence and adulthood of both intimate partner and sexual violence. Preventing child maltreatment can therefore help prevent both forms of violence - an association highlighted in Chapter $\mathbf{3}$ as part of the review of evidence-based prevention efforts. However, for more detail on the prevalence, consequences and causes of child maltreatment (0-14 years) and on how to prevent it see: Preventing child maltreatment: a guide to taking action and generating evidence (WHO-ISPCAN, 2006). ${ }^{2}$

In addition, different forms of violence have common underlying risk factors, which include certain social and cultural norms, social isolation, the harmful use of alcohol and income inequality. Prevention efforts that address these common factors thus have the potential to decrease the occurrence of multiple forms of violence.

\subsection{How prevalent are intimate partner and sexual violence?}

The prevalence of intimate partner violence and sexual violence can be measured with reference to both victimization and perpetration. Owing to the small proportion of cases recorded in routinely collected statistics from victim care facilities and the police, both victimization and perpetration are most accurately measured through populationbased surveys that count self-reports (Chapter $\mathbf{4}$ of this document discusses data collection in more detail). To date, few population-based surveys outside North America have measured the perpetration of intimate partner violence and sexual violence (but see Jewkes et al. 2009; Philpart et al., 2009), and the comparability of their findings is unclear. Furthermore, low disclosure rates may compromise the findings of populationbased perpetration surveys. This chapter thus focuses on victimization findings, which are more internationally available, more readily comparable and probably less subject to low disclosure rates.

The WHO Multi-country study on women's health and domestic violence against women (Garcia-Moreno et al., 2005) provides a comprehensive picture of the patterns of intimate partner violence and sexual violence victimization in low- and middle-income settings. Over 24000 women between the ages of 15 and 49 were interviewed in rural and urban areas in 10 countries. Its key findings include:

- between 1 and $21 \%$ of those interviewed reported experiencing child sexual abuse under the age of 15 years;

- physical abuse by a partner at some point in life up to 49 years of age was reported by $13-61 \%$ of interviewees across all study sites;

- sexual violence by a partner at some point in life up to 49 years of age was reported by $6-59 \%$ of interviewees; and

\footnotetext{
Child maltreatment - refers to the physical and emotional mistreatment, sexual abuse, neglect and negligent treatment of children, as well as to their commercial or other exploitation. It occurs in many different settings. The perpetrators of child maltreatment may be parents and other family members; caregivers; friends; acquaintances; strangers; others in authority - such as teachers, soldiers, police officers and clergy; employers; health care workers; and other children (WHO-ISPCAN, 2006).

2 To obtain this guide, please visit: www.who.int/violence_injury_prevention/violence/activities/child_ maltreatment/en/index.html
} 
- sexual violence by a non-partner any time after 15 and up to 49 years of age was reported by $0.3-11.5 \%$ of interviewees.

Table 1 summarizes the reported prevalence rates of physical and sexual violence against women in the study countries. These findings indicate that physical and sexual violence frequently co-occur within the context of intimate partner relationships, and highlight the differences in prevalence both between and within different countries. The rates of physical and/or sexual violence by an intimate partner ranged from 15\% in Japan to approximately $70 \%$ in Ethiopia and Peru, with most sites reporting rates of between 29 and $62 \%$.

TABLE 1

Physical and sexual violence against women by an intimate partner

\begin{tabular}{l|r|r|r|r|r|r}
\hline \multirow{2}{*}{ Site } & \multicolumn{2}{|c|}{ Physical violence } & \multicolumn{2}{c|}{ Sexual violence } & \multicolumn{2}{c}{$\begin{array}{c}\text { Physical or sexual violence } \\
\text { or both }\end{array}$} \\
\hline & Ever (\%) & Current (\%) & Ever (\%) & Current (\%) & Ever (\%) & Current (\%) \\
\hline Bangladesh City & 37.7 & 19.0 & 37.4 & 20.2 & 53.4 & 30.2 \\
\hline Bangladesh Province & 41.7 & 15.8 & 49.7 & 24.2 & 61.7 & 31.9 \\
\hline Brazil City & 27.2 & 8.3 & 10.1 & 2.8 & 28.9 & 9.3 \\
\hline Brazil Province & 33.8 & 12.9 & 14.3 & 5.6 & 36.9 & 14.8 \\
\hline Ethiopia Province & 48.7 & 29.0 & 58.6 & 44.4 & 70.9 & 53.7 \\
\hline Japan City & 12.9 & 3.1 & 6.2 & 1.3 & 15.4 & 3.8 \\
\hline Namibia City & 30.6 & 15.9 & 16.5 & 9.1 & 35.9 & 19.5 \\
\hline Peru City & 48.6 & 16.9 & 22.5 & 7.1 & 51.2 & 19.2 \\
\hline Peru Province & 61.0 & 24.8 & 46.7 & 22.9 & 69.0 & 34.2 \\
\hline Samoa & 40.5 & 17.9 & 19.5 & 11.5 & 46.1 & 22.4 \\
\hline Serbia \& Montenegro City & 22.8 & 3.2 & 6.3 & 1.1 & 23.7 & 3.7 \\
\hline Thailand City & 22.9 & 7.9 & 29.9 & 17.1 & 41.1 & 21.3 \\
\hline Thailand Province & 33.8 & 13.4 & 28.9 & 15.6 & 47.4 & 22.9 \\
\hline Tanzania City & 32.9 & 14.8 & 23.0 & 12.8 & 41.3 & 21.5 \\
\hline Tanzania Province & 46.7 & 18.7 & 30.7 & 18.3 & 55.9 & 29.1 \\
\hline
\end{tabular}

Source: Garcia-Moreno et al. (2005)

The study also found that reported levels of sexual violence by non-partners from the age of 15 years varied from under $1 \%$ in Ethiopia and Bangladesh (where a majority of women are married by age 15 years) to $10-12 \%$ in Peru, Samoa and urban Tanzania. In most cases only one perpetrator was mentioned, usually an acquaintance or a stranger. In South Africa, a survey of over 1300 women in three provinces found that women's first episode of rape was perpetrated in $42.5 \%$ of cases by a stranger, $20.8 \%$ by an acquaintance, $9.4 \%$ by someone from school, $8.5 \%$ by a relative, $7.5 \%$ by a partner and $11.3 \%$ by others (Jewkes et al., 1999).

Information from the United States National Violence Against Women Survey (Tjaden \& Thoennes, 2006) shows that most rape victims in the United States know their rapist. Among all female victims identified by the survey, $16.7 \%$ were raped by a stranger, and $43 \%$ of all female victims were raped by a current or former intimate partner. 


\section{Prevalence in adolescence}

In the WHO Multi-country study on women's health and domestic violence against women, $3-24 \%$ of women reported that their first sexual experience was forced, and that for a majority of respondents this occurred during adolescence (Garcia-Moreno et al., 2005). In 10 of the 15 settings investigated, over $5 \%$ of women reported that their first sexual experience was forced, with more than 14\% reporting forced first sex in Bangladesh, Ethiopia, Peru (province) and Tanzania. A Nigerian study found that $45 \%$ of females and $32 \%$ of males aged $12-21$ years reported having had forced sexual intercourse (Slap, 2003). In South Africa, a survey of over 280000 school pupils showed that up to the age of 15 years around $9 \%$ of both girls and boys reported forced sex in the past year, rising to $13 \%$ for males and $16 \%$ for females by age 19 years (CIETafrica, 2002).

Reviews of North American studies conclude that the prevalence of lifetime, past year, and current physical and sexual dating violence ${ }^{1}$ varies significantly across studies ranging from 9-49\% (Glass et al., 2003). This makes conclusions about the prevalence of teen dating violence premature (Hickman, Jaycox \& Aronoff, 2004). Internationally, population-based studies of dating violence are few but do suggest that this affects a substantial proportion of the youth population. For instance, one South African study (Swart, 2002) of 928 males and females aged $13-23$ years found that $42 \%$ of females and $38 \%$ of males reported being a victim of physical dating violence at some point in their lifetime. In Ethiopia, nearly $16 \%$ of 1378 male college students reported physically abusing an intimate partner or non-partner, and $16.9 \%$ reported perpetrating acts of sexual violence (Philpart et al., 2009).

\section{Prevalence in adulthood}

Population-based studies from various countries indicate that $10-69 \%$ of women aged 15-49 years experience physical abuse by a male intimate partner at least once in their lifetime (Heise, Ellsberg \& Gottemoeller, 1999; Heise \& Garcia-Moreno, 2002) while $6-47 \%$ of women report attempted or actual forced sex by an intimate partner in their lifetime (Jewkes, Sen \& Garcia-Moreno, 2002). The WHO Multi-country study on women's health and domestic violence against women found that between $6 \%$ and $59 \%$ of women reported experiencing sexual violence by an intimate partner in their lifetime, with the figures for most sites falling between 10\% and 50\% (Garcia-Moreno et al., 2005).

Population surveys in high-income countries (HIC) show that a significant proportion of men also report experiencing physical abuse from an intimate partner (see for example, Mirrlees-Black, 1999) although not necessarily with the same physical and emotional consequences as in women. Studies that asked for more detail about femaleto-male intimate partner violence generally found that men experienced violence less frequently, were less likely to be harmed by physical violence perpetrated by women, and did not report living in fear of their partner. Additionally, a proportion of the violence experienced by male partners may be a direct result of women attempting to defend themselves (Williams et al., 2008).

\footnotetext{
1 Dating violence refers to physical or sexual violence occurring in the context of a "dating relationship". A dating relationship is a term that frequently refers in Europe and the United States to neither a marriage nor a long-term cohabiting relationship that occurs during adolescence and young adulthood. These range from casual first encounters to longer-term sexual partnerships. In Asia and other parts of the world where marriage often takes place at a much younger age, the phenomenon of dating violence is rare and intimate partner violence begins at an earlier age.
} 
While most research has focused on intimate partner violence in heterosexual relationships, studies have shown that it also occurs in same-sex relationships. Some findings suggest that the rates of intimate partner violence in same-sex relationships are similar to those in heterosexual relationships (Shipway, 2004), while others indicate higher rates of violence in same-sex relationships. This may be due to increased levels of stress resulting from societal prejudice, and to the higher rates of alcohol and substance misuse reported in same-sex relationships. Additionally, due to the fear of discrimination, many people in violent same-sex relationships may not seek help (Shipway, 2004).

\subsection{What are the consequences of intimate partner and sexual violence?1}

Intimate partner and sexual violence have a significant impact upon individuals, families, communities and wider society. At an individual level, violence occurring during the younger years - particularly child sexual abuse - may affect that individual and their family for the rest of their lives. This can lead to negative consequences in many spheres of life, including educational and economic under-performance, unsafe sexual practices, reduced ability to bond as part of parenthood, increased uptake of health-risk behaviours (such as the harmful use of alcohol and illicit drugs) and the perpetration of intimate partner and sexual violence.

\section{Health-risk behaviours and outcomes associated with sexual violence in childhood and adolescence}

A history of sexual abuse in childhood and adolescence has consistently been found to be significantly associated with increased health risks and health-risk behaviours in both males and females (Mangioloi, 2009). Many of these have been identified as risk factors for both sexual violence victimization and perpetration in adulthood (see Chapter $\mathbf{2}$ for a full discussion of the risk and protective factors for intimate partner violence and sexual violence). For example, a meta-analysis of the prevalence of child sexual abuse and its lifetime health consequences showed that child sexual abuse contributes significantly to depression, alcohol and drug use and dependence, panic disorder, posttraumatic stress disorder and suicide attempts (Andrews et al., 2004). More recently, a study of over 20000 schoolchildren aged 13-15 years in Namibia, Swaziland, Uganda, Zambia and Zimbabwe (Brown et al., 2009) found that 23\% reported having experienced sexual violence (physically forced to have sexual intercourse) at some point in their lives. Such experiences were moderately-to-strongly associated with poor mental health, suicidal ideation, cigarette use, alcohol or drug misuse, multiple sexual partners and a history of a sexually transmitted infection.

In a national survey in Swaziland that examined the prevalence and circumstances of sexual violence against girls, some $33 \%$ of respondents reported experiencing an incident of sexual violence before they reached 18 years of age. Sexual violence was associated with significantly increased probability of reporting ever feeling depressed, thoughts of suicide, attempted suicide, unwanted pregnancy, pregnancy complications or miscarriages, sexually transmitted diseases, difficulty sleeping and alcohol consump-

\footnotetext{
1 Most studies that inform the following sections are cross-sectional, and it is difficult to be sure of the nature and direction of the interplay between intimate partner and sexual violence and their associated health-risk behaviours and outcomes. For example, increased drinking increases the risk of experiencing or perpetrating sexual violence - but at the same time, having previously experienced sexual violence potentially increases the risk of drinking.
} 
tion. Childhood sexual violence was, however, not associated with increased probability of women reporting sexual violence at 18-24 years of age (Reza et al., 2009).

Additionally, forced sexual initiation, intimate partner violence and/or sexual violence appear to increase the risk of pregnancy in early adolescence. In South Africa it was found that pregnant adolescents were over twice as likely to have a history of forced sexual initiation as non-pregnant adolescents (Jewkes et al., 2001). Similar findings in the United States have also been reported (Silverman, Raj \& Clements, 2004).

\section{Health-risk behaviours and outcomes associated with intimate partner and/or sexual violence in adulthood}

Intimate partner violence and sexual violence against women in adulthood can lead directly to serious injury, disability or death. They can also lead indirectly to a variety of health problems, such as stress-induced physiological changes, substance use and lack of fertility control and personal autonomy as is often seen in abusive relationships. Compared to their non-abused peers, abused women have higher rates of unintended pregnancies and abortions; sexually transmitted infections, including HIV; and mental disorders such as depression, anxiety, sleep and eating disorders. When this violence occurs during pregnancy, it is associated with adverse pregnancy events - such as miscarriage, pre-term births and stillbirths (Ahmed, Koenig \& Stephenson, 2006; AslingMonemi, Tabassum \& Persson, 2008; Boy \& Salihu, 2004; Campbell, 2002; Campbell et al., 2008; Dunkle et al., 2004; Plichta \& Falik, 2001; and Vos et al., 2006).

Intimate partner violence not only affects the women involved, but may also damage the health and well-being of children in the family. This is in part due to increased rates of depression and traumatic stress in the abused mothers, and the destructive effects of intimate partner violence on the quality of their attachment and parenting capacities. One review of studies examining the presence of both child maltreatment and intimate partner violence found that they occurred during the same period in $45-70 \%$ of studies (Holt, Buckley \& Whelan, 2008). In the majority of such cases, a child witnessing intimate partner violence appeared to precede the subsequent maltreatment of children by family members (McGuigan \& Pratt, 2001). Studies have shown that the children of abused mothers have lower rates of immunization and higher rates of diarrhoeal disease, and are more likely to die before the age of five years (Asling-Monemi, Tabassum \& Persson, 2008; Silverman et al., 2009).

Findings from a number of reviews show that witnessing intimate partner violence can also negatively affect the normal development of children in the family. For example, one meta-analysis concluded that children's exposure to violence between parents is significantly correlated with child problems in the areas of social, emotional, behavioural, cognitive and general health functioning (Kitzmann et al., 2003). However, not all children are similarly affected and a significant percentage of children in some review studies showed no negative developmental problems despite witnessing repeated violence (Edelson, 1999; Wolfe et al., 2003). This suggests that each child will experience adult intimate partner violence in a unique way depending upon a variety of factors. Such factors are likely to include whether there was also physical abuse of the child, the child's sex and age, the time since exposure to violence and the child's relationship with adults in the home.

Studies from several countries have found that HIV-positive women report higher rates of intimate partner violence (Dunkle et al., 2004; Maman et al., 2000) and there is increasing evidence that HIV risk is linked to lifetime exposure to violence in complex 
ways (Campbell et al., 2008). Rape is a potential cause of direct infection with HIV for some women, yet even in high-prevalence settings the low HIV transmission risk during a single sexual act makes it unlikely that rape results in a substantial proportion of population-level HIV cases. Violence and gender inequality are more likely to increase HIV risk through indirect pathways, including chronically abusive relationships where women are repeatedly exposed to the same individual, and are unable to negotiate condom use for safer sex (WHO/UNAIDS, 2010).

Qualitative research suggests that the intersections of HIV/AIDS, gender inequality and gender-based violence may involve notions of masculinity that are predicated on the control of women, and which value male strength and toughness (Jewkes \& Morrell, 2010). These ideals readily translate into sexually risky behaviours, sexual predation and other acts of violence against women as well as behaviours which increase the risk of acquiring HIV. Exposure to violence, including the controlling behaviour of a partner, is associated with high-risk sexual behaviour (such as multiple and concurrent sexual partnerships); higher number of overall partners; lower levels of condom use; increased substance use and sex while intoxicated; and increased participation in transactional sex as well as commercial sex work. Emerging evidence from India and South Africa indicates that men who perpetrate violence are more likely to be infected with HIV (Decker et al., 2009; Jewkes et al., 2009).

\subsection{Key messages}

\section{Prevalence}

- The prevalence of intimate partner violence reported by girls and women varies markedly between and within countries, with higher rates tending to occur in lower-income countries.

In some parts of the world, particularly where young people can have relationships outside of marriage, "dating violence" occurs frequently.

Sexual violence affects children of both sexes and adults, particularly women.

\section{Consequences}

Sexual violence - particularly during childhood - is associated with increased health-risk behaviours - including smoking, drug and alcohol misuse and risky sexual behaviours.

Sexual abuse and adverse experiences in childhood can cause lifelong health inequalities through increased risk behaviours.

Intimate partner violence harms the physical and mental health of women and their children women who have experienced intimate partner violence are more likely to report poor or very poor health, emotional distress and attempted suicide; and their children tend to have poorer health and educational outcomes.

Intimate partner violence in pregnancy increases the likelihood of abortion, miscarriage, stillbirth, pre-term delivery and low birth weight.

Intimate partner violence and sexual violence are both associated with increased vulnerability to HIV.

Children who grow up in families where there is intimate partner violence suffer a range of behavioural and emotional disturbances that can be associated with the perpetration or experiencing of violence later in life. 


\section{Risk and protective factors for intimate partner and sexual violence}

\subsection{The ecological model of violence}

As noted by the United States Centers for Disease Control and Prevention (CDC, 2004), in order to prevent sexual violence it is crucial to understand the circumstances, and the risk and protective factors, that influence its occurrence. Many different theoretical models attempt to describe the risk and protective factors for intimate partner and sexual violence, including those based upon biological, psychological, cultural and gender equality concepts. Each of these models contributes to a better understanding of intimate partner and sexual violence and helps to build programmes that aim to reduce modifiable risk factors and strengthen protective factors. Risk factors increase the likelihood of someone becoming a victim and/or perpetrator of intimate partner and sexual violence and their reduction should therefore be a key target of prevention efforts, as well as an integral concept in programme monitoring and evaluation efforts. Similarly, protective factors, which buffer against the risk of becoming a victim and/or perpetrator of intimate partner and sexual violence, may need to be fostered - including through structural and other interventions for achieving gender equality and the empowerment of women.

In this document, WHO has chosen to use the "ecological model" (Figure 1) as presented in the World report on violence and health (Dahlberg \& Krug, 2002) because it allows for the inclusion of risk and protective factors from multiple domains of influence. Thus, if there is evidence from psychological models on individual risk factors and from gender models on societal risk factors, this can be incorporated in the same ecological model.

\section{FIGURE 1}

The ecological model

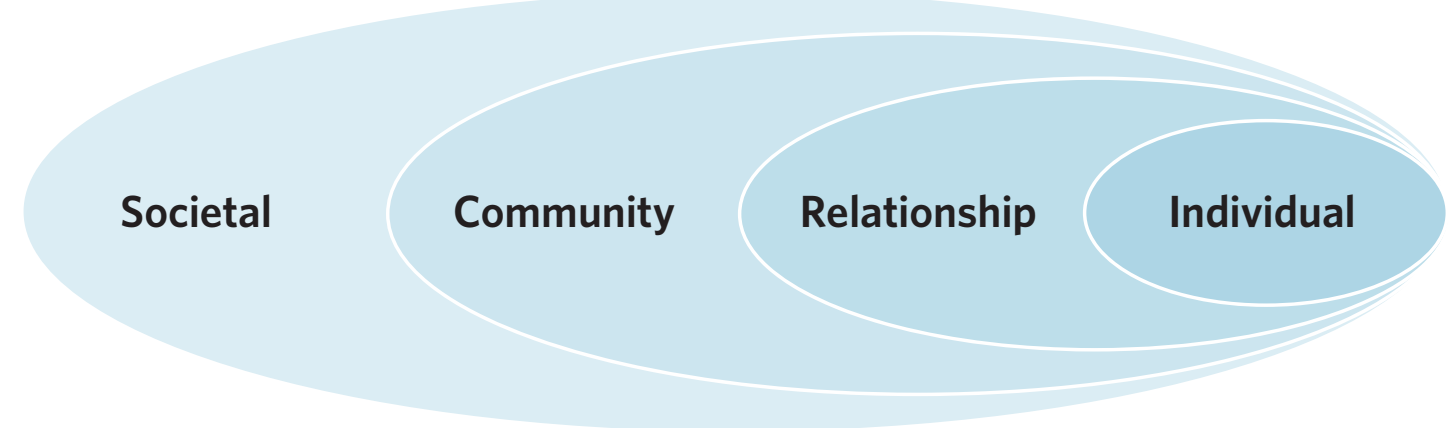


The ecological model organizes risk factors according to the following four levels of influence:

- Individual: includes biological and personal history factors that may increase the likelihood that an individual will become a victim or perpetrator of violence.

- Relationship: includes factors that increase risk as a result of relationships with peers, intimate partners and family members. These are a person's closest social circle and can shape their behaviour and range of experiences.

- Community: refers to the community contexts in which social relationships are embedded - such as schools, workplaces and neighbourhoods - and seeks to identify the characteristics of these settings that are associated with people becoming victims or perpetrators of intimate partner and sexual violence.

- Societal: includes the larger, macro-level factors that influence sexual and intimate partner violence such as gender inequality, religious or cultural belief systems, societal norms and economic or social policies that create or sustain gaps and tensions between groups of people.

Building such a model offers a framework for understanding the complex interplay of all the factors that influence intimate partner and sexual violence, and can therefore provide key points for prevention and intervention (Dahlberg \& Krug, 2002).

The ecological model also supports a comprehensive public health approach that not only addresses an individual's risk of becoming a victim or perpetrator of violence, but also the norms, beliefs and social and economic systems that create the conditions for intimate partner and sexual violence to occur. At the core of the approach is a strong emphasis on the multiple and dynamic interactions among risk factors within and between its different levels. For example, structural inequalities between women and men, social constructions of masculinity and gender norms are risk factors for intimate partner and sexual violence that would primarily be situated at the societal level of the model. Clearly, however, they also manifest themselves within other levels - for example, in communities and relationships - and are likely to be linked with other risk factors such as the witnessing of violence between parents and alcohol abuse by male perpetrators.

Using the ecological model also helps to promote the development of cross-sectoral prevention policies and programmes by highlighting the links and interactions between different levels and factors. As a result, when designing comprehensive approaches to prevent intimate partner and sexual violence, the embedding of effective strategies into mainstream programmes addressing such issues will increase both their relevance and sustainability.

Viewing the ways in which these risk factors come together and influence patterns of behaviour throughout the life-course provides insights into the key points at which interventions to break the cycle should be implemented (Chapter 3).

\subsection{Identifying risk factors}

The identification of risk factors is critically important for informing strategies and programmes to ameliorate or buffer against risk - and ultimately to guide prevention policy. The causes of intimate partner violence and sexual violence are best investigated through the use of longitudinal studies. These studies track people over time to docu- 
ment their experiences of such violence and how these experiences relate to other factors at various stages of their life. Unfortunately, few such studies exist - so much of the information in this section is derived from cross-sectional population surveys. These are good at providing a snapshot of how frequently something occurs and its associated factors, but they usually cannot provide information on whether an observed association actually "caused" a particular outcome.

This chapter draws on two main sources of information: first, the World report on violence and health chapters on intimate partner violence (Heise \& Garcia-Moreno, 2002) and sexual violence (Jewkes, Sen \& Garcia-Moreno, 2002) which reviewed the literature until 2002; and, second, a systematic review of more recent peer-reviewed literature on risk and protective factors associated with either the perpetration or experiencing of intimate partner violence, sexual violence or both.

Most of the literature is from high-income countries (HIC), and it is unclear whether factors identified in HIC also apply to low- and middle-income countries (LMIC) due to differences in economies, ecologies, histories, politics and cultures. Any primary studies from LMIC that identified factors associated with intimate partner violence and/or sexual violence were also included in the review of more recent literature.

As a result of this process, over 50 risk factors were identified for intimate partner violence and/or sexual violence - most at the individual and family/relationship levels. The paucity of risk factors that have currently been identified at the community and societal levels is probably due to a lack of research on risk factors at these levels rather than reflecting a true absence of risk factors.

\subsection{Risk factors associated with both intimate partner violence and sexual violence}

Table 2 lists the risk factors identified for the perpetration by men and the experiencing by women of both intimate partner and sexual violence. The risk factors are organized according to the individual, relationship, community and societal levels of the ecological model shown in Figure 1. Some of these risk factors can be modified (for example, the harmful use of alcohol) while others cannot (for example, sex and age). Those factors that have the strongest reported effect or are consistently reported across studies are highlighted in bold in the table.

\section{Individual-level factors}

Young age

Young age appears to be a risk factor for being either a perpetrator or victim of intimate partner violence, and a victim of sexual violence. Young age has consistently been found to be a risk factor for a man committing physical violence against a partner (Black et al., 2001) and for a woman experiencing intimate partner violence (Harwell \& Spence, 2000; Romans et al., 2007; Vest et al., 2002). Young women have been found to be more at risk of rape than older women (Jewkes, Sen \& Garcia-Moreno, 2002). According to data from justice systems and rape-crisis centres in Chile, Malaysia, Mexico, Papua New Guinea, Peru and the United States, between one third and two thirds of all victims of sexual assault are aged 15 years or under, although this also may reflect reporting bias. Certain forms of sexual violence, for instance, are very closely associated with young age, in particular violence taking place in schools and colleges, and the 
Risk factors for both intimate partner violence and sexual violence

\begin{tabular}{|c|c|}
\hline Perpetration by men & Victimization of women \\
\hline \multicolumn{2}{|c|}{ INDIVIDUAL LEVEL } \\
\hline $\begin{array}{l}\text { DEMOGRAPHICS } \\
\text { - Low income } \\
\text { - Low education }\end{array}$ & $\begin{array}{c}\text { DEMOGRAPHICS } \\
\text { - Young age } \\
\text { - Low education } \\
\text { - Separated/divorced marital status }\end{array}$ \\
\hline $\begin{array}{c}\text { EXPOSURE TO CHILD MALTREATMENT } \\
\text { - Sexual abuse } \\
\text { • Intra-parental violence }\end{array}$ & $\begin{array}{c}\text { EXPOSURE TO CHILD MALTREATMENT } \\
\text { • Intra-parental violence }\end{array}$ \\
\hline $\begin{array}{l}\text { MENTAL DISORDER } \\
\text { - Antisocial personality }\end{array}$ & $\begin{array}{l}\text { MENTAL DISORDER } \\
\text { - Depression }\end{array}$ \\
\hline $\begin{array}{l}\text { SUBSTANCE USE } \\
\text { - Harmful use of alcohol } \\
\text { - Illicit drug use }\end{array}$ & $\begin{array}{l}\text { SUBSTANCE USE } \\
\text { - Harmful use of alcohol } \\
\text { - Illicit drug use }\end{array}$ \\
\hline - Acceptance of violence & - Acceptance of violence \\
\hline \multicolumn{2}{|c|}{ RELATIONSHIP LEVEL } \\
\hline \multicolumn{2}{|c|}{$\begin{array}{l}\text { - Multiple partners/infidelity } \\
\text { - Low resistance to peer pressure }\end{array}$} \\
\hline \multicolumn{2}{|c|}{ COMMUNITY LEVEL } \\
\hline $\begin{array}{l}\text { - Weak community sanctions } \\
\text { - Poverty }\end{array}$ & $\begin{array}{l}\text { - Weak community sanctions } \\
\text { - Poverty }\end{array}$ \\
\hline \multicolumn{2}{|c|}{ SOCIETAL LEVEL } \\
\hline $\begin{array}{l}\text { - Traditional gender norms and social norms } \\
\text { supportive of violence }\end{array}$ & $\begin{array}{l}\text { - Traditional gender norms and social norms } \\
\text { supportive of violence }\end{array}$ \\
\hline
\end{tabular}

trafficking of women for sexual exploitation. Whether young age is also a risk factor for the perpetration of sexual violence by males is less clear. In South Africa, a generational effect was suggested by findings that men aged 20-40 years were more likely to have raped than younger and older men (Jewkes et al., 2009).

\section{Education}

The relationship between individual educational attainment and intimate partner violence and sexual violence is complex. Low level of education is however the most consistent factor associated with both the perpetration and experiencing of intimate partner violence and sexual violence across studies (Ackerson et al., 2008; Boy \& Kulczycki, 2008; Boyle et al., 2009; Brown et al., 2006; Chan, 2009; Dalal, Rahman \& Jansson, 2009; Gage, 2006; Jeyaseelan et al., 2004; Johnson \& Das, 2009; Koenig et al., 2006; Martin, Taft \& Resick, 2007; Tang \& Lai, 2008). For example, women who report lower levels of education (primary or none) have a 2 to 5 -fold increased risk of intimate partner violence compared to higher-educated women (Ackerson et al., 2008; Boy \& Kulczycki, 2008; Dalal, Rahman \& Jansson, 2009; Koenig et al., 2004; Martin, Taft \& Resick, 2007; Tang \& Lai, 2008). Similarly, studies have found that lower-educated males were 1.2 to 4.1 times more likely to perpetrate intimate partner violence than higher-educated men (Ackerson et al., 2008; Dalal, Rahman \& Jansson, 2009).

A higher level of education may act as a protective factor, since women with a higher level of education, or married couples with relatively equivalent education levels, report lower levels of intimate partner violence. Lower educational attainment reduces a wom- 
an's exposure and access to resources, increases the acceptance of violence and maintains unequal gender norms.

It would however be premature to assume that the relationship between educational attainment and intimate partner violence is the same regardless of the type of intimate partner violence involved. In contrast to the above studies, which included physical violence in their definition of intimate partner violence, Flake (2005) found that women with a higher level of education were at increased risk of sexual intimate partner violence. More research is needed on how educational attainment is associated with the different types of intimate partner violence.

Although there is a paucity of evidence, a relationship between lower female educational level and their experiencing sexual violence has also been indicated. One study (Brown et al., 2006) showed that women with primary or no education were twice as likely to experience sexual violence by a non-intimate partner compared to women with a secondary level of education or higher.

\section{Exposure to child maltreatment}

One factor consistently cited across countries as a risk factor for both the experiencing and perpetration of intimate partner violence and sexual violence is child maltreatment. A well-conducted systematic review summarized evidence from 10 studies to show that exposure to violence during childhood increased the likelihood of intimate partner violence perpetration among men by 3 or 4 -fold, compared to men without childhood exposure to violence (Gil-Gonzalez et al., 2007). Another meta-analysis found that exposure to any childhood sexual abuse (but not physical abuse alone) increased male perpetration of sexual violence towards women more than three-fold (Jespersen, Lalumiere \& Seto, 2009). A number of primary studies in LMIC found that childhood exposure to violence (particularly intra-parental violence and sexual abuse) was positively associated with the experiencing of intimate partner violence and sexual violence by females (Martin, Taft \& Resick, 2007; Söchting, Fairbrother \& Koch, 2004; Vung \& Krantz, 2009). Such exposure to violence during childhood may increase the likelihood of violence acceptance either as a victim or perpetrator in future partnerships and high-risk situations.

\section{Antisocial personality}

Several studies examined personality characteristics and their association with the perpetration of intimate partner violence and sexual violence. Three narrative reviews (two from a high-income and another from a middle-income country) reported a consistent association between antisocial personality disorders and related characteristics (such as impulsivity and lack of empathy) and the perpetration of intimate partner violence or sexual violence. These studies suggest that perpetrators with these characteristics are more likely to disregard social norms and have a tendency to become aggressive and impulsive, resulting in the perpetration of intimate partner violence or sexual violence (Abbey et al., 2004; Chan, 2009; Marshall, Panuzio \& Taft, 2005). More studies are needed to empirically support a causal relationship between personality disorders and the perpetration of intimate partner violence and/or sexual violence. 


\section{Harmful use of alcohol}

Harmful use of alcohol and illicit drug use are other commonly cited risk factors associated with the experiencing and perpetration of intimate partner violence and sexual violence (for example, see Graham et al., 2008). Although several studies have found an association between intimate partner violence or sexual violence and illicit drug use, most of the literature has focused on the relationship between harmful use of alcohol and intimate partner violence or sexual violence. Harmful use of alcohol was strongly associated with the perpetration of intimate partner violence in several of the reviews, which included studies from LMIC (Abrahams et al., 2004; Dalal, Rahman \& Jansson, 2009; Flake, 2005; Gage, 2006; Gil-Gonzalez et al., 2006; Johnson \& Das, 2009; Koenig et al., 2004; Marshall, Panuzio \& Taft, 2005; Martin, Taft \& Resick, 2007; Ramiro, Hassan \& Peedicayil, 2004; Tang \& Lai, 2008; Testa, 2004). One systematic review pooled the results of 11 studies and found that harmful use of alcohol was associated with a 4.6 times increased risk of exposure to intimate partner violence compared to mild or no alcohol use (Gil-Gonzalez et al., 2006). Two narrative reviews concluded that an association exists between harmful use of alcohol and the perpetration of sexual violence (Abbey et al., 2004; Testa, 2004). Cross-sectional studies from different LMIC report that men who misuse alcohol are 1.6 to 4.8 times more likely to perpetrate intimate partner violence (Abrahams et al., 2004; Dalal, Rahman \& Jansson, 2009; Flake, 2005; Gage, 2006; Johnson \& Das, 2009; Koenig et al., 2004; Ramiro, Hassan \& Peedicayil, 2004).

These findings should however be interpreted with caution since evidence for a causal association between harmful use of alcohol and violence is weak (Gil-Gonzalez et al., 2006). The role of alcohol use in the experiencing of intimate partner violence and sexual violence is less clear. Several narrative reviews found a weak relationship or no relationship at all between alcohol use and the experiencing of intimate partner violence or sexual violence (Abbey et al., 2004; Gutierres \& Van Puymbroeck, 2006; Söchting, Fairbrother \& Koch, 2004; Tang \& Lai, 2008; Testa, 2004).

\section{Acceptance of violence}

Men and women's attitudes towards violence are strongly correlated with exposure to intimate partner violence and sexual violence - both in terms of victimization and perpetration. Reviews and studies, including several from LMIC, found a strong association between attitudes towards violence and exposure to intimate partner violence or sexual violence (Abrahams et al., 2004; Boyle et al., 2009; Gage, 2006; Jewkes et al., 2006; Johnson \& Das, 2009; Tang \& Lai, 2008). Men who believe that it is acceptable to beat their wives have a two-fold risk of intimate partner violence perpetration (Abramson, 2004). This risk increased as acceptance of violence increased. Men who believe that it is always acceptable to beat their wives have a four-fold increased risk of intimate partner violence perpetration compared to a two-fold increased risk among those who believe it is sometimes acceptable to beat their wives (Johnson \& Das, 2009). Women's acceptance of violence is also positively associated with the experiencing of intimate partner violence (Boyle et al., 2009; Uthman, Lawoko \& Moradi, 2009). Women and men's acceptance of intimate partner violence; men's attitudes towards women as inferior; restrictive gender roles; and dominant patriarchal values may all perpetuate the occurrence of violence. These attitudes may be transferred across generations through learning processes, the media, schools, and witnessing and experiencing violence throughout life - and can therefore be changed. 


\section{Relationship-level factors}

Multiple partners

Men who report having multiple sexual partners are also more likely to perpetrate intimate partner violence or sexual violence. Multiple partnership and infidelity (as perceived by female partners) were also strongly associated with both the perpetration and experiencing of intimate partner violence. (Abrahams et al., 2004; Chan, 2009; Dalal, Rahman \& Jansson, 2009; Jewkes et al., 2006; Johnson \& Das, 2009; Koenig et al., 2004; Tang \& Lai, 2008; Vung \& Krantz, 2009). All the studies reported a strong association between women's perceived infidelity or multiple sexual partnerships by their partners and intimate partner violence or sexual violence. Estimates ranged from a 1.5-fold (India) to 17.1-fold (South Africa) greater risk of the perpetration of intimate partner violence and sexual violence, and a 1.5-fold (Uganda) to 2.4-fold (Viet Nam) greater risk of experiencing intimate partner violence (Jewkes et al., 2006; Koenig et al., 2004; Vung \& Krantz, 2009). It is thought that these men may seek out multiple sexual partners as a source of peer status and self-esteem, relating to their female partners impersonally and without the appropriate emotional bonding (Jewkes et al., 2006). Also, such men are more likely to engage in risky behaviours with multiple sexual partners by refusing to use condoms - thus exposing themselves and their partners to an increased risk of HIV infection. In most of the sites covered by the WHO Multi-country study on women's health and domestic violence against women (Garcia-Moreno et al., 2005) women whose current or most recent partner was violent were more likely than women in non-violent relationships to report at least one refusal to use a condom.

\section{Community-level factors}

\section{Weak community sanctions against intimate partner and sexual violence}

The World report on violence and health notes that how a community responds to partner violence may affect the overall levels of abuse in that community (Heise \& GarciaMoreno, 2002). In a comparative study of 16 societies with either high or low rates of intimate partner violence, Counts, Brown \& Campbell (1992) found that societies with the lowest levels of intimate partner violence were those that had community sanctions against it, and where abused women had access to sanctuary - either in the form of shelters or family support. Community sanctions, or prohibitions, could take the form either of formal legal sanctions or the moral pressure for neighbours to intervene if a woman was beaten. The "sanctions and sanctuary" framework suggests the hypothesis that intimate partner violence will be highest in societies where the status of women is in a state of transition. Where women have a very low status, violence is not needed to enforce male authority. On the other hand, where women have a high status, they will probably have achieved sufficient power collectively to change traditional gender roles. Intimate partner violence is thus usually highest at the transition point, as is the situation in most LMIC.

The likelihood of sexual violence is related to the extent to which beliefs in male superiority and male entitlement to sex are entrenched in a community, the general tolerance in the community of sexual assault and the strength of sanctions, if any, against perpetrators (Jewkes, Sen \& Garcia-Moreno, 2002). 


\section{Poverty}

Studies from a wide range of settings show that, while intimate partner violence and sexual violence cut across all socioeconomic groups, women living in poverty are disproportionately affected (Heise \& Garcia-Moreno, 2002; Jewkes, Sen \& Garcia-Moreno, 2002). It is not yet clear why poverty increases the risk of these forms of violence whether it is because of low income in itself or because of other factors that accompany poverty, such as overcrowding or hopelessness. For some men, living in poverty is likely to generate stress, frustration and a sense of inadequacy for having failed to live up to their culturally expected role of providers. Poverty may also provide ready material for marital disagreements or make it more difficult for women to leave violent or otherwise unsatisfactory relationships. Whatever the precise mechanisms, it is probable that poverty acts as a "marker" for a variety of social conditions that combine to increase the risks faced by women. Poor women and girls may be more at risk of rape in the course of their daily tasks than those who are better off, for example when they walk home on their own from work late at night, or work in the fields or collect firewood alone. Children of poor women may have less parental supervision when not in school, since their mothers may be at work and unable to afford childcare. The children themselves may be working and thus vulnerable to sexual exploitation. Poverty forces many women and girls into occupations that carry a relatively high risk of sexual violence, particularly sex work. It also creates enormous pressures for them to find or maintain jobs, to pursue trading activities and, if studying, to obtain good grades - all of which render them vulnerable to sexual coercion from those who can promise these things (Jewkes, Sen \& Garcia-Moreno, 2002).

\section{Societal-level factors}

\section{Traditional gender norms and social norms supportive of violence}

Research studies across cultures have revealed a number of societal and cultural factors that might give rise to higher levels of violence. For example, Levinson (1989) used statistical analysis of coded ethnographic data from 90 societies to examine the cultural patterns of wife beating - exploring the factors that consistently distinguish societies where wife beating is common from those where the practice is rare or absent. This analysis indicated that wife beating occurs more often in societies in which men have economic and decision-making power in the household, where women do not have easy access to divorce and where adults routinely resort to violence to resolve their conflicts. Another strong predictor in this study of the frequency of wife beating was the absence of all-women workgroups. It was suggested that the presence of female workgroups offers protection from wife beating because they provide women with a stable source of social support and economic independence from their husbands and families.

One of the most common theories to explain the perpetration and experiencing of intimate partner violence and sexual violence is the maintenance of patriarchy or male dominance within a society (Taft, 2009). Patriarchal and male dominance norms reflect gender inequality and inequities at a societal level, and legitimize intimate partner violence and sexual violence perpetrated by men (Russo \& Pirlott, 2006). While they are located at the societal level, these gender norms play out at the level of community, relationship and individual behaviours. Societal norms related to gender are believed to contribute to violence against women and gender inequality and other inequities by creating power hierarchies where men are viewed by society as economically 
and religiously superior, and of higher social status compared to women - who are sometimes viewed as a liability (Ali \& Bustamante-Gavino, 2008). As such, men are socialized to believe that they are superior to women, should dominate their partners and endorse traditional gender roles (Taft, 2009). Women's subordination and submission is then considered to be normal, expected, accepted and, in some cases, attractive to men (Russo \& Pirlott, 2006). Women who are more competent or educated are often stigmatized or disliked by society. This gender inequality and male dominance reduces the opportunities for women to be involved in decision-making at every level; decreases the resources available to women; and increases acceptance of the use of violence against women. Furthermore, it contributes to gender-based inequities in health and access to health care; in opportunities for employment and promotion; in levels of income; in political participation and representation; and in education. Thus, macrolevel interventions that increase structural supports and resources that decrease gender inequality - as well as interventions to reduce gender inequality at the community and individual levels - may serve to decrease intimate partner violence and sexual violence (Smith Fawzi et al., 2005).

In summary, there is a need for more research to identify modifiable factors that can influence the perpetration or experiencing of intimate partner violence and sexual violence at both community and societal levels. Potential community-level factors include education, the availability and accessibility of resources, and the readiness of individuals to use available community resources. Important societal-level factors include gender norms and other structural factors supportive of gender inequality and violence.

\subsection{Risk factors associated with intimate partner violence}

Most factors associated with the perpetration and experiencing of intimate partner violence identified to date are at the individual level, followed by the relationship and community level; fewer have been identified at the societal level (Table 3). Those factors that are most strongly and consistently associated with intimate partner violence are highlighted in bold in the table, and any not already discussed in Section 2.3 (Table 2) are examined below.

\section{Individual-level factors}

Past history of victimization or perpetration of violence

Women who have previously been abused by intimate or non-intimate partners during adulthood are more likely to experience future intimate partner violence compared to those without prior exposure to violence. For example, one study from India showed that women who reported previous non-intimate partner violence were 3.8 times more likely to report intimate partner violence compared to those without previous exposure (Boyle et al., 2009). A narrative review also found that previous exposure to abuse may contribute to future victimization by changing a woman's attitude towards violence; decreasing her ability to recognize risk; lowering her self-esteem; increasing her guilt, shame and embarrassment; and reducing her sexual assertiveness (Söchting, Fairbrother \& Koch, 2004). Similarly, a prior history of perpetration among men was a strong risk factor for intimate partner violence. Men with a history of abusive or violent behaviour were more likely to exhibit this behaviour in their future intimate partnerships, especially during pregnancy and the postnatal period (Chan, 2009; Jewkes et al., 2006; Martin, Taft \& Resick, 2007; Söchting, Fairbrother \& Koch, 2004; Tang \& Lai, 2008). 
TABLE 3

Risk factors for intimate partner violence ${ }^{a}$

\begin{tabular}{|c|c|}
\hline Perpetration by men & Victimization of women \\
\hline \multicolumn{2}{|c|}{ INDIVIDUAL LEVEL } \\
\hline $\begin{array}{c}\text { DEMOGRAPHICS } \\
\cdot \text { Young age } \\
\text { - Low socio-economic status/income } \\
\text { - Low education } \\
\text { - Unemployment }\end{array}$ & $\begin{array}{c}\text { DEMOGRAPHICS } \\
\text { - Young age } \\
\text { - Low socio-economic status/income } \\
\text { - Low education } \\
\text { - Separated/divorced marital status } \\
\text { - Pregnancy }\end{array}$ \\
\hline $\begin{array}{c}\text { EXPOSURE TO CHILD MALTREATMENT } \\
\text { - Intra-parental violence } \\
\text { - Sexual abuse } \\
\text { - Physical abuse }\end{array}$ & $\begin{array}{c}\text { EXPOSURE TO CHILD MALTREATMENT } \\
\text { - Intra-parental violence } \\
\text { - Sexual abuse }\end{array}$ \\
\hline $\begin{array}{l}\text { MENTAL DISORDER } \\
\text { - Antisocial personality }\end{array}$ & $\begin{array}{l}\text { MENTAL DISORDER } \\
\text { - Depression }\end{array}$ \\
\hline $\begin{array}{c}\text { SUBSTANCE USE } \\
\text { - Harmful use of alcohol } \\
\text { - Illicit drug use }\end{array}$ & $\begin{array}{l}\text { SUBSTANCE USE } \\
\text { - Harmful use of alcohol } \\
\text { - Illicit drug use }\end{array}$ \\
\hline - Acceptance of violence & - Acceptance of violence \\
\hline - Past history of being abusive & - Exposure to prior abuse/victimization \\
\hline \multicolumn{2}{|c|}{ RELATIONSHIP LEVEL } \\
\hline - Educational disparity & - Educational disparity \\
\hline - Multiple partners/infidelity & - Number of children \\
\hline $\begin{array}{l}\text { RELATIONSHIP QUALITY } \\
\text { - Marital dissatisfaction/discord } \\
\text { - Gender role disputes } \\
\text { - Marital duration }\end{array}$ & $\begin{array}{c}\text { RELATIONSHIP QUALITY } \\
\text { - Marital dissatisfaction/discord }\end{array}$ \\
\hline
\end{tabular}

- Acceptance of traditional gender roles NEIGHBOURHOOD CHARACTERISTICS

- High proportion of poverty

- High proportion of unemployment

- High proportion of male literacy

- Acceptance of violence

- High proportion of households that use corporal punishment
- Acceptance of traditional gender roles NEIGHBOURHOOD CHARACTERISTICS

- High proportion of poverty

- High proportion of unemployment

- High proportion of female literacy

- Acceptance of violence

- Low proportion of women with high level of autonomy - Low proportion of women with higher education

- Weak community sanctions

- Weak community sanctions

SOCIETAL LEVEL

- Divorce regulations by government

Lack of legislation on intimate partner violence within marriage

\section{- Protective marriage law}

- Traditional gender norms and social norms supportive of violence

- Traditional gender norms and social norms supportive of violence

a Some of these factors are also risk factors for sexual violence (see Table $\mathbf{2}$ for risk factors for both intimate partner and sexual violence). 
One high-quality study reported that South African men with a previous abusive history were almost three times more likely to have perpetrated intimate partner violence (Jewkes et al., 2006).

\section{Relationship-level factors}

\section{Educational disparity}

Disparities in educational attainment between male and female partners may also result in higher rates of intimate partner violence (Ackerson et al., 2008; Chan, 2009). Men may use violence to gain power within a relationship in which the woman's level of education is higher. Ackerson et al. (2008) found that Indian women with a higher level of education relative to their partner were more likely to experience physical intimate partner violence. Xu et al. (2005) found a similar relationship between relative educational attainment between partners and any type of intimate partner violence in China.

\section{Relationship quality/marital satisfaction}

Partnerships with low marital satisfaction, continuous disagreements and high marital discord are more likely to be associated with intimate partner violence compared to those without. Lack of marital satisfaction and marital discord are strongly correlated with the occurrence of both the perpetration and experiencing of intimate partner violence (Morrison, Ellsberg \& Bott, 2007; Stith et al., 2004; Tang \& Lai, 2008). Disagreements often occur over traditional gender roles, control in partnerships with status disparities (for example, in income, education or age) and sexual acts or refusals. Violence is perpetrated against a partner as a way of dealing with conflict or resolving the disagreement. Additionally, a woman's risk of victimization may be heightened in situations where women start an argument or when they fight back.

\section{Community-level and societal-level factors}

Fewer studies have examined community-level and societal-level risk factors for intimate partner violence, especially in LMIC. However, a number of recent studies (Ackerson et al., 2008; Boyle et al., 2009; Gage, 2005; Koenig et al., 2004; Koenig et al., 2006) show that several neighbourhood-level factors are associated with higher rates of intimate partner violence, including:

- lower proportion of women with a higher level of education;

- higher neighbourhood poverty;

- higher neighbourhood unemployment rate;

- higher proportion of male and female illiteracy;

- higher proportion of individuals with a positive view of violence;

- lower proportion of women with high level of autonomy; and

- higher proportion of households that use corporal punishment.

One study in 17 sub-Saharan African countries showed that intimate partner violence against women was widely accepted under certain circumstances by men and women in all the countries studied (Uthman, Lawoko \& Moradi, 2009). Women were more likely to justify it than men. "Neglecting the children" was the most common reason 
agreed to by both women and men for justifying intimate partner violence followed by "going out without informing husband" and "arguing back with the husband". The WHO Multi-country study on women's health and domestic violence against women (Garcia-Moreno et al., 2005) found that the percentage of women who agreed with one or more justifications for "wife beating" varied from $6 \%$ to over $65 \%$. Suspecting a wife of being unfaithful was the most commonly agreed justification. In all countries except Thailand the overall acceptance that wife beating could be justified for some reason was significantly greater among women who had experienced physical or sexual intimate partner violence (or both) than among women who had never experienced such violence. Increasing wealth, educational attainment, urbanization, access to media and joint decision-making were all associated with decreased levels of justification of intimate partner violence against women in most countries. Although the strength of the associations between these factors and intimate partner violence needs to be further validated, they remain potential targets for the development of programmes at a community level.

\subsection{Risk factors associated with sexual violence}

Of the factors associated with the perpetration and experiencing of sexual violence, most were identified at the individual level (Table 4). Those factors that have the strongest reported effect or are most consistently reported are highlighted in the table in bold font. Many of the risk factors listed as strong risk factors of sexual violence have been discussed above in previous sections, suggesting that few such factors are specific to sexual violence.

\section{Family honour and sexual purity}

Family responses to sexual violence that blame women without punishing men, and concentrate instead on restoring "lost" family honour, create an environment in which rape can occur with impunity. While such families will often try to protect their women from rape and may also put their daughters on contraception to prevent visible signs should rape occur, there is rarely much social pressure to control young men or persuade them that coercive sex is wrong. Instead, in some countries, there is frequently support for family members to do whatever is necessary - including murder of the victim - to alleviate the "shame" associated with a rape or other sexual transgression (Jewkes, Sen \& Garcia-Moreno, 2002).

\section{Ideologies of male sexual entitlement}

Sexual violence committed by men is to a large extent rooted in ideologies of male sexual entitlement. These belief systems grant women extremely few legitimate options to refuse sexual advances. Many men thus simply exclude the possibility that their sexual advances towards a woman might be rejected or that a woman has the right to make an autonomous decision about participating in sex. In many cultures, women as well as men regard marriage as entailing an obligation on women to be sexually available virtually without limit, though sex may be culturally proscribed at certain times, such as after childbirth or during menstruation. Societal norms around the use of violence as a means to achieve objectives have been strongly associated with the prevalence of rape. In societies where the ideology of male superiority is strong - emphasizing dominance, 
TABLE 4

Risk factors for sexual violence ${ }^{a}$

\begin{tabular}{|c|c|}
\hline Perpetration by men & Victimization of women \\
\hline \multicolumn{2}{|c|}{ INDIVIDUAL LEVEL } \\
\hline $\begin{array}{c}\text { DEMOGRAPHICS } \\
\text { - Low socio-economic status/income }\end{array}$ & $\begin{array}{c}\text { DEMOGRAPHICS } \\
\text { - Young age } \\
\text { - Lower education } \\
\text { - Separated/divorced and single women }\end{array}$ \\
\hline - Gang membership & - Early exposure to sexual activity \\
\hline $\begin{array}{c}\text { EXPOSURE TO CHILD MALTREATMENT } \\
\text { - Sexual abuse } \\
\text { - Physical abuse } \\
\text { - Intraparental violence }\end{array}$ & $\begin{array}{c}\text { EXPOSURE TO CHILD MALTREATMENT } \\
\text { - Intra-parental violence } \\
\text { - Sexual abuse }\end{array}$ \\
\hline $\begin{array}{l}\text { MENTAL DISORDER } \\
\text { - Antisocial personality }\end{array}$ & $\begin{array}{l}\text { MENTAL DISORDER } \\
\text { - Depression }\end{array}$ \\
\hline \multirow[t]{2}{*}{$\begin{array}{c}\text { SUBSTANCE USE } \\
\text { - Harmful use of alcohol } \\
\text { - Illicit drug use }\end{array}$} & $\begin{array}{c}\text { SUBSTANCE USE } \\
\text { - Harmful use of alcohol } \\
\text { - Illicit drug use }\end{array}$ \\
\hline & - Prior victimization \\
\hline \multicolumn{2}{|c|}{ RELATIONSHIP LEVEL } \\
\hline - Multiple partners/infidelity & - Multiple partners \\
\hline \multicolumn{2}{|l|}{ - Low resistance to peer pressure } \\
\hline \multicolumn{2}{|l|}{ - Family honour and sexual purity } \\
\hline \multicolumn{2}{|c|}{ COMMUNITY LEVEL } \\
\hline - Weak community sanctions & - Weak community sanctions \\
\hline - Poverty & • Poverty \\
\hline \multicolumn{2}{|c|}{ SOCIETAL LEVEL } \\
\hline $\begin{array}{l}\text { - Traditional gender norms and social norms } \\
\text { supportive of violence }\end{array}$ & $\begin{array}{l}\text { - Traditional gender norms and social norms } \\
\text { supportive of violence }\end{array}$ \\
\hline - Ideologies of male sexual entitlement & - Ideologies of male sexual entitlement \\
\hline - Weak legal sanctions & - Weak legal sanctions \\
\hline
\end{tabular}

Some of these factors are also risk factors for intimate partner violence (see Table $\mathbf{2}$ for risk factors for both intimate partner and sexual violence)

physical strength and male honour - rape is more common. Countries with a culture of violence, or where violent conflict is taking place, experience an increase in other forms of violence, including sexual violence (Jewkes, Sen \& Garcia-Moreno, 2002).

\section{Weak legal sanctions}

Factors operating at a societal level that influence sexual violence include laws and national policies relating to gender equality in general and to sexual and intimate partner violence more specifically, as well as norms relating to the use of violence. While the various factors operate largely at local level (within families, schools, workplaces and communities) there are also influences from the laws and norms working at national and even international level.

There are considerable variations between countries in their approach to sexual violence legislation. Some countries have far-reaching legislation and legal procedures, with a broad definition of rape that includes marital rape, heavy penalties for those convicted, 
and a strong response in supporting victims. A commitment to preventing or reducing sexual violence is also reflected in an emphasis on police training and an appropriate allocation of police resources to the problem; in the priority given to investigating cases of sexual assault; and in the resources made available to support victims and provide medico-legal services. However, even in countries with the best laws, the conviction rate for sexual violence is minimal.

At the other end of the scale, there are countries with much weaker approaches to the issue - where conviction of an alleged perpetrator on the evidence of the woman alone is not allowed, where certain forms or settings of sexual violence are specifically excluded from the legal definition, and where rape victims are strongly deterred from bringing the matter to court through the fear of being punished for filing an "unproven" rape case (Jewkes, Sen \& Garcia-Moreno, 2002).

\subsection{Protective factors for intimate partner violence and sexual violence}

Most of the research on the perpetration and experiencing of intimate partner violence and sexual violence has focused on factors associated with an increased likelihood of intimate partner violence and/or sexual violence (risk factors) rather than factors that decrease or buffer against risk (protective factors). However, several studies have shown that women who were more highly educated (secondary schooling or higher) were $20-55 \%$ less likely to be victims of intimate partner violence or sexual violence compared to less-educated women (Brown et al., 2006; Fehringer \& Hindin, 2009; Flake, 2005). Similarly, men who were more highly educated were approximately $40 \%$ less likely to perpetrate intimate partner violence compared to less-educated men (Johnson \& Das, 2009). Marital duration of more than 15 years was also identified as a potential protective factor against male perpetration of intimate partner violence in Bangladesh (Johnson \& Das, 2009). Other factors that may decrease or buffer against risk include:

- having benefited from healthy parenting as a child (protective against intimate partner violence and sexual violence);

- having own supportive family (intimate partner violence);

- living within extended family/family structure (intimate partner violence);

- belonging to an association; and

- women's ability to recognize risk (sexual violence)

(Ellsberg et al. 1999; Gidicyz et al., 2006; Schwartz et al., 2006).

However, much more scientific research into these protective factors is required.

\subsection{Gender norms and inequality}

Gender inequality and inequity are important societal-level factors that remain significantly under-researched in terms of their associations with intimate partner violence and sexual violence. However, two specific risk factors appear to be strongly associated with intimate partner and sexual violence - the unequal position of women in a particular relationship and in society (which is underwritten by ideologies of male superiority); and the normative use of violence to resolve conflicts (and during political struggles). These factors are manifested by distinct and hierarchical gender roles, notions of male sexual entitlement, the low social value and power of women, and ideas of manhood 
linked to the control or "disciplining" of women. These in turn are linked to factors such as low levels of education among women; few public roles for women; the lack of family, social and legal support for women; and the lack of economic power for women (Jewkes, 2002).

For the effective prevention of intimate partner and sexual violence, it is vital to shed a strong light on how gender norms and gender inequality and inequity are related to such violence. A thorough understanding based on sound empirical evidence of how gender norms and gender inequality and inequity function as risk and protective factors for, and as causes of, intimate partner and sexual violence in different sociocultural contexts is required. Acquiring such an understanding should be a top priority of research into the risk and protective factors for intimate partner and sexual violence.

\subsection{Key messages}

\section{Risk and protective factors Intimate partner and sexual violence}

Women and men with lower levels of education are at increased risk of experiencing and perpetrating, respectively, intimate partner violence.

Exposure to child maltreatment is strongly associated with:

- the perpetration by men of intimate partner and sexual violence; and

- the experiencing by women of intimate partner and sexual violence.

An antisocial personality disorder is a strong risk factor for the perpetration of both intimate partner and sexual violence.

Harmful use of alcohol is frequently found to be associated with the perpetration of both intimate partner and sexual violence.

Males who have multiple partners or are suspected by their partners of infidelity are more likely to perpetrate both intimate partner and sexual violence.

Attitudes that are accepting of violence are strongly associated with both the perpetration and experiencing of intimate partner and sexual violence.

\section{Risk factors specific to intimate partner violence}

Past history of violence as a perpetrator or victim is a strong risk factor for future intimate partner violence.

Marital discord and dissatisfaction are strongly associated with both the perpetrating and experiencing of intimate partner violence.

\section{Risk factors specific to sexual violence}

Beliefs in family honour and sexual purity are associated with a lack of social pressure to persuade young men that coercive sex is wrong.

Sexual violence committed by men is to a large extent rooted in ideologies of male sexual entitlement. These belief systems grant women extremely few legitimate options to refuse sexual advances.

Weak legal sanctions for sexual violence send the message that such violence is condoned, and may even exclude certain forms of sexual violence from the legal definition. 


\section{Prevention implications}

- Different risk and protective factors may operate in different countries and settings. Hence, it is important to identify and then address those risk factors most strongly associated with intimate partner violence and sexual violence in each setting.

Primary prevention efforts should focus on younger age groups.

- Preventing all forms of violence and abuse, especially child maltreatment, will help to reduce the levels of intimate partner and sexual violence.

Reducing overall alcohol consumption in a population may help to reduce the harmful use of alcohol and with it the perpetration and experiencing of intimate partner and sexual violence.

There are several modifiable factors associated with intimate partner violence that can be targeted by primary prevention measures such as reducing acceptance of violence, increasing women's access to education, changing laws that discriminate against women and implementing more gender equitable policies. Although targeting these factors will in all likelihood also reduce sexual violence, the required evidence is currently lacking. 


\section{Primary prevention strategies - the evidence base}

\subsection{Introduction}

Intimate partner and sexual violence are not inevitable - their levels vary over time and between places due to a variety of social, cultural, economic and other factors. As outlined in Chapter 1, this can result in substantial differences between and within countries in the prevalence of intimate partner and sexual violence. Most importantly, this variation shows that such violence can be reduced through well-designed and effective programmes and policies. As discussed in Chapter 2, there are important factors related to both perpetration and victimization - such as exposure to child maltreatment, witnessing parental violence, attitudes that are accepting of violence and the harmful use of alcohol - that can be addressed.

At present, evidence on the effectiveness of primary prevention strategies for intimate partner and sexual violence is limited, with the overwhelming majority of data derived from HIC - primarily the United States. Consequently, current high priorities in this field include adapting effective programmes from high-income to lower-income settings; further evaluating and refining those for which evidence is emerging; and developing and testing strategies that appear to have potential, especially for use in low-resource settings, with rigorous evaluation of their effectiveness. At the same time, the dearth of evidence in all countries means that the generating of evidence and the incorporation of well-designed outcome evaluation procedures into primary prevention programmes are top priorities everywhere. This will help to ensure that the efforts made in this area are founded upon a solid evidence base. Furthermore, programme developers should be encouraged to explicitly base programmes on existing theoretical frameworks and models of behaviour change to allow underlying mechanisms to be identified and to make replication easier.

Most of the evaluated strategies aimed at preventing intimate partner and sexual violence have targeted proximal risk factors - primarily at the individual and relationship levels of the ecological model.

\section{The need for upstream action}

In the public health framework, primary prevention means reducing the number of new instances of intimate partner and sexual violence by addressing the factors that make the first-time perpetration of such violence more likely to occur. Primary prevention therefore relies on identifying the "upstream" determinants and then taking action to address these. The impact of widespread, comprehensive programmes can then be measured at the population level by comparing the rates at which such violence is either 
experienced or perpetrated. Given the lifetime prevalence of intimate partner and sexual violence shown in Table 1 (Chapter 1), the hundreds of millions of women worldwide in need of services would outstrip the capacity of even the best-resourced countries. A problem on this scale requires a major focus on primary prevention.

Upstream actions can target risk factors across all four levels of the ecological model presented in Chapter 2. To decrease intimate partner and sexual violence at the population level, it is particularly important to address the societal or outer level of the model. Such measures include national legislation and supportive policies aimed at social and economic factors - such as income levels, poverty and economic deprivation, patterns of male and female employment, and women's access to health care, property, education, and political participation and representation. It is sometimes even argued that programmes that aim to reduce intimate partner and sexual violence against women without increasing male-female equity will ultimately not succeed in reducing violence against women. However, while many strategies involving legal and educational reform and employment opportunities are being implemented to increase gender equality, few have been assessed for their impact on intimate partner and sexual violence, making the evaluation of such strategies a priority. Any comprehensive intimate partner and sexual violence prevention strategy must address these sociocultural and economic factors through legislative and policy changes and by implementing related programmes.

\section{Creating a climate of non-tolerance}

Addressing risk factors at the societal level may increase the likelihood of successful and sustainable reductions of intimate partner and sexual violence. For example, when the law allows husbands to physically discipline wives, implementing a programme to prevent intimate partner violence may have little impact. National legislation and supportive policies should therefore be put in place to ensure that women have equal rights to political participation, education, work, social security and an adequate standard of living. They should also be able to enter freely into a marriage or to leave it, to obtain financial credit, and to own and administer property. Laws and policies that discriminate against women should be changed, and any new legislation and policies should be examined for their impact upon women and men. Legislation and policies that address wider socioeconomic inequalities are likely to reduce other forms of interpersonal violence which will in turn help to reduce intimate partner and sexual violence.

Legislation and policies that address wider socioeconomic inequalities can make a vital contribution to empowering women and improving their status in society; to creating cultural shifts by changing the norms, attitudes and beliefs that support intimate partner and sexual violence; and to creating a climate of non-tolerance for such violence.

The human rights of girls and women need to be respected, protected and fulfilled as part of ensuring the well-being and rights of everyone in society. As a first step towards this, governments should honour their commitments in implementing the following international legislation and human-rights instruments:

- Convention on the Elimination of All Forms of Discrimination Against Women (1979);

- The Convention on the Rights of the Child (1991);

- The Declaration on the Elimination of Violence Against Women (1993);

- The Beijing Declaration and Platform for Action (1995); 
- The Millennium Declaration (2000); and

- The Inter-American Convention on the Prevention, Punishment and Eradication of Violence against Women (Convention of Belem do Para, 1994).

Legislation and criminal justice systems must also be in place to deal with cases of intimate partner and sexual violence after the event. These systems should aim to help prevent further violence, facilitate recovery and ensure access to justice - for example through the provision of specialized police units, restraining orders and multi-agency sexual assault response teams. Potentially, legal protection against intimate partner and sexual violence helps to reinforce non-violent social norms by sending the message that such acts will not be tolerated. Measures to criminalize abuse by intimate partners and to broaden the definition of rape have been instrumental in bringing these issues out into the open and dispelling the notion that such violence is a private family matter. In this regard, they have been very important in shifting social norms (Heise \& GarciaMoreno, 2002; Jewkes, Sen \& Garcia-Moreno, 2002). However, the evidence surrounding the deterrent value of arrest in cases of intimate partner violence shows that it may be no more effective in reducing violence than other police responses, such as issuing warnings or citations, providing counselling or separating couples (Fagan \& Browne 1994; Garner, Fagan \& Maxwell, 1995). Some studies have also shown increased abuse following arrest, particularly for unemployed men and those living in impoverished areas (Fagan \& Browne 1994; Garner, Fagan \& Maxwell, 1995). Protective orders can be useful, but enforcement is uneven and there is evidence that they have little effect on men with serious criminal records (Heise \& Garcia-Moreno, 2002). In cases of rape, reforms related to the admissibility of evidence and removing the requirement for victims' accounts to be corroborated have also been useful, but are ignored in many courts throughout the world (Du Mont \& Parnis, 2000; Jewkes, Sen \& Garcia-Moreno, 2002). Currently, on the whole, sufficient evidence of the deterrent effect of criminal justice system responses on intimate partner and sexual violence is still lacking (Dahlberg \& Butchart, 2005).

Dismantling hierarchical constructions of masculinity and femininity predicated on the control of women, and eliminating the structural factors that support inequalities are likely to make a significant contribution to preventing intimate partner and sexual violence. However, these are long-term goals. Strategies aimed at achieving these longterm objectives should be complemented by measures with more immediate effects that are informed by the evidence base presented in this chapter.

\subsection{Assessing the evidence for different prevention approaches}

From the perspective of public health, a fundamental question is "do intimate partner and sexual violence prevention programmes work"? That is to say, are there certain programmes or strategies that are effective in preventing or reducing intimate partner and sexual violence? Effectiveness can only be demonstrated using rigorous research designs, such as randomized-controlled trials or quasi-experimental designs. These typically compare the outcomes of an experimental group (which receives the programme) with a control or comparison group (which is as equivalent as possible to the experimental group but which does not receive the programme). One major concern is to be able to rule out alternative explanations for any observed changes in outcome in order to be confident that the changes really were due to the programme and not some other factor. This issue is discussed further in section $\mathbf{4 . 6}$ of this document. 
Although "testimonials" are not a sound basis for evaluating the effectiveness of a programme, they can provide insights into its running and on whether participants find it worthwhile. However, approaches that are based upon testimonials might expend significant resources and capacity on programmes that may be ineffective or may even make things worse (Dahlberg \& Butchart, 2005). Various criteria have now been proposed to more systematically evaluate the effectiveness of different programmes. The most stringent criteria involve programme evaluation using experimental or quasi-experimental designs; evidence of significant preventive effects; evidence of sustained effects; and the independent replication of outcomes.

In spite of the emphasis on and visibility of efforts to promote gender equality and prevent intimate partner and sexual violence, very few of the programmes reviewed in this chapter meet all of these criteria, while others have not been subjected to any kind of scientific evaluation. Rigorous scientific evaluation of programmes for preventing intimate partner and sexual violence are even rarer in LMIC. The field of intimate partner and sexual violence prevention must therefore be considered to be at its earliest stages in terms of having an established evidence base for primary prevention strategies, programmes and policies. The limited evidence base for intimate partner and sexual violence prevention has three important implications for this chapter.

First, the chapter extrapolates, when relevant, from the stronger evidence base for child maltreatment and youth violence prevention, but clearly signals that these extrapolations remain speculative. Much, however, can be learned from the literature on youth violence and child maltreatment prevention.

Second, the chapter describes those primary prevention programmes which have the potential to be effective either on the grounds of theory or knowledge of risk factors - even if there is currently little or no evidence to support them or where, in certain cases, they have not yet been widely implemented. In the process, an attempt is made to draw attention to the underlying theories, principles and mechanisms on which the programmes are based. However, it is noted that a firm theoretical base and consistency with identified risk factors does not guarantee the success of a programme.

Third, the chapter includes programmes developed in LMIC settings on condition that they have some supporting evidence (even if it is weak) or are currently in the process of being evaluated, that they appear to have potential on theoretical grounds, or that they address known risk factors. The inclusion criteria are designed on the one hand to avoid setting the bar of methodological standards too high - which would lead to the exclusion of many of the programmes developed in low-resource settings on the grounds that they have no or low-quality evidence supporting them. On the other hand, setting the bar too low would run the risk of appearing to endorse programmes unsupported by evidence. However, the limitations of the evidence presented are clearly spelt out and the need for rigorous outcome evaluation studies emphasized.

Although still in its early stages, there are sound reasons to believe that this field is poised to expand rapidly in coming years. Some programmes have been demonstrated to be effective following rigorous outcome evaluations, evidence is beginning to emerge to support the effectiveness of many more, and suggestions for potential strategies have proliferated. Furthermore, tried and tested methods for developing effective evidencebased primary prevention programmes and policies for other forms of interpersonal violence have been reported (for example, Flay et al., 2005; Mzarek \& Haggerty, 1994; Olds, Sadler \& Kitzman, 2007). The field of evidence-based intimate partner and sex- 
ual violence prevention now requires an open mind to promising approaches, and to innovative new ideas at all stages of the life cycle.

\subsection{Summary tables of primary prevention strategies and programmes ${ }^{1}$}

Table 5 summarizes the strength of evidence for the effectiveness of those strategies to prevent intimate partner violence and sexual violence for which some evidence is available. Strategies are grouped according to life stage. An important distinction must be drawn between a strategy and a specific programme. Although specific programmes may have been demonstrated to be effective, this in no way implies that all other programmes categorized under the same strategy are also effective. For example, the Nurse Family Partnership, developed in the USA, is a home-visitation programme that has been demonstrated to be effective in preventing child maltreatment. Nevertheless, it is the only programme within the broader strategy of home visitation (which includes a multitude of different programmes) that is supported by solid evidence of its effectiveness (MacMillan et al., 2009).

Strategies are ranked for their effectiveness in preventing intimate partner violence and sexual violence as follows:

- Effective: strategies which include one or more programmes demonstrated to be effective; effective refers to being supported by multiple well-designed studies showing prevention of perpetration and/or experience of intimate partner and/or sexual violence;

Emerging evidence: strategies which include one or more programmes for which evidence of effectiveness is emerging; emerging evidence refers to being supported by one well-designed study showing prevention of perpetration and/or experience of intimate partner and/or sexual violence or studies showing positive changes in knowledge, attitudes and beliefs related to intimate partner violence and/or sexual violence;

? Effectiveness unclear: strategies which include one or more programmes of unclear effectiveness due to insufficient or mixed evidence;

$X$ Emerging evidence of ineffectiveness: strategies which include one or more programmes for which evidence of ineffectiveness is emerging; emerging evidence refers to being supported by one well-designed study showing lack of prevention of perpetration and/or experience of intimate partner and/or sexual violence or studies showing an absence of changes in knowledge, attitudes and beliefs related to intimate partner violence and/or sexual violence;

X Ineffective: strategies which include one or more programmes shown to be ineffective; ineffective refers to being supported by multiple well-designed studies showing lack of prevention of perpetration and/or experience of intimate partner and/or sexual violence;

XX Probably harmful: strategies which include at least one well-designed study showing an increase in perpetration and/or experiencing of intimate partner and/

\footnotetext{
1 Since the development of prevention strategies has not mirrored the identification of risk and protective factors, the organization of this chapter does not parallel that of Chapter 2. However, the previously identified risk factors are highlighted in this chapter.
} 
or sexual violence or negative changes in knowledge, attitudes and beliefs related to intimate partner and/or sexual violence;

As shown in Table 5, there is currently only one strategy for the prevention of intimate partner violence that can be classified "effective" at preventing actual violence. This is the use of school-based programmes to prevent violence within dating relationships. However, only three such programmes - described below - have been demonstrated to be effective and these findings cannot be extrapolated to other school-based programmes using a different approach, content or intensity. At present, there are no correspondingly evaluated effective programmes against sexual violence.

Table 6 lists those strategies for which there is currently no evidence or very weak evidence but which appear to have potential on the grounds of theory, known risk factors, or outcome evaluations that are methodologically of lower quality; it also includes some promising strategies that are currently undergoing evaluation.

All the strategies reviewed have been organized according to the main life stages. When strategies are relevant to more than one stage of life, they have been categorized under the stage at which they are most often delivered. Strategies relevant to all life stages are described last. In contrast to the formal definitions in section 1.1 and because of the way programmes are organized, intimate partner violence is considered here to include instances of sexual violence that occur within an intimate partnership, while sexual violence is used here to refer to sexual violence occurring outside intimate partnerships (i.e. perpetrated by friends, acquaintances or strangers). Dating violence can be considered to incorporate both possibilities since dating partners can range from being little more than acquaintances to more intimate partners. However, in Table 5 and Table 6, dating violence is classified for the sake of convenience under intimate partner violence.

\section{$\mathrm{BOX} 2$}

\section{Outcome measures of effectiveness}

The effectiveness of a programme can be evaluated in terms of three different types of outcome - each of which can be measured at different intervals after the programme:

1. Changes in knowledge, attitudes and beliefs regarding intimate partner and sexual violence. This is the weakest of the three outcomes because changes in knowledge, attitudes and beliefs do not necessarily lead to changes in violence behaviour. In this respect, even successful programmes in this area cannot be assumed to be effective at preventing actual intimate partner or sexual violence without further research demonstrating corresponding reductions in violent behaviour.

2. Reductions in the perpetration of intimate partner or sexual violence.

3. Reductions in the experiencing of intimate partner or sexual violence.

Intimate partner violence is not a unitary construct and can take different forms, including physical, sexual and psychological violence. Despite this, outcome evaluations generally do not examine effectiveness in relation to these different types of violence - nor are programmes generally designed to address specific types of intimate partner violence in particular. It is possible that programmes considered to be effective or promising may only be so for certain forms of intimate partner violence (Whitaker, Baker \& Arias, 2007). 
TABLE 5

Primary prevention strategies for intimate partner violence and sexual violence for which some evidence is available

\begin{tabular}{|c|c|c|}
\hline STRATEGY & $\begin{array}{l}\text { INTIMATE } \\
\text { PARTNER } \\
\text { VIOLENCE }\end{array}$ & $\begin{array}{l}\text { SEXUAL } \\
\text { VIOLENCE }\end{array}$ \\
\hline \multicolumn{3}{|l|}{ DURING INFANCY, CHILDHOOD AND EARLY ADOLESCENCE } \\
\hline $\begin{array}{l}\text { Interventions for children and adolescents subjected to child maltreatment } \\
\text { and/or exposed to intimate partner violence }\end{array}$ & $\square$ & $?$ \\
\hline $\begin{array}{l}\text { School-based training to help children recognize and avoid potentially } \\
\text { sexually abusive situations }\end{array}$ & $?$ & $\square$ \\
\hline \multicolumn{3}{|l|}{ DURING ADOLESCENCE AND EARLY ADULTHOOD } \\
\hline School-based programmes to prevent dating violence & $\mathbf{\square}$ & NA \\
\hline Sexual violence prevention programmes for school and college populations & NA & $?$ \\
\hline $\begin{array}{l}\text { Rape-awareness and knowledge programmes for school and college } \\
\text { populations }\end{array}$ & NA & $x$ \\
\hline $\begin{array}{l}\text { Education (as opposed to skills training) on self-defence strategies for } \\
\text { school and college populations }\end{array}$ & NA & $\mathbf{x}$ \\
\hline Confrontational rape prevention programmes & NA & $\mathbf{x X}$ \\
\hline \multicolumn{3}{|l|}{ DURING ADULTHOOD } \\
\hline $\begin{array}{l}\text { Empowerment and participatory approaches for addressing gender } \\
\text { inequality: Microfinance and gender-equality training }\end{array}$ & $\square$ & $?$ \\
\hline $\begin{array}{l}\text { Empowerment and participatory approaches for addressing gender } \\
\text { inequality: Communication and relationship skills training (e.g. Stepping } \\
\text { Stones) }\end{array}$ & $\square$ & $?$ \\
\hline Home-visitation programmes with an intimate partner violence component & $?$ & $?$ \\
\hline \multicolumn{3}{|l|}{ ALL LIFE STAGES } \\
\hline Reduce access to and harmful use of alcohol & $\square$ & $?$ \\
\hline $\begin{array}{l}\text { Change social and cultural gender norms through the use of social norms } \\
\text { theory }\end{array}$ & $?$ & $\square$ \\
\hline $\begin{array}{l}\text { Change social and cultural gender norms through media awareness } \\
\text { campaigns }\end{array}$ & $\square$ & $?$ \\
\hline $\begin{array}{l}\text { Change social and cultural gender norms through working with men and } \\
\text { boys }\end{array}$ & $\square$ & $?$ \\
\hline
\end{tabular}

- Effective: strategies which include one or more programmes demonstrated to be effective; effective refers to being supported by multiple well-designed studies showing prevention of perpetration and/or experiencing of intimate partner and/or sexual violence;

$\square \quad$ Emerging evidence of effectiveness: strategies which include one or more programmes for which evidence of effectiveness is emerging; emerging evidence refers to being supported by one well-designed study showing prevention of perpetration and/or experiencing of intimate partner and/or sexual violence or studies showing positive changes in knowledge, attitudes and beliefs related to intimate partner violence and/or sexual violence;

? Effectiveness unclear: strategies which include one or more programmes of unclear effectiveness due to insufficient or mixed evidence;

$X \quad$ Emerging evidence of ineffectiveness: strategies which include one or more programmes for which evidence of ineffectiveness is emerging; emerging evidence refers to being supported by one well-designed study showing lack of prevention of perpetration and/or experiencing of intimate partner and/or sexual violence or studies showing an absence of changes in knowledge, attitudes and beliefs related to intimate partner violence and/or sexual violence;

X Ineffective: strategies which include one or more programmes shown to be ineffective; ineffective refers to being supported by multiple well-designed studies showing lack of prevention of perpetration and/or experiencing of intimate partner and/or sexual violence;

XX Probably harmful: strategies which include at least one well-designed study showing an increase in perpetration and/or experiencing of intimate partner and/or sexual violence or negative changes in knowledge, attitudes and beliefs related to intimate partner and/or sexual violence;

NA Not applicable. 
TABLE 6

Primary prevention strategies for intimate partner violence and sexual violence with potential

\begin{tabular}{l}
\hline STRATEGY \\
\hline DURING INFANCY, CHILDHOOD AND EARLY ADOLESCENCE \\
\hline Home-visitation programmes to prevent child maltreatment \\
\hline Parent education to prevent child maltreatment \\
\hline Improve maternal mental health \\
\hline Identify and treat conduct and emotional disorders \\
\hline School-based social and emotional skills development \\
\hline Bullying prevention programmes \\
\hline DURING ADOLESCENCE AND EARLY ADULTHOOD \\
\hline School-based multi-component violence prevention programmes \\
\hline DURING ADULTHOOD \\
\hline United States Air Force multi-component programme to prevent suicide \\
\hline Empowerment and participatory approaches for addressing gender inequality - SASA! \\
\hline
\end{tabular}

\subsection{During infancy, childhood and early adolescence}

\section{Home-visitation and parent-education programmes to prevent child maltreatment}

As noted in earlier sections of this document, a history of child maltreatment substantially increases the risk of an individual becoming either a perpetrator or victim of intimate partner violence and of sexual violence. It is therefore reasonable to assume that preventing child maltreatment has the potential to reduce subsequent intimate partner and sexual violence (Foshee, Reyes \& Wyckoff., 2009). However, direct evidence of the effect of such programmes on the levels of intimate partner violence is currently still lacking.

In general however, reducing the risk of the different forms of child maltreatment reviewed in Preventing child maltreatment: a guide to taking action and generating evidence (WHO-ISPCAN, 2006) ${ }^{1}$ can contribute to reducing the intergenerational transmission of violence and abuse. The most promising strategies for preventing child maltreatment in this area include home visitation and parent education programmes (Mikton \& Butchart, 2009). However, neither type of programme has been evaluated for its long-term effects on the prevention of intimate partner and sexual violence among the grown-up children of parents who were involved in such programmes.

\section{Improve maternal mental health}

Maternal depression (which affects at least 1 in 10 new mothers) can interfere with good bonding and attachment processes. This in turn increases the risk of persistent conduct disorders in children (a key risk factor for the later perpetration of violence) by as much as five-fold (Meltzer et al., 2003). Effective approaches for addressing maternal depression include early recognition (antenatally and postnatally) followed by peer and

\footnotetext{
1 To obtain this guide, please visit: www.who.int/violence_injury_prevention/violence/activities/child_
} maltreatment/en/index.html 
social support, psychological therapies and antidepressant medication (National Collaborating Centre for Mental Health, 2007). The long-term effects on the children of mothers treated for maternal depression in terms of their later involvement in intimate partner and sexual violence have not been assessed, but the approach appears to have potential.

\section{Identify and treat conduct and emotional disorders in children}

Conduct disorders in childhood and adolescence - a precursor of antisocial personality disorder - are associated with an increased risk of experiencing and/or perpetrating intimate partner and sexual violence. Additionally, emotional disorders are associated with later depression and anxiety in adult years and can increase the risk of postnatal depression and persistent maternal depression. As outlined above, these in turn contribute to as much as a five-fold increased risk of emotional or conduct disorders in the children of mothers with poor mental health (Meltzer et al., 2003). The early identification and effective treatment of conduct and emotional disorders in childhood and adolescence could therefore be expected to reduce the occurrence of subsequent intimate partner and sexual violence.

Good evidence exists of the links between early conduct disorder and later involvement in violence as both victim and perpetrator, and of the effectiveness of interventions to reduce conduct disorder and youth offending. However, despite their potential, there is at present no evidence showing that the strategy of identifying and treating conduct and emotional disorders in childhood or early adolescence leads to reductions in intimate partner and sexual violence during later adolescence and adulthood.

Interventions for children and adolescents subjected to child maltreatment and/or exposed to intimate partner violence

As discussed in section 2.3, because children or adolescents who have been subjected to child maltreatment or exposed to parental violence are at increased risk of becoming the perpetrators and victims of intimate partner and sexual violence, interventions in this area are particularly important.

One meta-analysis (Skowron \& Reinemann, 2005) examined 21 programmes involving psychological interventions targeted at children and adolescents who had experienced child maltreatment. Results suggested that psychological treatments for child maltreatment yielded improvements among participants: some $71 \%$ of treated children appeared to be functioning better than their non-treated counterparts. All of the interventions were designed to improve cognitive, emotional and behavioural outcomes, with 11 of the studies considered to be experimental. A randomized trial of one of these programmes (the Youth Relationship Project - section 3.5) used adolescent dating violence as an outcome and found a reduction in the experiencing and perpetration of physical and emotional abuse (Wolfe et al., 2003).

Psychological interventions for children and adolescents subjected to child maltreatment and/or exposed to intimate partner violence therefore appear to represent a strategy for the prevention of intimate partner violence supported by emerging evidence. Their effect on sexual violence remains unclear at present. 


\section{School-based social and emotional skills development}

Factors such as impulsiveness, lack of empathy and poor social competence - which may be indicative of conduct disorder, a precursor of antisocial personality disorder - are important individual risk factors for perpetrating various forms of violence, including intimate partner and sexual violence. Cognitive-behavioural skills training programmes and social development programmes that address these factors in children and young adolescents are therefore promising strategies for preventing subsequent violence. These programmes seek to promote pro-social behaviour and to provide social and emotional skills such as problem-solving, anger management, increased capacity for empathy, perspective-taking and non-violent conflict resolution. They can either be population-based or targeted at those at high risk, and are typically delivered in schools.

While there is strong evidence that such programmes can be effective in reducing youth violence and improving social skills (e.g. Lösel \& Beelmann, 2003), there is currently no evidence that they can reduce sexual and dating violence among adolescents and young adults, or intimate partner and sexual violence later in life. Nonetheless, they appear to have potential in preventing subsequent intimate partner violence and sexual violence.

\section{School-based training to help children to recognize and avoid potentially sexually} abusive situations

School-based programmes to prevent child sexual abuse by teaching children to recognize and avoid potentially sexually abusive situations are run in many parts of the world, but evaluated examples come mainly from the United States.

A recent systematic review of reviews (Mikton \& Butchart, 2009) found that although school-based programmes to prevent child sexual abuse are effective at strengthening knowledge and protective behaviours against this type of abuse, evidence showing whether such programmes reduce its actual occurrence is lacking. Two studies that measured future experience of sexual abuse as an outcome reported mixed results (Finkelhor, Asdigian \& Dziuba-Leatherman, 1995; Gibson \& Leitemberg, 2000). Nonetheless, emerging evidence of their effectiveness in preventing subsequent sexual abuse victimization appears to support the use of such programmes. Further research on the long-term impact on actual sexual abuse victimization is however required (Finkelhor, 2009).

\section{Bullying prevention programmes}

Bullying has both immediate and long-term consequences on perpetrators and victims, including social isolation and the exacerbation of antisocial behaviour that can lead to juvenile and adult crime (for perpetrators) and depression, suicidal ideation, social isolation and low self-esteem (for victims). Some of these consequences may increase the risk of later involvement in intimate partner and/or sexual violence either as perpetrator or victim. A number of reviews have concluded that bullying prevention programmes are effective in reducing bullying (Baldry \& Farrington, 2007; Smith et al., 2004). A systematic review and meta-analysis of school-based programmes to reduce bullying and victimization (Farrington \& Ttofi, 2009) showed that, overall, school-based bullying prevention programmes are effective in reducing both bullying and being bullied. On average, bullying perpetration decreased by $20-23 \%$ and the experiencing of being bullied decreased by $17-20 \%$. 
Although such programmes are likely to have broader potential benefits, evidence of their effect on the experiencing or perpetrating of intimate partner and/or sexual violence later in life is limited. A number of studies, however, have demonstrated an association between bullying and sexual harassment. Some sexual violence prevention programmes in the United States include bullying prevention components for elementary and middle school age children (Basile, Hertz \& Back, 2009).

\subsection{During adolescence and early adulthood}

\section{School-based programmes to prevent dating violence}

Dating violence is an early form of partner violence, occurring primarily in adolescence and early adulthood, and experienced within a "dating relationship". Dating violence prevention programmes have been the most evaluated of all intimate partner violence prevention programmes with 12 evaluations of adolescent dating violence prevention programmes, including five randomized trials (Foshee et al., 2008). Targeted at early sexual relationships, in contexts where marriage is usually entered into from about 20 years of age, these programmes have been shown to prevent dating violence and sexual violence. Furthermore, dating violence appears to be a risk factor for intimate partner violence later in life (Smith, White \& Holland, 2003) and is also associated with injuries and health-compromising behaviours, such as unsafe sex, substance abuse and suicide attempts (Wolfe et al., 2009). Accordingly, the prevention of dating violence can be assumed to be preventive of intimate partner and sexual violence in later life (Foshee, Reyes \& Wyckoff., 2009).

One dating violence prevention programme that has been well evaluated using a randomized-controlled design is Safe Dates. Positive effects were noted in all four published evaluations (Foshee et al., 1998; Foshee et al., 2000; Foshee et al., 2004; Foshee et al., 2005). Foshee et al. (2005) examined the effects of Safe Dates in preventing or reducing perpetration and victimization over time using four waves of follow-up data. The programme significantly reduced psychological, moderate physical and sexual dating violence perpetration at all four follow-up periods. The programme also significantly reduced severe physical dating abuse perpetration over time, but only for adolescents who reported no or average prior involvement in severe physical perpetration at baseline. Programme effects on the experiencing of sexual dating violence over time were marginal. Safe Dates did not prevent or reduce the experiencing of psychological dating abuse. Programme effects were primarily due to changes in dating violence norms, gender role norms and awareness of community services. The programme did not affect conflict-management skills. The programme was found to have had a greater impact upon primary prevention as opposed to preventing re-abuse among those with a history of previous abuse (Foshee et al., 1996; 1998; 2000; 2004; 2008).

Two school-based programmes for preventing dating violence in Ontario, Canada have also been evaluated (Wolfe et al., 2003; Wolfe et al., 2009). An outcome evaluation of The Fourth R: Skills for Youth Relationships used a cluster-randomized design and found that, based on self-reported perpetration at 2.5-year follow-up, rates of physical dating violence were $7.4 \%$ in the programme group and $9.8 \%$ in the control group - a difference of $2.4 \%$. However, for reasons not fully understood, this decrease of self-reported perpetration was found in boys $(7.1 \%$ in controls versus $2.7 \%$ in intervention students) 
but not in girls $(12.1 \%$ versus $11.9 \%) .{ }^{1}$ The programme - evaluated by sampling over 1700 hundred students aged 14-15-years from 20 public schools - was integrated into the existing health and physical education curriculum, and taught in sex-segregated classes. An underlying theme of healthy, non-violent relationship skills was woven throughout the 21 lessons, which included extensive skills development using graduated practice with peers to develop positive strategies for dealing with pressures and the resolution of conflict without abuse or violence. The cost of training and materials averaged 16 Canadian dollars per student (Wolfe et al., 2009).

The other Canadian school-based programme which has been evaluated (Wolfe et al., 2003) is the Youth Relationship Project. This community-based programme aimed to help 14-16 year-olds who had been maltreated as children to develop healthy non-abusive relationships with dating partners. The programme educated participants on both healthy and abusive relationships and helped them to acquire conflict resolution and communication skills. A randomized-controlled trial showed that the programme had been effective in reducing incidents of physical and emotional abuse, and the symptoms of emotional distress over a 16-month period after the programme (Wolfe et al., 2003).

These three school-based programmes therefore appear to be effective for the prevention of physical, sexual and emotional violence in dating relationships in adolescents, and may also help to prevent intimate partner and sexual violence among adults. However, there are a number of necessary caveats concerning dating violence prevention programmes. Although high-quality evaluations of the three programmes described above found reduced violence at moderately long follow-up periods, the evaluations of most other programmes have been of poor quality, used short follow-up periods, and only included knowledge and attitude changes as outcomes (for which some positive effects were found). Whether changes in knowledge and attitudes lead to corresponding changes in behaviour is uncertain (Whitaker et al., 2006). Moreover, further research is needed to evaluate the effectiveness of dating violence prevention programmes in the longer term, when integrated with programmes for the prevention of other forms of violence, and when delivered outside North America and in resource-poor settings. A particular concern that has been raised about programmes such as Safe Dates is the extent to which they are culture-bound to North America and hence may be of limited value in LMIC.

\section{School-based multi-component violence prevention programmes}

Universal multi-component programmes are the most effective school-based violence prevention programmes (Adi et al., 2007; Dusenbury et al., 1997; Hahn et al., 2007). Such programmes are delivered to all pupils and go beyond the normal components of curriculum-based teaching to include teacher training in the management of behaviour, parenting education and peer mediation. There can also be after school activities and/or community involvement. One systematic review (Hahn et al., 2007) estimated that on average, universal multi-component programmes reduced violence by $15 \%$ in schools that delivered the programmes compared to those that did not.

1 These rates of perpetration by boys and girls are broadly in keeping with findings of sex-symmetry in young men and women's self-reported partner assaults in North America mentioned in the Introduction. 
School-based multi-component violence prevention programmes have mostly focused upon bullying and youth violence as outcomes. Given that the risk factors for youth violence and intimate partner and sexual violence are to some extent shared, such programmes would appear to have some potential for preventing these latter forms of violence. However, there is currently no evidence of their effectiveness in these areas.

\section{Sexual violence prevention programmes for school and college populations}

In the United States, the majority of programmes for the primary prevention of sexual violence by strangers, acquaintances and non-intimate dating partners have focused on college students - though they have also increasingly been delivered to high school and middle school pupils. In settings where few go into higher education this approach has obvious limitations. Developmentally, it makes sense to educate young people in appropriate and inappropriate sexual behaviour at a time when their sexual identities are forming and their attitudes to romantic partners are beginning to take shape. However, once again there is a severe paucity of evidence to confirm the effectiveness or otherwise of such programmes (Schewe, 2007).

Two recent systematic reviews in the United States have evaluated the effectiveness of specific primary prevention programmes in this area. The first of these (Morrison et al., 2004) included both college, high-school and middle-school populations, and found that programmes usually included several components (most often the challenging of rape myths; information on acquaintance and date rape; statistics on rape; and riskreduction and protective prevention skills). Of the 50 studies reviewed, seven (14\%) showed exclusively positive effects on knowledge and attitudes, but none used the actual experiencing or perpetration of violence as outcomes; 40 (80\%) reported mixed effects; and three $(6 \%)$ indicated no effect. The studies also had a number of serious methodological limitations that led the reviewers to conclude that the effectiveness of such programmes remains unclear. These limitations included the use of knowledge and attitude as the only outcome measures; studies of higher-quality design showing poorer results; and the positive effects of the programmes being found to diminish over time.

The second systematic review (Anderson \& Whiston, 2005) examined 69 education programmes for college students on sexual assault, and found little evidence of the effectiveness of such programmes in preventing such assaults, or in increasing levels of rape empathy (the cognitive-emotional recognition of a rape victim's trauma) or awareness. However, the programmes evaluated were found to increase factual knowledge about rape and to beneficially change attitudes towards it. The acute shortage of studies that use behaviour as outcomes led the authors to conclude that more research using such outcomes was needed before definitive conclusions could be reached. The effectiveness of such programmes, on the basis of these two reviews, is currently unclear.

It has been found that the provision of "factual" information" as part of addressing rape myths appears to have no effect on attitudes to rape or on the levels of empathy for its victims (Schewe, 2007). Evaluation studies indicate that rape awareness and knowledge programmes based on imparting such information rarely work. Similarly, educating women on effective self-defence strategies without teaching them actual self-defence

\footnotetext{
1 Such information typically includes: the legal definition of rape and associated legal terms; statistics on the prevalence of rape; descriptions of typical perpetrators and of the rape trauma syndrome; and information on available resources for rape victims.
} 
skills has been found to be of questionable value, and may even be potentially harmful in some contexts (Schewe, 2007). Two evaluations of programmes that focused on a discussion of self-defence strategies without teaching the corresponding skills found no reduction in sexual assault risk at follow-up (Breitenbecher \& Gidycz, 1998; Breitenbecher \& Scarce, 2001). Rape prevention programmes that use a style of personal confrontation with participants actually appear to be harmful. One study evaluating such a programme found that it resulted in greater tolerance among men of the justifiability of rape (Fisher, 1986).

A number of other approaches have been tried for which there is presently very limited evidence of effectiveness. Encouraging victim empathy has been associated with both improvements and worsening of attitudes towards sexual violence and the acceptance of rape myths (Schewe, 2007). Educating women on how to avoid high-risk situations (such as hitchhiking, abusing alcohol or becoming involved with older men) has also led to mixed results and it too has been associated with greater acceptance of rape myths. To avoid the encouragement of victim-blaming, it is crucial that such education is delivered to female-only audiences. There have also been mixed indications of the effectiveness of programmes that emphasize the negative consequences of sexual violence to men, and that try to persuade them to see such sex as less rewarding than consensual sex.

Finally, several programmes for preventing sexual violence have been proposed that have as yet been neither widely implemented nor evaluated. These include providing universal rape prevention education, and parent education in sexual violence prevention, throughout schools and workplaces; educating teachers and coaches about sexual violence and its prevention; and changing organizational practices to include activities such as mandatory training in the prevention of violence against women.

\subsection{During adulthood}

\section{Empowerment and participatory approaches to reduce gender inequality}

Empowerment is an approach that helps individuals and communities to identify their own problems and to develop, through participatory methods, the resources, skills and confidence needed to address them. This approach emphasizes the role of individuals and communities as agents of change and prioritizes community ownership and leadership of the entire process. Comprehensive programmes deal with the community as a whole or with multiple subgroups of the population; have several components; and are designed to effect social change by creating a supportive environment for changing individual and community attitudes and behaviour. Such approaches often utilize a combination of participatory rapid needs assessment, education or training, public awareness campaigns and community action (Lankester, 1992; Morley et al, 1983). Two examples of empowerment approaches for preventing intimate partner violence are the use of microfinance with gender-equality training and the Stepping Stones training package.

A number of initiatives involving microfinance have now been established to increase the economic and social power of women. These initiatives provide small loans to mobilize income-generating projects that can alleviate poverty. Stand alone credit and rural development programmes such as Grameen Bank and the Bangladesh Rural Advancement Committee target women and appear to show some promise in reducing intimate partner violence. However, the evaluation of such programmes needs to take into 
account reports of lenders exploiting disadvantaged borrowers with very high rates of interest which can trap people in debt and contribute to further poverty (Rhyne, 2001) as well as reports of increases in intimate partner violence (Kabeer, 2001). Disagreements over the control of newly acquired assets and earnings, combined with women's changing attitudes towards traditional gender roles, improved social support and greater confidence in defending themselves against male authority, has sometimes led to marital conflicts and violence against women perpetrated by their partners (Schuler et al., 1996). Increases in violence following participation in credit programmes have also been reported elsewhere, at least in the initial stages of membership (Ahmed, 2005; Rahman, 1999). Pre-existing gender roles appear to affect the violence-related outcomes of credit programmes - in communities with rigid gender roles, women's involvement can result in increased levels of intimate partner violence not seen in communities with more-flexible gender roles (Koenig et al., 2003). The outcome evaluations conducted to date of such stand alone microfinance programmes have not been as rigorous as that of the Intervention with Microfinance for AIDS and Gender Equity (IMAGE) programme described in Box 3.

\section{$\mathrm{BO} 3$}

\section{Intervention with Microfinance for AIDS and Gender Equity (IMAGE)}

One of the most rigorously evaluated and successful microfinance and women's empowerment programmes to date has been the Intervention with Microfinance for AIDS and Gender Equity (IMAGE) in South Africa. This programme targets women living in the poorest households in rural areas, and combines a microfinance programme with training and skills-building sessions on preventing HIV infection, and on gender norms, cultural beliefs, communication and intimate partner violence.

The programme also encourages wider community participation to engage men and boys. It aims to improve women's employment opportunities, increase their influence in household decisions and their ability to resolve marital conflicts, strengthen their social networks and reduce HIV transmission.

A randomized-controlled trial found that two years after completing the programme, participants reported experiencing 55\% fewer acts of violence by their intimate partners in the previous 12 months than did members of a control group. In addition, participants were more likely to disagree with statements that condone physical and sexual violence towards an intimate partner (52\% of participants versus $36 \%$ of the control group).

While microfinance programmes can operate as discrete entities, IMAGE is an example of such a programme which also incorporates education sessions and skills-building workshops to help change gender norms, improve communication in relationships and empower women in other ways and has been shown to be effective at reducing intimate partner violence (Kim et al., 2009). Through education and skills-building for women and engagement with boys and men, and the broader community, IMAGE was effective in reducing intimate partner violence and supporting women. This was achieved without producing the type of negative effects seen in other settings where cultural shifts and other changes have taken place in the absence of efforts to engage men. 
The Stepping Stones training package ${ }^{1}$ is another participatory approach that promotes communication and relationship skills within communities. Training sessions are run in parallel for single-sex groups of women and men. Originally designed for the prevention of HIV infection, several communities have now incorporated elements of violence prevention. The approach has been used in 40 LMIC in Africa, Asia, Europe and Latin America. Versions of the programme have now been evaluated in a number of countries (Welbourn, 2009). ${ }^{2}$ The most thorough evaluation to date has been a randomized-controlled trial in the Eastern Cape province of South Africa, with participants aged 15-26 years. This study indicated that a lower proportion of men who had participated in the programme committed physical or sexual intimate partner violence in the two years following the programme, compared with men in a control group (Jewkes et al., 2008). Furthermore, an evaluation in Gambia compared two villages where the programme was carried out with two control villages, and followed participating couples over one year. It found that compared to couples not receiving the programme, communication was improved and quarrelling reduced in participating couples. In addition, participating men were found to be more accepting of a wife's refusal to have sex and less likely to beat her (Paine et al., 2002).

$S A S A$ ! is an "activist kit" for mobilizing communities to prevent violence against women, focusing in particular on the connection between HIV/AIDS and violence against women. "Sasa" is a Kiswahili word meaning "now" and the kit includes practical resources; activities monitoring and assessment tools to support local activism, media and advocacy activities; and communication and training materials. It targets community norms and traditional gender roles and aims to change knowledge, attitudes, skills and behaviour to redress the power imbalance between men and women. It was created by Raising Voices, a Uganda-based nongovernmental organization that works in the Horn of Africa, and Southern Africa. The London School of Hygiene and Tropical Medicine, Raising Voices, the Kampala-based Center for Domestic Violence Prevention and Makerere University are currently conducting a joint randomized-controlled trial to evaluate the effectiveness of the approach.

Thus evidence is emerging of the effectiveness in LMIC of empowerment and participatory approaches in preventing intimate partner violence through microfinance combined with gender-equality training, and through the Stepping Stones training package. The results of the $S A S A$ ! evaluation are expected to provide further evidence on the effectiveness of this type of programme which seems to have potential for reducing intimate partner violence. There is a need to replicate and scale up this type of approach.

Several other participatory and community-empowerment strategies to prevent intimate partner violence may be of value, although these have seldom been implemented as primary prevention strategies or rigorously evaluated. Couples counselling focuses on violence and/or substance abuse, and may be effective for couples who have not resorted to intimate partner violence but who may be at risk. Family programmes to promote positive communication and healthy relationships, and prevent family violence, might also be effective in preventing both intimate partner and sexual violence given the importance of family factors in their development. In Ecuador, one intimate partner violence prevention programme that was implemented (but not evaluated) consisted of close

\footnotetext{
1 See: www.steppingstonesfeedback.org

See also: www.creativexchange.org/chd/case3

See: www.raisingvoices.org/sasa/index.php
} 
friends or relatives being assigned to "monitor" newlyweds and to intervene should serious conflict arise. There is also some initial evidence that social cohesion among residents increases a community's capacity to manage crime and violence (by increasing "collective efficacy") leading to decreases in both lethal and non-lethal intimate partner violence. Such community-level interventions can beneficially change community-level characteristics and warrant further evaluation.

\section{Home visitation programmes to prevent intimate partner violence}

A systematic review of home visitation programmes (Bilukha et al., 2005) identified only one evaluation study (Eckenrode, 2000 in the United States) which examined the effect of home visitation on levels of intimate partner violence. No significant difference in the incidence of such violence among the programme and control groups was found.

A five-year project (2007-2012) funded by United States Centers for Disease Control and Prevention is currently under way, which will develop, test and evaluate a programme to reduce intimate partner violence among low-income women enrolled in the Nurse Family Partnership during pregnancy and in the first two years postpartum. The Nurse Family Partnership is a nurse home visitation programme of demonstrated effectiveness in reducing child maltreatment. The primary aims are to develop a model for an in-home intimate partner violence prevention programme for enrolled mothers at risk of such violence; to test the feasibility and acceptability of the programme; and in a randomized-controlled study to compare the effectiveness of the approach to that of the Nurse Family Partnership alone.

An evaluation of the Hawaii Healthy Start Program - an early childhood home visitation programme - found that when compared with a control group, the participation of mothers was associated with reduced perpetration and experiencing of intimate partner violence. The effect persisted for the first three years of a child's life, with small decreases in both the perpetration and experiencing of maternal intimate partner violence at follow-up when the child was seven and nine years-old (Bair-Merrit et al., 2010). Evidence for the effectiveness of such programmes can currently thus be considered to be unclear.

\section{United States Air Force (USAF) multi-component programme to prevent suicide}

This programme was primarily aimed at reducing the rate of suicide among USAF personnel, but was also shown to reduce "family violence" which included both intimate partner violence and child maltreatment. The programme was based upon:

- the full involvement of the USAF leadership to ensure the programme had the support of the entire service;

- incorporation of suicide prevention into professional military education;

- community education and training of military personnel to identify risk factors, provide appropriate intervention, and refer individuals who were potentially at risk of suicide; and

- the creation of a multidisciplinary team consisting of mental health providers, medical providers and chaplains who could respond to traumatic events at the community level, including suicides. 
The programme reduced the rate of suicide by $33 \%$ and the rates of severe and moderate family violence by $54 \%$ and $30 \%$ respectively. Due to the combining of intimate partner violence and child maltreatment in the same outcome measure, it is not possible to determine the effect of the programme on intimate partner violence specifically (Knox et al., 2003), hence this programme is considered to have potential, rather than being supported by emerging evidence.

\subsection{All life stages}

\section{Reduce access to and harmful use of alcohol}

As described in section 2.3, harmful use of alcohol is associated with the perpetration of intimate partner and sexual violence. It can therefore be hypothesized that reducing both access to alcohol and its harmful use will lead to reductions in intimate partner and sexual violence. However, the relationship between harmful use of alcohol and violence is complex - not everyone who drinks is at equally increased risk of committing violence, and intimate partner and sexual violence can occur at high rates in cultures where alcohol use is taboo. Furthermore, there is disagreement among experts on whether or not alcohol can be considered to be a "cause" of intimate partner and sexual violence or whether it is better viewed as a moderating or contributory factor. It seems clear, however, that individual and societal beliefs that alcohol causes aggression can lead to violent behaviour being expected when individuals are under the influence of alcohol, and to alcohol being used to prepare for and excuse such violence. To date, research focusing on the prevention of alcohol-related intimate partner and sexual violence is scarce. There is, however, some emerging evidence suggesting that the following strategies aimed at reducing alcohol consumption may be effective in preventing intimate partner violence.

- Reducing alcohol availability: In Australia, a community intervention that included restricting the hours of sale of alcohol in one town reduced the number of domestic violence victims presenting to hospital (Douglas, 1998). In Greenland, a coupon-based alcohol rationing system implemented in the 1980s that entitled adults to alcohol equivalent to 72 beers per month saw a subsequent $58 \%$ reduction in the number of police call outs for domestic quarrels (Room et al, 2003).

- Regulating alcohol prices: Increasing the price of alcohol is an effective means of reducing alcohol-related violence in general (Chaloupka, Grossman \& Saffer, 2002). Although research evaluating the effectiveness of this approach in reducing intimate partner violence specifically is scarce, one study using economic modelling estimated that in the United States a 1\% increase in the price of alcohol may decrease the probability of intimate partner violence towards women by about 5\% (Markowitz, 2000).

- Treatment for alcohol-use disorders: In the United States, treatment for alcohol dependence among males significantly decreased husband-to-wife and wife-to-husband intimate partner violence 6 and 12 months later (Stuart et al., 2003), suggesting that such treatment may also be an effective primary prevention measure.

Intimate partner and sexual violence may also be reduced through primary prevention programmes to reduce the more general harms caused by alcohol (Anderson, Chisholm \& Fuhr, 2009). Approaches for which effectiveness is well supported by evidence include: 
- Making alcohol less available: This can be achieved by introducing minimum purchase-age policies, and reducing the density of alcohol retail outlets and the hours or days alcohol can be sold. Such an approach has been shown to lead to fewer alcohol-related problems, including homicide and assaults (Duailibi et al., 2007).

- Banning of alcohol advertising: Alcohol is marketed through increasingly sophisticated advertising in mainstream media, through the linking of alcohol brands to sports and cultural activities; through sponsorships and product placements; and through direct marketing via the Internet, podcasting and mobile telephones. The strongest evidence for the link between alcohol advertising and consumption comes from longitudinal studies on the effects of various forms of alcohol marketing including exposure to alcohol advertising in traditional media and promotion in the form of movie content and alcohol-branded merchandise - on the initiation of youth drinking, and on riskier patterns of youth drinking (Anderson et al., 2009). However, evidence showing that such measures reduce intimate partner and sexual violence is currently lacking.

- Individually directed interventions to drinkers already at risk: These include screening and brief interventions. Alcohol screening (such as AUDIT; Babor et al., 2001) and brief interventions in primary health care settings have proven effective in reducing levels and intensity of consumption in LMIC and HIC (Room et al., 2003). However, their direct effect on alcohol-related intimate partner violence has not been measured. Evidence indicates that drinkers may reduce their consumption by as much as $20 \%$ following a brief intervention, and that heavy drinkers who receive such an intervention are twice as likely to reduce their alcohol consumption as heavy drinkers who receive no intervention. Brief interventions include the opportune provision of advice and information in health or criminal justice settings (typically during a 5-10 minute period) but can also extend to several sessions of motivational interviewing or counselling (FPH, 2008; Sheehan, 2008).

School-based education on alcohol does not appear to reduce harm, but public-information and education programmes (while again apparently ineffective at reducing alcoholrelated harm) can increase the attention given to alcohol on public and political agendas (Anderson et al., 2009).

As with most primary prevention programmes to prevent intimate partner and sexual violence, programmes to reduce access to and harmful use of alcohol have mainly been conducted and evaluated in HIC and little is known of their suitability or effectiveness outside such countries. For many LMIC, programmes such as efforts to strengthen and expand the licensing of outlets could be of great value in reducing alcohol-related intimate partner and sexual violence. In many developing societies, a large proportion of alcohol production and sales currently takes place in unregulated informal markets. One study in São Paolo, Brazil (Laranjeira \& Hinkly, 2002) found that just 35\% of alcohol outlets surveyed had a licence of some form, and that alcohol vendors (whether licensed or not) faced few apparent restrictions on trading. Furthermore, in many LMIC there are far fewer specialist health facilities, reducing the opportunities for alcohol treatment or screening. In such settings, it may instead be beneficial to develop the role of primary health care workers or general practitioners in identifying and alleviating the harmful use of alcohol.

Although evidence for the effectiveness of measures to reduce access to and harmful use of alcohol is only beginning to emerge, and high-quality studies showing their 
impact on intimate partner and sexual violence are still largely lacking, alcohol-related programmes for the prevention of intimate partner violence and sexual violence appear promising. The strong association between alcohol and intimate partner and sexual violence suggests that primary prevention interventions to reduce the harm caused by alcohol could potentially be effective. Approaches to preventing alcohol-related intimate partner and sexual violence should also address the social acceptability of excessive drinking as a mitigating factor in violence, while altering normative beliefs about masculinity and heavy drinking. There remains a pressing need for additional research to evaluate the effectiveness of such approaches in reducing intimate partner and sexual violence, especially in LMIC.

\section{Change social and cultural norms related to gender that support intimate partner and sexual violence}

Cultural and social gender norms are the rules or "expectations of behaviour" which regulate the roles and relationships of men and women within a specific cultural or social group. Often unspoken, these norms define what is considered appropriate behaviour, govern what is and is not acceptable, and shape the interactions between men and women. Individuals are discouraged from violating these norms through the threat of social disapproval or punishment, or because of feelings of guilt and shame in contravening internalized norms of conduct. Often traditional social and cultural gender norms make women vulnerable to violence from intimate partners, place women and girls at increased risk of sexual violence, and condone or support the acceptability of violence (Box 4).

Efforts to change social norms that support intimate partner and sexual violence are therefore a key element in the primary prevention of these forms of violence. Approaches have been adopted, although rarely evaluated, throughout the world to break the

\section{BOX 4}

\section{Examples of social and cultural norms that support violence against women}

- A man has a right to assert power over a woman and is considered socially superior e.g. India (Mitra \& Singh, 2007); Nigeria (Ilaka, 2005); and Ghana (Amoakohene, 2004).

A man has a right to physically discipline a woman for "incorrect" behaviour - e.g. India (Go et al., 2003); Nigeria (Adegoke \& Oladeji, 2008); and China (Liu \& Chan, 1999).

- Physical violence is an acceptable way to resolve conflict in a relationship - e.g. the United States (Champion \& Durant, 2001).

- Intimate partner violence is a "taboo" subject - e.g. South Africa (Fox et al., 2007).

- Divorce is shameful - e.g. Pakistan (Hussain \& Khan, 2008).

- Sex is a man's right in marriage - e.g. Pakistan (Hussain \& Khan, 2008).

- Sexual activity (including rape) is a marker of masculinity - e.g. South Africa (Petersen, Bhana \& McKay, 2005).

Girls are responsible for controlling a man's sexual urges - e.g. South Africa (Ilika, 2005; Petersen, Bhana \& McKay, 2005). 
silence that often surrounds intimate partner and sexual violence; to try to inform and influence social attitudes and social norms on the acceptability of violence; and to build political will to address the problem. The use of research findings for advocacy has been shown to be promising in bringing attention to, and raising awareness of, the problem and in contributing to the shaping of reforms and policies (for example, see Ellsberg, Liljestrand \& Winkwist, 1997). Currently the three main approaches for changing social and cultural norms that support intimate partner and sexual violence are: social norms theory (i.e. correcting misperceptions that the use of such violence is a highly prevalent normative behaviour among peers); media awareness campaigns; and working with men and boys. Often several approaches are used in one programme.

Social norms theory assumes that people have mistaken perceptions of other people's attitudes and behaviours. The prevalence of risk behaviours (such as heavy alcohol use or tolerance of violent behaviour) is usually overestimated, while protective behaviours are normally underestimated. This affects individual behaviour in two ways: (i) by increasing and justifying risk behaviours; and (ii) by increasing the likelihood of an individual remaining silent about any discomfort caused by risky behaviours (thereby reinforcing social tolerance). The social norms approach seeks to rectify these misperceptions by generating a more realistic understanding of actual behavioural norms, thereby reducing risky behaviour.

In the United States, the social norms approach has been applied to the problem of sexual violence among college students. Among such students, men appeared to underestimate both the importance most men and women place on sexual consent and the willingness of most men to intervene against sexual assault (Fabiano et al., 2003). Although the evidence is limited, some positive results have been reported. In one university in the United States, the A Man Respects a Woman project aimed to reduce the sexual assault of women, increase accurate perceptions of non-coercive sexual behaviour norms and reduce self-reported coercive behaviours by men. The project used a social norms marketing campaign targeting men, a theatre presentation addressing socialization issues and male peer-to-peer education. Evaluation of the campaign two years after its implementation found that men had more accurate perceptions of other men's behaviour, and improved attitudes and beliefs regarding sexual abuse. For example, a decreased percentage of men believed that the average male student has sex when his partner is intoxicated; will not stop sexual activity when asked to if he is already sexually aroused; and, when wanting to touch someone sexually, tries and sees how they react. However, the percentage of men indicating that they have sex when their partner is intoxicated increased (Bruce, 2002).

Media awareness campaigns are a common approach to the primary prevention of intimate partner and sexual violence. Campaign goals might include raising public awareness (for example, about the extent of the problem, about intimate partner violence and sexual violence as violations of women's human rights and about men's role in ending violence against women); providing accurate information; dispelling myths and stereotypes about intimate partner violence and sexual violence; and changing public opinion. Such campaigns have the potential to reach large numbers of people.

An example of a media-awareness campaign is Soul City in South Africa. ${ }^{1}$ This multimedia health promotion and change project examines a variety of health and development issues, imparts information and aims to change social norms, attitudes and

\footnotetext{
1 www.soulcity.org.za
} 
practice. It is directed at individuals, communities and the socio-political environment. One of its components aims to change the attitudes and norms that support intimate partner and sexual violence. This multi-level intervention was launched over six months and consisted of a series of television and radio broadcasts, print materials and a helpline. In partnership with a national coalition on preventing intimate partner violence, an advocacy campaign was also directed at the national government with the aim of achieving implementation of the Domestic Violence Act of 1998. The strategy aimed for impact at multiple levels from individual knowledge, attitudes, self-efficacy and behaviour; to community dialogue, shifting social norms and the creating of an enabling legal and social environment for change. An independent evaluation of the programme included national surveys before and after the intervention, focus groups and in-depth interviews with target audience members and stakeholders at various levels. It found that the programme had facilitated implementation of the Domestic Violence Act of 1998, had positively impacted on problematic social norms and beliefs (such as that intimate partner violence is a private matter) and had improved levels of knowledge of where to seek help. Attempts were also made to measure its impact on violent behaviour but there was insufficient data to determine this accurately (Usdin et al., 2005).

As the Soul City project indicates, evidence is emerging that media campaigns combined with other educational opportunities can change knowledge, attitudes and beliefs related to intimate partner and sexual violence. While good campaigns can increase knowledge and awareness, influence perceptions and attitudes and foster political will for action, evidence of their effectiveness in changing behaviour remains insufficient (Whitaker, Baker, \& Arias, 2007).

Working with men and boys - there has been an increasing tendency to focus efforts to change social and cultural norms on adolescent males or younger boys using universal or targeted programmes that are delivered through a variety of mechanisms, including school-based initiatives, community mobilization and public awareness campaigns. Objectives typically include increasing an individual's knowledge, changing attitudes towards gender norms and violence and changing social norms around masculinity, power, gender and violence. Some programmes also aim to develop the capacity and confidence of boys and young men to speak up and intervene against violence, with the goal of changing the social climate in which it occurs (Katz, 2006). Failure to engage men and boys in prevention may result in the type of negative effects seen in some settings where cultural shifts and other changes have taken place in the absence of efforts to engage them (Box 5).

A review of programmes that work with men and boys to prevent violence against women (Barker, Ricardo \& Nascimento, 2007) included 13 primary prevention programmes, five of which were implemented in LMIC. Four of these programmes were judged by the reviewers to be "effective"; six "promising"; and three "unclear". For example, one community outreach and mobilization campaign in Nicaragua judged to be effective was called Violence against women: a disaster we can prevent as men (Solórzano, Abaunza \& Molina, 2000). This was aimed at men aged between 20-39 years who were affected by Hurricane Mitch. The campaign's main messages addressed men's ability and responsibility to help prevent or reduce violence against their partners. Constructing masculinity without intimate partner violence was a group-education programme aimed at men in periurban districts of Managua, Nicaragua (Welsh, 1997). The effect of the programme was, however, unclear due to the weakness of the outcome evaluation. Indeed, the methodological quality of most of the outcome evaluations was very low 


\section{BOX 5}

\section{Nicaraguan backlash shows the need to engage men as well}

Since 2000, Nicaragua has pioneered a number of initiatives to protect women against domestic violence. These have included:

a network of police stations for women (Comisaria de la Mujer) where women who have been abused can receive psychological, social and legal support;

- a ministry for family affairs (Mi Familia) which among other responsibilities ensures that shelter is available to women and children who suffer domestic violence; and

reform of the national reproductive health programme to address gender and sexual abuse.

During the same period, civil society groups have campaigned to promote the rights of women and to empower them to oppose domestic abuse. Because of these efforts, the reported frequency of intimate partner violence and sexual violence against women has increased dramatically. The more advocacy and awareness, the more likely women will report violence against them. For example, the number of reported cases of sexual violence received by the Comisaria de la Mujer rose from 4174 (January to June 2003) to 8376 (January to June 2004).

Researchers at the Universidad Centro Americana and the Institute for Gender Studies say a number of factors explain this increase - growing awareness among women that the cultural traditions that foster violence are no longer acceptable under international law and the Nicaraguan Domestic Violence Law; and better reporting of cases as women are encouraged to speak out. However, as Nicaraguan women have more actively opposed male hegemony, domestic conflicts have also increased and more men have resorted to intimate partner violence.

These findings suggest that responses to intimate partner violence must not focus exclusively on women, but must also target men to prevent this type of backlash (Schopper, Lormand \& Waxweiler, 2006).

and outcome measures consisted mainly of attitude changes and self-reported rates of gender-based violence, often using only small sample sizes.

One campaign in New South Wales in Australia - Violence against women: it's against all the rules ${ }^{1}$ - targeted 21-29 year-old men and aimed to influence their attitudes. Sports celebrities delivered the message that violence towards women is unacceptable and that a masculine man is not a violent man. It also sought to enhance the community's capacity to challenge and address violence against women. A post-campaign survey indicated that the campaign achieved some positive results: $83 \%$ of the respondents reported that the message of the campaign was that violence against women is "not on" and $59 \%$ of respondents could recall the campaign slogan. However, $91 \%$ of the target group reported that the issue was not one they would talk about with their peers, irrespective of the campaign.

Similarly, in the United States, Men can stop rape $e^{2}$ runs a public education campaign for men and boys with the message: "my strength is not for hurting". This campaign runs in conjunction with Men of Strength (MOST) clubs - a primary prevention pro-

\footnotetext{
${ }^{1}$ http://lawlink.nsw.gov.au/lawlink/vaw/ll_vaw.nsf/vwPrint1/vaw_vaw_iaatrcampaign

2 www.mencanstoprape.org
} 
gramme which provides high-school-age young men with a structured and supportive space to learn about healthy masculinity, and the redefining of male strength.

While programmes to alter cultural and social norms are among the most visible and ubiquitous of all strategies for preventing intimate partner and sexual violence, they remain one of the least evaluated. Even where evaluations have been undertaken, these have typically measured changes in attitudes and beliefs rather than in the occurrence of the violent behaviours themselves, making it difficult to draw firm conclusions on their effectiveness in actually preventing intimate partner and sexual violence. Nonetheless, some evidence is emerging to support the use of the three types of programmes reviewed above in changing the social and cultural gender norms that support intimate partner and sexual violence. However, these must now be taken to scale and more rigorously evaluated.

\subsection{Key messages}

To achieve change at the population level it is important to target societal-level factors in the primary prevention of intimate partner and sexual violence. Approaches include the enactment of legislation and the development of supporting policies that protect women; addressing discrimination against women; and helping to move the culture away from violence - thereby acting as a foundation for further prevention work.

Currently, there are no strategies of demonstrated effectiveness for preventing sexual violence outside intimate partner or dating relationships. Only one strategy has been demonstrated to be effective in preventing intimate partner violence, namely school-based programmes for adolescents to prevent violence within dating relationships - and this still needs to be assessed for use in resource-poor settings.

Although it is too early to consider them proven, evidence is emerging of the effectiveness of several other strategies for the prevention of intimate partner and sexual violence, particularly the use of microfinance with gender equality training and of programmes that promote communication and relationship skills within communities.

Developing the evidence base for programmes for the primary prevention of intimate partner and sexual violence is still very much in the early stages. But there is every reason to believe that rigorous outcome evaluations of existing programmes and the development of new programmes based on sound theory and known risk factors will lead to a rapid expansion in coming years. 


\section{Improving programme planning and evaluation}

This chapter is based upon the six-step framework shown in Figure $\mathbf{2}$ for implementing intimate partner and sexual violence prevention policies and programmes.

\subsection{Step 1: Getting started}

Identify key partners and develop partnership working arrangements

Partnership involves different sectors and agencies working collaboratively to deliver intimate partner and sexual violence prevention programmes in a coordinated way. Programmes are likely to cut across the activity areas of many different sectors and organizations, and can be large-scale and/or multi-component, often running for extended periods. As a result, effective prevention will require the planning of actions together, and the sharing of funding or other resources according to the strengths and abilities of each partner.

It is important to understand the different activities and agendas of the various sectors working to prevent intimate partner and sexual violence, and to define clear roles and contributions accordingly. Working in partnership to prevent intimate partner and sexual violence has many benefits, and will enhance the understanding of how such violence affects different sectors, and how each sector can contribute to its prevention.

Many of the recognized potential solutions rely upon good working partnerships as intimate partner and sexual violence affect people at every stage of life. Establishing joint working practices and ensuring that processes are in place from the beginning for continued collaboration will help to increase ownership and engagement in the issue, and will help to ensure that the approaches taken are both comprehensive and sustainable. Accordingly all the steps outlined in this chapter should be conducted as a partnership of all the key agencies which are likely to include:

- the health sector (Box 6);

- those working with children and young people, including the educational sector;

- the police and criminal justice sector;

- local government;

- communities; and

- nongovernmental organizations. 
FIGURE 2

Steps for implementing intimate partner and sexual violence prevention policies and programmes

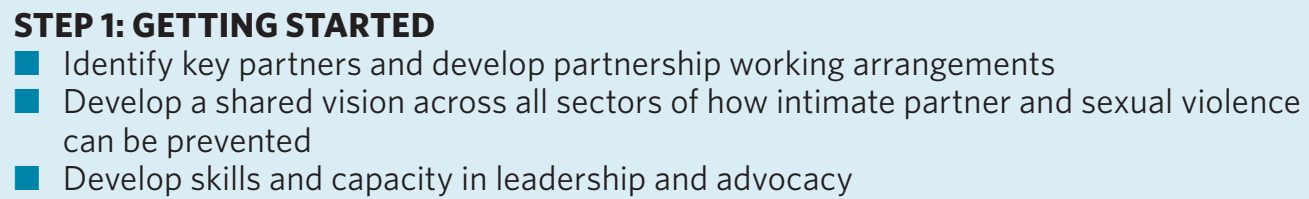

\section{STEP 2: DEFINE AND DESCRIBE THE NATURE OF THE PROBLEM}

Define intimate partner and sexual violence, and describe the size and nature of each problem

- Develop capacity to assess health needs and health impacts

\section{STEP 3: IDENTIFY POTENTIALLY EFFECTIVE PROGRAMMES}

- Identify potentially effective programmes with reference to the nature of the problem and to the evidence base for prevention

\section{$\checkmark$}

STEP 4: DEVELOP POLICIES AND STRATEGIES

- Agree upon a framework for joint policy and strategy development, and prioritize effective programmes

\section{STEP 5: CREATE AN ACTION PLAN TO ENSURE DELIVERY}

- Agree upon the process and timetable for implementation

- Agree upon and define the roles and responsibilities of partners

- Develop professional skills, undertake further training and establish effective networks

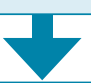

\section{STEP 6: EVALUATE AND SHARE LEARNING}

- Plan and implement appropriate evaluation

- Learn - and then share evidence and promising practice

Factors that are likely to increase the likelihood of success in this area are the development of a shared vision and objectives, clear leadership and established roles as part of a joint strategy and action plan that brings together all these and other partners.

Develop a shared vision across all sectors of how intimate partner and sexual violence can be prevented

Creating a climate for prevention will require a clear and shared vision of how primary prevention programmes can stop intimate partner and sexual violence occurring in the first place. Primary prevention will necessarily involve different sectors and new ways of working together. As part of this, a good "vision statement" can influence people in different sectors and encourage their participation and should be:

- created by a representative group of senior people from key sectors, organizations and affected groups and/or populations; 
BOX 6

\section{The role of the health sector in primary prevention}

The health sector has a key role to play in creating a climate for primary prevention by:

sharing knowledge and raising awareness of the acute and long-term damage to health caused by intimate partner and sexual violence;

raising awareness of the wider health impacts of intimate partner and sexual violence on the development of children and adults, and on the functioning of families and communities; and

applying and sharing public health skills including knowledge of the patterns of, and risk and protective factors for, intimate partner and sexual violence; the critical appraisal of evidence; a whole-population focus; evaluation skills; and working in partnership.

- a statement of a future that everyone wants;

- a statement that shows the benefits for all who participate;

- easy to communicate and understand;

- easily remembered by the widest range of people;

- verifiable in terms of knowing when it has been achieved; and

- reviewed to check that it is strategically aligned with the relevant policies.

\section{Develop skills and capacity in leadership and advocacy}

Leadership skills are essential in supporting those who will turn the shared vision for the prevention of intimate partner and sexual violence into a reality. Good leadership can also help sustain continued ownership of a programme by all sectors and organizations. This will be vital if programmes are to be sustained long enough to achieve the behaviour changes required to reduce the rates of intimate partner and sexual violence. Leadership skills include:

- strong communication and interpersonal skills;

- an ability to accommodate multiple viewpoints and work collaboratively across different sectors with different and sometimes competing needs and interests;

- an ability to adapt to emerging and changing needs;

- maintaining a focus on the realistic delivery of outcomes; and

- helping people to look for and share creative solutions.

Intimate partner and sexual violence often disproportionately affect disadvantaged and vulnerable people who, due to the nature of the violence and their relative lack of power in society, may find it difficult to speak out. Advocacy involves working with and on behalf of those who experience intimate partner and sexual violence to challenge the social and cultural acceptability of such forms of violence and to promote their prevention.

Advocacy can be defined as raising the awareness of an issue for the purpose of affecting the policies, programmes and resources devoted to it. It is a fundamental compo- 
nent of efforts to prevent intimate partner and sexual violence, and is often needed when there is insufficient leadership and/or little or no preventive action being taken. Such advocacy can be carried out by a range of individuals and sectors including voluntary community groups, and nongovernmental and governmental organizations.

Government-sponsored advocacy campaigns can inform people about the magnitude, determinants and consequences of intimate partner and sexual violence in their country and about how these can be prevented. They can also correct public misconceptions surrounding the causes and preventability of such violence. Informational campaigns can then accompany prevention efforts, highlighting for example the unacceptability of violence against women, or the importance of laws to reduce the harmful use of alcohol, or the need to ensure women's rights to property and inheritance. The launch of new policies, programmes, research findings or publications on intimate partner and sexual violence often provides a good opportunity for governments to conduct advocacy efforts. Research findings can be translated into simple figures and pie charts and used to develop advocacy messages for different target audiences. Partnerships between researchers and advocates can be useful in this regard.

Advocacy campaigns can also be built around high-profile events on the global calendar, such as the International day for the elimination of violence against women (25 November) and the annual 16 Days of activism against gender violence campaign ${ }^{1}$ (25 November-10 December). Involving prominent public figures and the local and national media in campaigns built around these events can boost their impact. Advocacy can be made more powerful by using local data, combined with international agreements such as the United Nations resolutions on the elimination of violence against women, human-rights conventions, and World Health Assembly and WHO regional committee resolutions on violence prevention.

Another approach to raising the profile of intimate partner and sexual violence prevention efforts is to identify and cultivate a leading figure in business, political or community life who has demonstrated a strong and authentic interest in championing the prevention of such violence. To be effective this champion must:

- clearly explain the benefits of preventing intimate partner and sexual violence, and encourage others to collaborate in achieving this;

- have credibility or authority at national, regional and local levels;

- maintain good relationships with people across different organizations, sectors and areas; and

- work collaboratively with all sectors that share the goal of preventing intimate partner and sexual violence.

Nongovernmental organizations also play an important advocacy role in helping to prevent intimate partner and sexual violence. Their focus may vary and include, for example, lobbying the government to adopt new legislation and policies. Many nongovernmental organizations also raise awareness at community level and may run education programmes to support this work.

\footnotetext{
1 www.cwgl.rutgers.edu/16days/home.html
} 


\subsection{Step 2: Define and describe the nature of the problem}

\section{Define intimate partner and sexual violence, and describe the size and nature of each problem}

In many parts of the world, information on intimate partner and sexual violence is lacking. As a result, policies and plans to address such violence are often made on the basis of very little information. For example, policies are sometimes created in response to single cases that create significant public and political concern, or are based upon issues that receive a lot of media attention. However, developing policy on this basis can result in misdirected plans that focus on the symptoms rather than the underlying causes, and that consequently have no impact on the problem. Myths and misconceptions surrounding the risk factors, the characteristics of victims and perpetrators, and the likely effects of such violence may also exist. It is only through obtaining accurate information and replacing conjecture with facts that such misconceptions can be dispelled. The study of how often and for what reasons a health problem occurs in specific groups of people is known as "epidemiology" and epidemiological information is crucial in planning and evaluating strategies for the prevention of intimate partner and sexual violence (Box 7).

Ideally, intimate partner and sexual violence will be defined by way of authoritative epidemiological and other reports based upon regularly updated statistics on the nature, extent and consequences of the problems, and their underlying causes and risk factors. Such reports will provide the basis for designing prevention efforts and a baseline against which to measure prevention effectiveness. Data collection should be conducted with input from experts including epidemiologists, statisticians and social scientists.

\section{BOX 7}

\section{What are the benefits of accurate epidemiological information?}

Accurate epidemiological information on intimate partner violence and sexual violence, and on their causes and consequences, can contribute directly to preventing such forms of violence by:

making visible and providing a quantitative description of a problem that for various cultural and social reasons may otherwise remain hidden;

providing ongoing and systematic data on the incidence, causes and consequences of intimate partner and sexual violence at local, regional and national levels;

suggesting priority prevention strategies based on those risk factors for perpetrating and experiencing intimate partner and sexual violence identified in epidemiological studies;

enabling the early identification of emerging trends and problem areas in intimate partner and sexual violence so that appropriate prevention programmes can be established;

giving an overview of the geographical distribution of such violence that can help in targeting programmes aimed at reducing the number of new cases, and in planning the provision of future victim-support services;

providing a baseline against which the impact of prevention efforts can be measured; and

monitoring changes over time in the prevalence and characteristics of intimate partner and sexual violence, and in their associated risk factors. 
Establishing the precise nature and extent of intimate partner and sexual violence in a specific setting will require complementing the conceptual definitions provided in Chapter 1 of this document with operational definitions. An operational definition is a clear, concise and detailed specification of the concept of interest that enables its measurement. This helps to ensure that different people in different settings and at different points in time will be measuring the same precisely defined phenomenon. Further information on the development and use of operational definitions is provided in Annex A.

Different types of data are needed to produce information for different purposes, including: describing the magnitude and impact of intimate partner and sexual violence; understanding the risk factors involved; and determining the efficacy of prevention programmes. Table 7 lists a number of data categories along with the potential sources of such data and the type of information that can typically be collected for each category.

As shown in Table 7, potential data sources range from individual, agency or institutional records, to local programme, community and government records and to population-based and other surveys and special studies. Almost all these sources include basic demographic information (such as age and sex). Some sources (such as medical records, police records, death certificates and mortuary reports) include information specific to the violent event or injury. Data from emergency departments, for example, may provide information on the nature of an injury, how it was sustained, and when and where the incident occurred (though often not on the perpetrator involved). Data collected by the police may include information on the relationship between the victim and the perpetrator, whether a weapon was involved, and other circumstances related to the event. Surveys and special studies can provide detailed information about the victim or perpetrator, and their background, attitudes, behaviours and possible previous involvement in violence. Such sources can also provide a truer estimate of the prevalence of violence compared to records of what is reported to the police or other agencies.

The majority of victims of intimate partner and sexual violence do not seek help. Injuries and other physical and mental health problems resulting from these types of violence are either self-treated or treated by primary care or other health providers such as pharmacists - without necessarily an awareness of the underlying cause. Large-scale population surveys are therefore another particularly important source of data as they provide a more complete picture of the occurrence and consequences of intimate partner and sexual violence. In some settings, an approach has been to forge international partnerships with academic institutions and nongovernmental organizations to obtain funding for an in-country survey or study, although efforts to engage governments in national or smaller surveys are also under way. In many countries, however, accurately describing the nature of the problem remains a major difficulty, especially if there is little routine data or previous studies to draw upon. Time pressures in some settings can also mean that "shortcuts" must be taken. In these situations, information from international studies in similar settings can be used. For example, results obtained from comparable countries in the WHO Multi-country study on women's health and domestic violence against women (Garcia-Moreno et al., 2005), the Demographic and Health Surveys or in other studies presented in Chapter $\mathbf{1}$ of this document can be used. 
TABLE 7

Potential sources of data and information by data category

\begin{tabular}{|c|c|c|}
\hline Data category & Potential data sources & Examples of collected information \\
\hline Mortality & $\begin{array}{l}\text { Death certificates; vital statistics } \\
\text { registries; and reports from } \\
\text { mortuaries, medical examiners } \\
\text { or coroners }\end{array}$ & $\begin{array}{l}\text { Individual characteristics; cause of death; and } \\
\text { time, place and location of death }\end{array}$ \\
\hline $\begin{array}{l}\text { Morbidity and } \\
\text { health related }\end{array}$ & $\begin{array}{l}\text { Hospital, clinical and medical } \\
\text { records }\end{array}$ & $\begin{array}{l}\text { Information on disease, injuries, and physical } \\
\text { or mental health; and on the circumstances and } \\
\text { severity of injury }\end{array}$ \\
\hline $\begin{array}{l}\text { Self-reported } \\
\text { attitudes, beliefs } \\
\text { and practices }\end{array}$ & $\begin{array}{l}\text { Surveys; focus groups; and the } \\
\text { media }\end{array}$ & $\begin{array}{l}\text { Information on attitudes, beliefs and practices; } \\
\text { the experiencing and perpetration of violence; } \\
\text { exposure to violence in the community and } \\
\text { home; and risk behaviours }\end{array}$ \\
\hline Community based & $\begin{array}{l}\text { Demographic records; and local } \\
\text { government records }\end{array}$ & $\begin{array}{l}\text { Population counts; income levels; educational } \\
\text { levels; and unemployment rates }\end{array}$ \\
\hline Criminal data & $\begin{array}{l}\text { Police records; judiciary records; } \\
\text { prison records; and crime } \\
\text { laboratories }\end{array}$ & $\begin{array}{l}\text { Offence type; characteristics of offenders and } \\
\text { victims; and circumstances of event }\end{array}$ \\
\hline Socioeconomic & $\begin{array}{l}\text { Institutional or agency records; } \\
\text { and special studies }\end{array}$ & $\begin{array}{l}\text { Health expenditures; use of services; access to } \\
\text { health care; costs of treatments; personal and } \\
\text { household income; and distribution of income }\end{array}$ \\
\hline $\begin{array}{l}\text { Policy or } \\
\text { legislative }\end{array}$ & $\begin{array}{l}\text { Government and legislative } \\
\text { records }\end{array}$ & $\begin{array}{l}\text { Information on laws and decrees; and on } \\
\text { institutional policies and practices }\end{array}$ \\
\hline
\end{tabular}

Adapted from: Dahlberg \& Krug (2002)

\section{Develop capacity to assess health needs and health impacts}

Most countries lack routinely available information on intimate partner violence and sexual violence. Where this is the case, there are a number of options:

- Dedicated surveys on intimate partner and sexual violence provide the most reliable and in-depth data as these can collect information on prevalence and frequency, impact on health, contextual factors, and on risk and protective factors. However, they are costly and not always easy to repeat. Integrating a module on intimate partner and sexual violence into existing information collection systems and surveys to allow the sustainable and repeated collection of data is a useful alternative, but consideration needs to be given to ensuring ethical and safety standards (Ellsberg \& Heise, 2005). Caution is required, however, as integrating such modules into very broad health surveys may result in underestimates of the problem. Adding only a small number of questions on violence is not recommended as this has been shown to lead to such underestimates and other misleading results. If new research is being developed, it is important to obtain specialized advice and to fully consider safety, confidentiality, ethical and other issues. WHO has developed guidance on the ethical and safety considerations in researching intimate partner violence (WHO, 2001). A manual for researchers and activists on researching violence against women is also available and provides practical advice on implementing surveys and other violence against women studies (WHO/PATH, 2005).

- Data from registers that rely upon professional or public reporting (for example, hospital or police data) are a potentially useful ongoing source of information, and have been used to monitor trends in child abuse in the United States. However, caution should be taken in interpreting this data, as they are subject to changes in report- 
ing policies and tend to under-represent an issue when compared to the findings of representative population surveys.

- Rapid appraisal techniques ${ }^{1}$ are low-cost methods for describing the nature of a problem and can be quickly implemented in a local setting. They usually involve a combination of methods - for example, interviews with stakeholders; focus groups; mapping exercises; and collection and analysis of available data from health facilities, nongovernmental organizations and local authorities (Palmer, 1999). The whole approach can be completed in 2-3 months, and the results provided to the community to stimulate local action and inform planning.

In order to advocate for investment in prevention, inform the design of intimate partner and sexual violence prevention policies and programmes, and monitor the effects of such programmes, it is highly useful to produce information in the following areas:

- Prevalence and incidence of intimate partner and sexual violence - how commonly they affect the population and their trends over time.

- Distribution of such violence - for example, by age, sex, socioeconomic status, setting and location.

- Health consequences - mortality: the number of deaths related to intimate partner or sexual violence. Data can be used to monitor changes over time in fatal violence, identify individuals and groups at high risk of death from such violence and to make comparisons within and between countries. Morbidity/health outcomes: data on diseases, injuries and other health conditions arising from being a victim of intimate partner and/or sexual violence; and on the impact of these on the ability to work and carry out basic living activities.

- Risk factors - at the individual level, for example, sex, young age, history of maltreatment, alcohol misuse and conduct and antisocial behaviours; at the relationship level, for example, multiple partners/infidelity and marital satisfaction/discord; at the community level, for example, related to population characteristics and levels of income, education and unemployment; and at the societal level, for example, social norms related to gender relationships and to the acceptability of violence and laws and policies related to violence.

- Protective factors - for example, school attendance, volunteering and community action and involvement in group activities. This can also include the mapping of services and policies that are effective in prevention.

- Crime data - on the characteristics and circumstances of violent events and violent offenders that come to the attention of the police; on the progress of cases through the courts; and on the proportion of events that end in conviction.

- Economic data - related to the costs of treatment and social services; the economic burden on health care systems; and the possible savings arising from prevention programmes.

- Policies and legislation - including the introduction of policies; and the enactment and enforcement of laws that address a population's experience of risk factors (such as alcohol misuse).

1 For further information, including free resources and examples of rapid-appraisal techniques, see: The Managers Electronic Resource Centre - part of Management Services for Health at: http://erc.msh. org $/$ mainpage.$c f m$ file $=2 \cdot 1.1 \mathrm{~b} \cdot \mathrm{htm} \&$ module $=$ chs $\&$ language $=$ English 
Available data will be essential in informing the next steps. Given limited resources, the data can help to decide upon priority groups (for example, by showing who has the highest number of risk factors for perpetration) and on potential entry points for action. This will then inform the next step of identifying interventions.

\subsection{Step 3: Identify potentially effective programmes}

Identify potentially effective programmes with reference to the nature of the problem and to the evidence base for prevention

In Chapter 3, a summary of the evidence for the effectiveness or otherwise of a broad range of programmes was presented. As noted, most of this evidence comes from HIC and it is therefore important that policy-makers and planners decide what is likely to be most relevant and effective in their own local context, informed by available data. Evidence of effectiveness in a high-income setting may for example assume access to resources and infrastructure that would not be available in a low-income setting, so all programmes will need to be adapted to the local context. In addition, some programmes which are often implemented (such as rape education programmes) have been shown to be ineffective.

Given the scarce resources available for addressing intimate partner and sexual violence, it is crucial that programmes are carefully planned. Implementation should also be stepwise, carefully monitored and on a sufficient scale and over a long enough period to allow for the documentation and evaluation of changes. Capacity to plan, monitor and evaluate programmes will need to be developed in order to ensure this happens.

Prior to the selection and implementation of specific programmes there will be considerable advantages in undertaking a process of "formative evaluation". This process will help to better understand the needs and resources available in a particular setting, and to inform the best approach to take. Together with an understanding of risk factors, this process will help to guide the selection and development of prevention activities (such as whether to employ a media campaign, policy initiative or other prevention strategy).

Once a programme is identified, the broader issues to address will typically include:

- Will the perceived needs of the community be met?

- Are the language and cultural approaches selected respectful of the anticipated audience?

- Are resources being used in the most efficient way to support activities that achieve prevention goals?

- Can the programme be improved?

- Are there ways to make the programme more effective?

- How are people likely to respond to prevention efforts?

- How are people likely to change and benefit from these efforts?

- What real effect is the programme likely to have on preventing intimate partner and sexual violence?

Sources of information will include local or national statistics; surveys or questionnaires; focus groups, interviews, or debriefings; and pre-testing or trial runs. The answers to the questions above can then inform the theory underlying the programme, its goals 
and activities and the implementation of the programme itself. Engaging in formative evaluation can be a highly practical and cost-effective way of ensuring the quality, feasibility and relevance of a prevention approach or message before committing resources on a broad scale.

Different sectors can then work in partnership to identify which programmes are most appropriate for their area, and those approaches that could be developed further to maximize their prevention impact. Taking the sectors listed above in section 4.1, a typical distribution of activity areas might then be:

- The health sector - maternal mental health, parenting, alcohol misuse treatment;

- Those working with children and young people, including the educational sector - violence and abuse prevention skills for children and young people, social and emotional skills development, early intervention for conduct and emotional disorders;

- The police and criminal justice sector - development and enforcement of legislation;

- Local government - reduce access to alcohol and poverty-reduction programmes; and

- Communities and nongovernmental organizations - change cultural norms, microfinance projects, education programmes.

\subsection{Step 4: Develop policies and strategies}

Agree upon a framework for joint policy and strategy development and prioritize effective programmes

Working in partnership, efforts will need to be made to incorporate the outcomes of the three previous steps of the framework into policies and strategies for the prevention of intimate partner and sexual violence. Developing such policies and strategies will be easier where there is clear leadership driving the process, and where working arrangements are developed in meaningful partnership with all key stakeholders as described in Step 1. Developing a joint policy and strategy would then involve the following sequential steps (see also: Schopper, Lormand \& Waxweiler, 2006):

- Agree upon a shared vision and overall framework for preventing intimate partner and sexual violence - for example, the promotion of equal and healthy relationships.

- Clearly set out the nature and importance of the problem - for example, how many people are affected, their age, sex, risk factors, and the impact on individuals (including on their health and education), and on families, communities and the economy.

- Prioritize effective programmes - work with all partners to identify a small set of priority programmes for further action, selected for their appropriateness in a particular setting.

- Ensure that policy leads to action - for example, by gaining endorsement from all the different partners, setting clear priorities and reaching high-level agreement on the steps to take.

This sequential process of developing a specific policy and strategy for the prevention of intimate partner and sexual violence will also help to engage different sectors and 
raise awareness of the issues among decision-makers and the general public. Additionally, efforts are likely to be far more powerful if the relevant activity areas are integrated into wider policy and strategies (for example, on maternal or mental health, alcohol use, education, crime, economic development and urban planning). The degree to which a programme could feasibly be incorporated into such mainstream activities is one of the guiding principles that should be considered and agreed upon by the key partners as part of the prioritizing process (Box 8).

\subsection{Step 5: Create an action plan to ensure delivery}

\section{Agree upon the process and timetable for implementation}

Following the development of policies and an agreed strategy it will be necessary to formulate an action plan - once again ideally in partnership with other sectors. An action plan provides the detail of how to deliver the programmes identified in the strategy. Some strategies contain an action plan at the end of the written report. The following suggested outline areas might usefully be adapted for the development of an action plan according to local context and setting:

- Timetable: specify a timetable for managing all the various steps required to achieve the programme aims (for example, training staff before they provide parenting skills to mothers).

\section{BOX 8}

\section{Factors to consider when prioritizing programmes}

What is the size of the population that would benefit from the programme?

What is the estimated level of health gains among this population after the programme in the short, medium and long term?

What would be the wider gains of the intervention - such as educational, social or economic improvements?

How feasible is mainstreaming the programme within existing established services (for example, for identifying and managing maternal depression as part of antenatal care services)?

What are the approximate costs of implementing the programme based upon current capacity and resources?

- Is there any potential for harm caused by implementing the programme?

- Does the implementing agency have the necessary capacity? If not, can it be built?

- Is the community ready for the programme or are certain steps needed to enhance community readiness?

Are there any financial or cultural barriers, or other obstacles, to implementing the programme, and how easy would it be to overcome these?

Are there any opportunities available that would make a specific programme easier to implement? For example, new policy, funding or resources available in a particular activity area. 
- Define roles and responsibilities, and identify the resources and skills needed: nominate a lead from each sector to take responsibility for ensuring the delivery of each recommended programme and ensure they have the capacity and skills to do it. Different partners will have different resources and capacities that may need to be available at various points in the project. It is important to agree who will provide what input at which time. For example, health-sector staff may train education-sector staff to teach violence prevention skills while local community development workers may be responsible for ensuring that vulnerable children attend events.

- Plan communications: it is important to agree on a plan for communicating the progress and expected benefits of the programme. This may be achieved through the use of media, community meetings or discussions with key individuals (for example, community leaders).

- Engage communities: community engagement emphasizes the role of individuals and communities as agents of change, rather than passive programme recipients. It also places a priority on ensuring community ownership and influence over the change process. All programmes stand to benefit significantly from the increased support and receptiveness to change that results from successful community engagement.

\section{Agree upon and define the roles and responsibilities of partners}

Clearly identifying who will take the leadership role, and coordinating the specific roles and responsibilities of each of the sectors and organizations involved will greatly facilitate the implementation of the agreed strategies and programmes. Each sector should play its part in coordinating efforts so as to ensure synergy and avoid inadvertently undermining the efforts of other partners. This will also require identifying the resources and skills needed to ensure effective implementation.

Develop professional skills, undertake further training and establish effective networks

Developing the necessary skills and training is one of the elements that may need to be put in place. There is a need generally to build capacity for the prevention of intimate partner and sexual violence through, for example, including these issues in the curricula for nurses, doctors and public health practitioners, as well as in-service training for health personnel. In addition, there may be a need, for example, for technical skills to carry out research and set up surveillance systems, or for advocacy and leadership work, including skills in fundraising, media and communications.

Specific training is also likely to be needed in order to implement whichever of the strategies discussed in Chapter $\mathbf{3}$ are selected for the prevention of intimate partner and sexual violence. Where feasible, organizations should support training with other partners, for example, through exchange visits, mentoring and collaboration with other institutions. Such technical exchanges can speed up the uptake of best practices, help formulate policy agendas and create effective networks. These exchanges can also link practitioners with potential technical resources and other forms of assistance. 


\subsection{Step 6: Evaluate and share learning}

Plan and implement appropriate evaluation

Monitoring and evaluation - and dissemination of the results - are core components of the public health approach to preventing intimate partner and sexual violence outlined in the Introduction to this document. Both are necessary to promote evidence-based programme planning and implementation, and programme evaluation is key to programme improvement. Evaluations of a programme can be designed to answer different types of questions - which are likely to vary depending upon the approach taken and the stage reached. Although incorporating evaluation as an integral part of a programme allows for constant monitoring and adjustment as needed, different types of evaluation may be more appropriate at different stages as different questions arise. Evaluation components can then be added or modified as the programme evolves. These components can be divided into the following three principal categories of evaluation:

- Process evaluation to document whether a programme can be (or is being) implemented as planned;

- Outcome evaluation to determine whether a programme has the intended effect on intimate partner and sexual violence (or on its risk and/or protective factors); and

- Economic evaluation to identify the resources needed to conduct, replicate or expand programmes, and to assess the costs and benefits to help determine if the benefits of a programme outweigh its costs.

Process evaluation assesses specific elements of a programme (such as the curriculum, training activities or practical support) to find out if it is being delivered as planned, and to identify gaps between its intended and actual delivery. It can, for example, identify whether the programme is reaching the intended audience, describe what is provided (and how well) and assess the perceptions of audiences and participants and their level of satisfaction with the programme. Process evaluation can also document programme accomplishments.

Information is obtained both on what is working well and what may require refinement. Challenges and barriers can then be identified as they emerge to permit improvements in future responses, or to document those that could not be overcome. If a programme is eventually viewed as successful in preventing intimate partner and sexual violence, then documenting exactly what occurs allows the approach to be continued in the same way. It also increases the likelihood that other groups will be able to achieve similar success if the programme is used elsewhere. If there has been only limited or no success, then process evaluation will help to determine if this can be attributed to problems with the way in which the programme was implemented. This will greatly reduce the risk of discarding a potentially effective programme simply because of implementation issues.

With newer programmes, the questions in a process evaluation might usefully focus on aspects of establishing and delivering programme components. With more established programmes, evaluation could focus on assessing whether or not the current processes are working optimally. With ongoing programmes, process evaluation may be incorporated as a routine part of daily activities so that the programme can be continually monitored and reviewed. The frequency of monitoring can also be adjusted as needs and resources change. 
Regardless of how fully established a programme is, the first step in evaluating whether it is being implemented as intended is to identify the key components (for example, critical content areas or activities required to implement a prevention curriculum, make changes in policy, or conduct a media campaign). The second step is to then develop criteria against which the degree of implementation of these components can be judged. In many cases, these criteria will already have been discussed as part of the prioritysetting process - as outlined above in section 4.5. Finally, information will need to be collected to monitor and document each component to determine how well the actual implementation matches the proposed plan.

Annex B provides examples of the type of elements that can be considered during the process evaluation of different types of prevention activities, and lists some of the potential sources of this information. Ultimately, the process evaluation methods selected will need to be informed by the type of programme and the questions to be answered - and the degree of confidence needed in the results, as well as available resources and the level of expertise required by different evaluation approaches.

Outcome evaluation - the ultimate outcomes that intimate partner or sexual violence prevention approaches are trying to achieve are reductions in the perpetration of these types of violence, or reductions in the injuries, non-injury health impacts and deaths they cause. However, assessing these long-term changes can be difficult and costly. It often takes time to observe such changes, requiring that data be collected over long periods. This is particularly true when the behaviour or outcome of interest occurs relatively infrequently. A more realistic objective for many prevention programmes may therefore be to change the risk factors that contribute to violence (Chapter 2) with the ultimate goal of preventing violent behaviour. Whatever outcomes are selected should be based upon the theory underlying the prevention approach; the programme objectives; the extent to which the programme and its activities are fully established; and the resources available for evaluation.

Outcome evaluation specifically seeks to determine if a programme was successful in bringing about the intended changes (for example, in risk factors, behaviours, or levels of injuries, illness and deaths). The main concern when designing an outcome evaluation is to ensure that any alternative explanations for the changes observed can be ruled out to provide confidence that such changes were due to the programme and not to some other factor. This will help to ensure that resources are not wasted on ineffective or less-effective programmes.

One way to address this is to collect data on the outcome(s) of interest at multiple time intervals before, after (and sometimes during) implementation to see at what point changes occur ("time-series design"). This approach is often used to evaluate broadbased community programmes such as policy changes. The data collected are often derived from community-level sources such as community surveys or from community-level records such as the information routinely collected in surveillance or monitoring systems (see section $\mathbf{4 . 2}$ for a fuller discussion of potential data sources).

Another approach is to use "experimental" and "control" groups as part of a "controlled trial" in which the experimental group receives the programme and the control group does not. Although differences over time between the two groups could still result from other events happening simultaneously (such as other prevention activities, policy changes or community events) the use of the control group(s) will help rule out this possibility. However, this will rely upon both groups being equally exposed to the 
outside events and other activities, and it is therefore necessary to monitor the degree to which each group was exposed to these external influences.

It is also possible that the programme might "seep" into the control group and distort the results. For example, students who take part in a programme might share information they learned with students in the control group. Or a control community may be exposed to a media campaign or legislation. These effects can be minimized by selecting a control group that is geographically distant from (or otherwise unlikely to interact with) the experimental group. For example, students may be less likely to interact with students from a distant school than with students in a different class in the same school or in a different school in the same neighbourhood.

Collecting data as soon as a programme ends or very shortly afterwards will provide information on its immediate effects. Collecting "follow-up" data at some interval (or intervals) after the immediate post-programme data have been collected can help to determine whether changes are maintained or diminish once the programme ends. Follow-up data can also provide information on later changes that were not apparent immediately after the programme (sometimes called "sleeper effects"). The decision to collect follow-up data will be guided by the questions to be answered. The capacity of the programme to collect further information from participants and the availability of evaluation resources need to be addressed from the start.

Because of the severely limited evidence base for effective or promising programmes for the primary prevention of intimate partner and sexual violence, the inclusion of outcome evaluation in evaluation planning can provide valuable and much needed information. Programme evaluations for programme improvement requires some technical capacity but can be done using existing sources of information discussed above. However, a rigorous outcome evaluation to build an evidence base for prevention requires scientific expertise from the very beginning of the planning phase to ensure:

- the appropriate selection of prevention objectives;

- the development of a logic model $;^{1}$ and

- the correct choice of research design, study population(s), outcomes, data sources and methods of analysis.

As a result, partnership with an academic or research institution with the relevant expertise is necessary. Box 9 describes how a public health agency reached out to a grassroots organization to improve the evidence base for one particular programme for preventing intimate partner and sexual violence.

Ultimately, the selection of which outcome evaluation approach to take will be guided by the questions to be answered and the degree of certainty required in attributing observed effects to the programme. The benefits of each approach will need to be weighed against the practical and financial constraints of the programme. Different types of outcome evaluation may also be helpful at different programme stages. However, whatever evaluation approach is used, the routine incorporation of ongoing outcome-data collection will be needed to monitor the continued effectiveness of the programme. For example, at the beginning of a new prevention strategy, collecting preand post-programme implementation data from participants can help to determine if

\footnotetext{
1 See: CDC Evaluation Working Group: www.cdc.gov/eval/resources.htm\#logic\%20model and Centre for Health Services and Policy Research (CHSPR): A Results-Based Logic Model for Primary Health Care: www.chspr.ubc.ca/files/publications/2004/chspr04-19.pdf
} 


\section{Improving the evidence base through improved evaluation}

Concerned with the lag between the discovery of effective programmes and their widespread adoption, the United States Centers for Disease Control and Prevention decided to reach out to sexual violence prevention programmes with demonstrated realworld feasibility in order to build a scientific evidence base for the interventions used. First, existing programmes were identified based on published and unpublished documents, website searches and interviews with experts, practitioners and programme agencies. Publicly available information on each programme was supplemented with structured telephone interviews to compile summary descriptions of each programme identified.

Following an open competition for funds, four programmes, each delivered in a multisession format, were selected based on their focus on first-time male perpetration, prior experience with evaluation, commitment to using evaluation for programme improvement, and their ability to commit staff to the evaluation process. An outside evaluator then served as a facilitator, trainer and coach to help programme stakeholders design and conduct their own evaluations. This process utilized empowerment principles to build evaluation capacity among the programmes and to generate information about programme activities. Participating programmes subsequently reported substantial enhancements to their evaluation capacity, to the extent and sophistication of their evaluation practices and greater allocation of resources devoted to evaluation. Numerous examples were then provided of the successful application of evaluation findings to programme-improvement efforts.

For further information, see:

www.cdc.gov/ncipc/delta/

www.cdc.gov/ncipc/DELTA/DELTA_AAG.pdf

the approach looks promising. Positive indications would include that changes appeared to be in the right direction, of sufficient magnitude, or similar or better than other programmes targeting similar outcomes. The findings can then be used to help improve the programme. Later, a controlled trial (or randomized controlled trial) design can be used to provide more evidence that the programme was indeed contributing to the desired changes, thus building the evidence base on primary prevention.

Economic evaluation is a systematic method of assessing the impact of strategies, policies and programmes on outcomes and costs (Haddix, Teustch \& Corso, 2003). Economic evaluation can help to identify and understand the use of resources by a programme, determine what is feasible given available resources, allow for the more efficient use of resources, and plan or prioritize activities should resources be reduced or removed. In addition, administrators, funding agencies and the public are increasingly concerned about how programme costs relate to programme benefits. Economic evaluation can help demonstrate that a programme is worth the investment. For example, practitioners in the field of youth violence have been able to tell their policy-makers that a programme based on nurse home visits costs US $\$ 6142$ per family. However, by reducing the risk of youth involvement in violence and crime by $16 \%$ the programme generates savings per programme participant of about US $\$ 4600$ for the taxpayer and US $\$ 8100$ for potential victims (Aos, Miller \& Drake, 2006). Such cost-benefit analyses require the effectiveness of a programme to have been determined beforehand. Economic evaluation is usually carried out by researchers and requires methodological expertise. 


\section{Learn - and then share evidence and promising practice}

Prevention partners interested in receiving the results of evaluations should be identified in the preparatory stages. During the course of implementing and evaluating the programme, other parties may also have learned of the programme and demonstrated an interest. Presenting the results of the evaluation to various audiences may garner wider support from decision-makers and the community for a programme and for the larger goal of preventing violence. By sharing the evidence supporting the use of a particular programme with other prevention partners, local capacity can be built and practice improved. The scope, degree of detail and method of reporting evaluation results will vary depending on the interest and needs of the various audiences.

Internal audiences such as staff, volunteers, the board of directors and other stakeholders closely involved in the programme will be familiar with the objectives and expectations of the evaluation and may instead want detailed information. In this case, a verbal presentation (with accompanying visual material to illustrate key points or summarize data) that allows for discussion of the findings, and alternative interpretations and applications of the findings to the programme may be most useful. Sharing and discussing the results with the internal audience promotes investment in the programme and in the process of evaluation. To avoid the misuse of evaluation results, it is helpful to remind stakeholders of earlier agreements on the purpose of the evaluation and on how the results and recommendations would be shared and used to improve the programme.

Verbal briefings may also be appropriate for different external audiences, such as legislators and funding agencies. However, such audiences often require a written report with a description of the aim(s), rationale, activities, evaluation design and findings of the programme, possibly supplemented with anecdotes, case histories or graphics. Reports that are succinct and clear are more likely to be read. Depending on the audience, an executive summary or brief fact sheet may suffice, with interested individuals being referred to a longer and more detailed report.

Communicating findings to the media - and through it to the public at large - may require a slightly different approach. Working with the media is not complicated, but it does take planning. First, it is necessary to reach out to news media contacts in the community to begin to build relationships, and to establish the group as an expert source of information on intimate partner and sexual violence. Useful, timely and accurate new information will capture a reporter's attention. For example, offer local statistics if possible, or show how new services might be helping to reduce intimate partner and sexual violence for the benefit of the community. Develop a media contact list (using the Internet or phone book) and then determine the best method to reach reporters with the available information. Examples of products for news media outreach include:

- Press release - for timely and new information; key findings are presented at the beginning followed by supporting descriptive information; and it should be easily formatted for sending electronically.

- Media advisory - used to advise reporters to attend a photo opportunity or other event.

- Letters to the Editor - for experts sharing a specific point of view; each newspaper and other media outlet will have guidelines available on their web site on the submission process and required length. 
- Opinion-Editorial - some newspapers accept guest opinion editorials (“op-eds") and the media web sites should again be checked for details.

- Press kit - should be kept simple and include one-page fact sheets, flyers and charts; consideration should be given to making the press kit available online.

New media innovations such as blogs and Twitter can also be useful for disseminating intimate partner and sexual violence prevention messages. The Internet has increasingly become a source of up-to-date information. A brief notice can be posted to a relevant programme or agency web site, with a link provided to the full report(s). Collaborating with colleagues in the sharing of links to various programmes and reports may also be a useful option.

Sharing the programme and evaluation findings both within and between countries is an important element of developing and disseminating the knowledge and skills required for the prevention of intimate partner and sexual violence. Networks require good coordination to connect people whose prevention activities can be distributed across a range of public and private sectors. Networks can also be set up to meet local needs, and these too can link across sectors for the more efficient exchange of information on planning and action. How evaluation findings are shared - and with whom - will depend upon the focus of a programme and the community or country context. A key point in all cases is to be succinct and clear, and to tailor the reporting appropriately for each audience.

\subsection{Key messages}

To implement prevention policies and programmes, the following steps are essential:

\section{Step 1: Getting started}

Identify key partners and develop partnerships

Develop a shared vision

Develop skills and capacity in leadership and advocacy

\section{Step 2: Define and describe the nature of the problem}

Define intimate partner and sexual violence

Describe the size and nature of each problem

Develop capacity to assess health needs and health impacts

\section{Step 3: Identify potentially effective programmes with reference to the nature of the problem and the evidence base for prevention}

\section{Step 4: Develop policies and strategies}

Agree upon a framework for joint policy and strategy development

Prioritize effective programmes

\section{Step 5: Create an action plan to ensure delivery}

Agree upon the process and timetable for implementation

Agree upon and define the roles and responsibilities of partners

Develop professional skills, undertake further training and establish effective networks

\section{Step 6: Evaluate and share learning}

Plan and implement appropriate evaluation

Learn - and then share evidence and promising practice 


\section{Future research priorities and conclusions}

\section{Future research priorities}

Research is urgently needed to build the evidence base and address the current lack of information on effective programmes for primary prevention. The major constraints on research in this area are the long time scales and high costs of producing results. However, without such research it will be difficult to develop new policy that is both effective and cost effective. Gathering data on the prevalence and health outcomes of both intimate partner violence and sexual violence will be important in settings where these data are not available. It can serve to raise awareness of the existence and impact of these relatively hidden issues and to provide baseline information that can eventually be used for monitoring. To strengthen the evidence base and help develop urgently required guidelines and recommendations, the following areas should be addressed as a priority:

- Evaluate promising programmes and further develop and test potential programmes - especially in LMIC where rates of intimate partner violence are often high.

- Prioritize programmes and evaluations that focus on younger age groups since the evidence clearly suggests that this may be a more effective primary prevention approach.

- Consider new settings for primary prevention programmes. At present a disproportionate number of interventions are designed to be delivered in schools, colleges and universities. However, the individuals most at risk of perpetrating or experiencing intimate partner and sexual violence may no longer be attending school or may have difficulty engaging in school-based activities. Far more consideration should be given to the use of other venues and settings, such as the home, health-care settings, and the facilities available to community-based (including faith-based) organizations and others.

- Once the effectiveness of a programme has been determined, obtain more information on the relative cost effectiveness and the wider social and emotional benefits of specific programmes in a variety of settings. The information such studies can provide is crucial in convincing policy-makers of the importance of investing in primary prevention programmes. Ideally, such cost-effectiveness evaluations should also examine the relative cost effectiveness and benefits of programmes for the primary prevention of intimate partner and sexual violence at each of the major life stages. Having relative cost-effectiveness evidence will then help policy-makers to decide which programmes to prioritize according to their beneficial effects at different ages and in different settings. 
- Evaluations of different policies - for example, those that combine a variety of programmes - in terms of their feasibility, cost and outcomes will greatly accelerate their development and implementation in other settings.

- Although some evidence now exists in most regions on the prevalence, consequences of, and risk factors for both intimate partner and sexual violence, still more is needed. In particular, far more evidence is needed on community and societal level risk factors, such as gender norms and gender inequality; the impact of such violence on child development, health and associated outcomes using longitudinal studies, especially in LMIC; and on educational and economic outcomes.

\section{Methodological issues}

- Programme developers should be encouraged to explicitly base programmes on clearly articulated theoretical frameworks to allow the underlying mechanisms to be identified and to make replication easier.

- Determining whether or not changes in knowledge, attitudes, beliefs and behavioural intention actually result in reduced levels of intimate partner and sexual violence is an urgent need. Too often, outcome evaluations have relied upon the former measures instead of measuring the effects of a programme on the actual levels of violence.

- Follow-up periods should be longer to ensure that any beneficial effects of programmes do not fade.

- Efforts should be made to build research capacity and to work collaboratively - including with national and international agencies - to support local research and to identify the research priorities for different types of settings.

\section{Conclusions}

The evidence-based prevention of intimate partner and sexual violence is still in its early days and much remains to be accomplished. At present, only one approach has evidence supporting its effectiveness - and this only relates to intimate partner violence. The approach in question is the use of school-based programmes to prevent violence within dating relationships. Evidence is, however, emerging of the effectiveness of a number of other approaches to preventing intimate partner and sexual violence, including microfinance programmes for women combined with gender-equality education, efforts to reduce access to (and harmful use of) alcohol and changing social and cultural gender norms. Many more approaches appear to have potential, either on theoretical grounds or because they target known risk factors, but most of these have never been systematically implemented - let alone evaluated.

In the United States, the significant declines seen in intimate partner violence since the mid-1970s have been attributed to the cumulative effects of prevention interventions that target not only intimate partner violence but also child maltreatment (Smithey \& Straus, 2004). Direct robust evidence for this contention is nonetheless missing and these declines could be due to other economic, cultural and social changes. This underscores the urgent need to generate evidence of the effectiveness of primary prevention interventions for intimate partner and sexual violence. The possibility of backlash effects when implementing certain programmes - as seen in microfinance programmes for women in the absence of gender-equality education - further demonstrates the com- 
plexities that need to be understood and addressed if inadvertent harmful effects are to be avoided by well-meaning approaches.

Most of the current evidence base on prevalence, risk and protective factors, health outcomes and evidence of effectiveness has been derived in HIC, especially the United States. If future research is to inform practice and policy in any meaningful way, considerably more now needs to be known about prevention effectiveness in other settings, particularly in LMIC. Additionally, an improved evidence base needs to be built up on the variations found in different cultural and religious settings, and in rural and urban settings. Research institutions in HIC can work together with LMIC on joint research programmes that could help spread both the costs and benefits of research.

Research is needed in particular to identify and develop approaches that are most feasible and cost effective, and which significantly reduce the risk factors for intimate partner and sexual violence; the severity of their outcomes; and the frequency of their occurrence. Such research should encompass a range of different settings and degrees of integration into other services. The majority of programmes that have been evaluated so far have been implemented relatively narrowly - however, in practice, it may often be easier to incorporate activities into existing delivery structures, for example, mental health and parenting programmes integrated into existing maternal health programmes. Additionally, school-based skills programmes may best be linked to wider health-promotion programmes, for example, for addressing sexual and reproductive health, mental health, or alcohol and drug misuse, particularly among adolescents.

Although pressing, the need for evidence and further research in all these areas in no way precludes taking action now to prevent both intimate partner violence and sexual violence in all countries. Those programmes that have evidence supporting their effectiveness should be implemented and, where necessary, adapted. Those that have shown promise or appear to have potential can also play an immediate role - with strenuous efforts made to incorporate at the outset rigorous outcome evaluations. It is only by taking action and generating evidence that intimate partner and sexual violence will be prevented, and the field of evidence-based primary prevention of such violence will successfully mature. 


\section{References}

Abbey A et al. (2004). Sexual assault and alcohol consumption: what do we know about their relationship and what types of research are still needed? Aggression and Violent Behavior, 9(3):271-303.

Abrahams $\mathrm{N}$ et al. (2004). Sexual violence against intimate partners in Cape Town: prevalence and risk factors reported by men. Bulletin of the World Health Organization, 82(5):330-337.

Ackerson LK et al. (2008). Effects of individual and proximate educational context on intimate partner violence: A population-based study of women in India. American fournal of Public Health, 98(3):507-514.

Adegoke TG, Oladeji D (2008). Community norms and cultural attitudes and beliefs factors influencing violence against women of reproductive age in Nigeria. European Fournal of Scientific Research, 20:265-273.

Adi Y et al. (2007). Systematic review of the effectiveness of interventions to promote mental wellbeing in children in primary education. Report 1: universal approaches (non-violence related outcomes). London, National Institute for Health and Clinical Excellence.

Ahmed SM (2005). Intimate partner violence against women: experiences from a woman-focused development programme in Matlab, Bangladesh. Fournal of Health, Population and Nutrition, 23(1):95-101.

Ahmed S, Koenig MA, Stephenson R (2006). Effects of domestic violence on perinatal and early-childhood mortality: evidence from north India. American fournal of Public Health, 96(8):1423-1428.

doi:10.2105/AJPH.2005.066316 PMID:16809594

Ali PA, Bustamante-Gavino MI (2008). Violence against women in Pakistan: a framework for Analysis. Fournal Pakistan Medical Association, 58(4):198-203.

Amoakohene MI (2004). Violence against women in Ghana: a look at women's perceptions and review of policy and social responses. Social Science and Medicine, 59:23732385 .

Anda RF et al. (2001). Abused boys, battered mothers, and male involvement in teen pregnancy. Pediatrics, 107(2):e19.

Anderson KL (2005). Theorizing gender in intimate partner violence Research. Sex Roles, 52(11/12):853-865. 
Anderson, LA, Whiston SC (2005). Sexual assault education programs: a meta-analytic examination of their effectiveness. Psychology of Women Quarterly, 29:374-388.

Anderson P, Chisholm D, Fuhr DC (2009). Effectiveness and cost-effectiveness of policies and programmes to reduce the harm caused by alcohol. The Lancet, 373(9682):2234-2246.

Andrews G et al. (2004). Child sexual abuse. In: Ezzati M et al., eds. Comparative quantification of health risks: global and regional burden of disease attributable to selected major risk factors. Volume 2. Geneva, World Health Organization.

Aos S, Miller M, Drake E (2006). Evidence-based public policy options to reduce Future Prison Construction, Criminal Fustice Costs, and Crime Rates. Available at: www.wsipp. wa.gov/rptfiles/06-10-1201.pdf

Archer J (2000). Sex differences in aggression between heterosexual partners: a metaanalytic review. Psychological Bulletin, 126:651-680.

Archer J (2006). Cross cultural differences in physical aggression between partners: a social role analysis. Personality and Social Psychology Review, 10 (2):133-153.

Arias I, Corso P (2005). Average cost per person victimized by an intimate partner of the opposite gender: a comparison of men and women. Violence and Victims, 20 (4):379391.

Asling-Monemi K, Tabassum NR, Persson LA (2008). Violence against women and the risk of under-five mortality: analysis of community-based data from rural Bangladesh. Acta Paediatrica, 97:226-232.

doi:10.1111/j.1651-2227.2007.00597.x PMID:18254912

Babor TF et al. (2001). AUDIT, the alcohol use disorders identification test: guidelines for use in primary care, 2nd Edition. Geneva, World Health Organization.

Baldry, AC, Farrington DP (2007). Effectiveness of programs to prevent school bullying. Victims and Offenders, 2(2):183-204.

Bair-Merritt MH et al. (2010). Reducing maternal intimate partner violence after the birth of a child: a randomized controlled trial of the Hawaii Healthy Start Home Visitation Program. Archives of Pediatrics \& Adolescent Medicine, 164(1):16-23.

Barker G, Ricardo C, Nascimento M (2007). Engaging men and boys in changing genderbased inequity in health: evidence from programme interventions. Geneva, World Health Organization.

Basile KC, Hertz MF, Back SE (2007). Intimate partner violence and sexual violence victimization assessment instruments for use in healthcare settings: Version 1 . National Center for Injury Prevention and Control, Atlanta (GA), Centers for Disease Control and Prevention.

Bilukha O et al. (2005). The effectiveness of early childhood home visitation in preventing violence: a systematic review. American fournal of Preventive Medicine, 28:11-39.

Black DA et al. (1999). Partner, child abuse risk factors literature review. National Network of Family Resiliency, National Network for Health. Available at: www.nnh.org/risk

Boy A, Kulczycki A (2008). What we know about intimate partner violence in the Middle East and North Africa. Violence Against Women, 14(1):53-70. 
Boy A, Salihu HM (2004). Intimate partner violence and birth outcomes: a systematic review. International Fournal of Fertility and Women's Medicine, 49:159-164.

Boyle MH et al. (2009). Community influences on intimate partner violence in India: women's education, attitudes towards mistreatment and standards of living. Social Science and Medicine, 69(5):691-697.

Breitenbecher KH, Gidycz CA (1998). Empirical evaluation of a program designed to reduce the risk of multiple sexual victimization. Fournal of Interpersonal Violence, 13:472-488.

Breitenbecher KH, Scarce M (2001). An evaluation of the effectiveness of a sexual assault education program focusing on psychological barriers to resistance. Fournal of Interpersonal Violence, 16:387-407.

Brown L et al. (2006). Sexual violence in Lesotho. Studies in Family Planning, 37(4):269280.

Brown DW et al. (2009). Exposure to physical and sexual violence and adverse health behaviours in African children: results from the Global School-based Student Health Survey. Bulletin of the World Health Organization, 87(6):447-455.

Bruce S (2002). The "A Man" campaign: marketing social norms to men to prevent sexual assault. The report on social norms. Working paper number 5, July 2002. Little Falls (NJ), PaperClip Communications.

Campbell JC (2002). Health consequences of intimate partner violence. The Lancet, 359:1331-1336.

doi:10.1016/S0140-6736(02)08336-8 PMID:11965295

Campbell JC et al. (2008). The intersection of intimate partner violence against women and HIV/AIDS: a review. International Fournal of Injury Control and Safety Promotion, 15:221-231.

doi:10.1080/17457300802423224 PMID:19051085

CDC (2004). Sexual violence prevention: beginning the dialogue. Centers for Disease Control and Prevention.

Chaloupka FJ, Grossman M, Saffer H (2002). The effects of price on alcohol consumption and alcohol-related problems. Alcohol Research and Health, 26(I):22-34.

Champion HL, Durant RH (2001). Exposure to violence and victimization and the use of violence by adolescents in the United States. Minerva Pediatrics, 53:189-197.

Chan KL (2009). Sexual violence against women and children in Chinese societies. Trauma Violence \& Abuse, 10(1):69-85.

CIETafrica (2002). Sexual violence and HIV/AIDS: executive report on the 2002 survey. Project report PR-ZA-hn2-02. Available at: www.ciet.org/en/documents/projects_ library_docs/2006316174822.pdf (accessed 11 November 2009).

Counts DA, Brown J, Campbell J (1992). Sanctions and sanctuary: cultural perspectives on the beating of wives. Boulder (CO), Westview Press.

Currie DH (1998). Violent men or violent women: whose definition counts? In RK Bergen, ed. Issues in intimate violence, pp. 97-111. Thousand Oaks (CA), Sage. 
Dahlberg LL, Butchart A (2005). State of the science: violence prevention efforts in developing and developed countries. International fournal of Injury Control and Safety Promotion, 12(2):93-104.

Dahlberg LL, Krug EG (2002). Violence - a global public health problem. In: Krug EG et al., eds. World report on violence and health, pp. 3-21. Geneva, World Health Organization.

Dalal K, Rahman F, Jansson B (2009). Wife abuse in rural Bangladesh. Fournal of Biosocial Science, 41(5):561-573.

Davey Smith G (2000). Learning to live with complexity: ethnicity, socioeconomic position and health in Britain and the United States. American fournal of Public Health, 90:1694-1698.

Decker MR et al. (2009). Intimate partner violence functions as both a risk marker and risk factor for women's HIV infection: findings from Indian husband-wife dyads. Fournal of Acquired Immune Deficiency Syndrome, 51:593-600.

Douglas M (1998). Restriction of the hours of sale of alcohol in a small community: a beneficial impact. Australian and New Zealand Journal of Public Health, 22:714-719.

Du Mont J, Parnis D (2000). Sexual assault and legal resolution: querying the medical collection of forensic evidence. Medicine and Law, 19:779-792.

Duailibi S et al. (2007). The effect of restricting opening hours on alcohol-related violence. American Fournal of Public Health, 97:2276-2280.

Dube SR et al. (2002). Exposure to abuse, neglect, and household dysfunction among adults who witnessed intimate partner violence as children: implications for health and social services. Violence and Victims, 17(1):3-17.

Dunkle KL et al. (2004). Gender-based violence, relationship power, and risk of HIV infection in women attending antenatal clinics in South Africa. The Lancet, 363:14151421.

doi:10.1016/S0140-6736(04)16098-4 PMID:15121402

Dusenbury L et al. (1997). Nine critical elements of promising violence prevention programs. Fournal of School Health, 67:409-414.

Eckenrode J (2000). What works in nurse home visiting programs. In: Alexander G, Curtis PA, Kluger MP, eds. What works in child welfare, pp. 35-43. Washington DC, Child Welfare League of America.

Edleson J (1999). Children's witnessing of adult domestic violence. Fournal of Interpersonal Violence, 14:839-870.

Ellsberg M, Heise L (2005). Researching violence against women: a practical guide for researchers and activists. Washington DC, United States; and World Health Organization, PATH. Available at: www.path.org/files/GBV_rvaw_front.pdf

Ellsberg $\mathrm{M}$ et al. (1999). Domestic violence and emotional distress: results from a population based study. American Psychologist, 54:30-36.

Ellsberg M, Liljestrand J, Winkwist A (1997). The Nicaraguan network of women against violence: using research and action for change. Reproductive Health Matters, 5(10):82-92. 
Fabiano P et al. (2003). Engaging men as social justice allies in ending violence against women: evidence for a social norms approach. Fournal of American College Health, $52: 105-112$.

Fagan J, Browne A (1994). Violence between spouses and intimates: physical aggression between women and men in intimate relationships. In Reiss AJ, Roth JA, eds. Understanding and preventing violence: panel on the understanding and control of violent behavior. Volume 3: Social Influences, pp. 115-292. Washington DC, National Academy Press.

Farrington DP, Ttofi MM (2009). School-based programs to reduce bullying and victimization. Campbell Systematic Reviews. Oslo: Campbell Collaboration.

Fehringer JA, Hindin MJ (2009). Like parent, like child: Intergenerational transmission of partner violence in Cebu, the Philippines. Fournal of Adolescent Health, 44(4):363371.

Finkelhor D (2009). The prevention of childhood sexual abuse. The Future of Children, 19(2):169-194.

Finkelhor D, Asdigian N, Dziuba-Leatherman J (1995). The effectiveness of victimization prevention instruction: an evaluation of children's responses to actual threats and assaults. Child Abuse E Neglect, 19:141-153.

Fisher GJ (1986). College student attitudes toward forcible date rape: changes after taking a human sexuality course. Fournal of Sex Education and Therapy, 12:42-46.

Flake DF (2005). Individual, family, and community risk markers for domestic violence in Peru. Violence Against Women, 11(3):353-373.

Flay BR et al. (2005). Standards of evidence: criteria for efficacy, effectiveness and dissemination. Prevention Science, 6:151-175.

Foshee VA et al. (1996). The Safe Dates Project: theoretical basis, evaluation design, and selected baseline findings. American Fournal of Preventive Medicine 12(5):39-47.

Foshee VA et al. (1998). An evaluation of Safe Dates, an adolescent dating violence prevention program. American fournal of Public Health, 88(1):45-50.

Foshee VA et al. (2000). The Safe Dates program: 1-year follow-up results. American Fournal of Public Health, 90(10):1619-1622.

Foshee VA et al. (2004). Assessing the long-term effects of the Safe Dates program and a booster in preventing and reducing adolescent dating violence victimization and perpetration. American Fournal of Public Health, 94(4):619-624.

Foshee VA et al. (2005). Assessing the effects of the dating violence prevention program "Safe Dates" using random coefficient regression modeling. Prevention Science, 6: $245-258$.

Foshee VA et al. (2008). What accounts for demographic differences in trajectories of adolescent dating violence? An examination of intrapersonal and contextual mediators. Fournal of Adolescent Health, 42(6):596-604.

Foshee VA, Reyes ML, Wyckoff S (2009). Approaches to preventing psychological, physical, and sexual partner abuse. In O'Leary D, Woodin E, eds. Psychological and physical aggression in couples: Causes and Interventions, pp. 165-190. Washington DC, American Psychological Association. 
Fox AM et al. (2007). In their own voices: a qualitative study of women's risk for intimate partner violence and HIV in South Africa. Violence Against Women, 13:583-602.

FPH (2008). Alcohol and Public Health. Faculty of Public Health Position Statement, UK Faculty of Public Health. Available at: www.fph.org.uk

Gage AJ (2005). Women's experience of intimate partner violence in Haiti. Social Science and Medicine, 61(2):343-364.

Garcia-Moreno C et al. (2005). WHO Multi-Country study on women's health and domestic violence against women. Geneva, World Health Organization.

Garner J, Fagan J, Maxwell C (1995). Published findings from the spouse assault replication program: a critical review. Fournal of Quantitative Criminology, 11:3-28.

Gibson LE, Leitemberg H (2000). Child sexual abuse prevention programs: do they decrease the occurrence of child sexual abuse? Child Abuse \& Neglect, 24:1115-1125.

Gil-Gonzalez D et al. (2006). Alcohol and intimate partner violence: do we have enough information to act? European fournal of Public Health, 16(3):278-284.

Gil-Gonzalez D et al. (2008). Childhood experiences of violence in perpetrators as a risk factor of intimate partner violence: a systematic review. Fournal of Public Health, $30(1): 14-22$.

Glass $\mathrm{N}$ et al. (2003). Adolescent dating violence: prevalence, risk factors, health outcomes, and implications for clinical practice. Fournal of Obstetric, Gynecologic, E Neonatal Nursing, 32(2):227-238.

Go VF et al. (2003). Crossing the threshold: engendered definitions of socially acceptable domestic violence in Chennai, India. Culture, Health and Sexuality, 5:393-408.

Graham K et al., eds. (2008). Unhappy hours: alcohol and partner aggression in the Americas. Washington DC, Pan American Health Organization.

Gutierres SE, Van Puymbroeck C (2006). Childhood and adult violence in the lives of women who misuse substances. Aggression and Violent Behavior, 11(5):497-513.

Haddix AC, Teustch SM, Corso PS (2003). Prevention effectiveness: a guide to decision analysis and economic evaluation. New York, Oxford University Press.

Hahn RA et al. (2007). Effectiveness of universal school-based programs to prevent violent and aggressive behavior: a systematic review. American fournal of Preventive Medicine 33(2):S114-S129.

Harwell TS, Spence MR (2000). Population surveillance for physical violence among adult men and women, Montana 1998. American fournal of Preventive Medicine, 19(4): $321-324$.

Heise L (1998). Violence against women: An integrated, ecological framework. Violence Against Women, 4:262-490.

Heise L, Ellsberg M, Gottemoeller M (1999). Ending violence against women. (Population Reports, Series L, No. 11). Baltimore (MD), Johns Hopkins University School of Public Health, Center for Communications Programs.

Heise L, Garcia-Moreno C (2002). Violence by intimate partners. In: Krug EG et al., eds. World report on violence and health, pp. 87-121. Geneva, World Health Organization. 
Hickman LJ, Jaycox LH, Aronoff J (2004). Dating violence among adolescents: prevalence, gender distribution, and prevention program effectiveness. Trauma Violence $\mathcal{E}$ Abuse, 5(2):123-142.

Holt S, Buckley H, Whelan S (2008). The impact of exposure to domestic violence on children and young people. Child Abuse \& Neglect, 32:797-810.

Hussain R, Khan A (2008). Women's perceptions and experiences of sexual violence in marital relationships and its effect on reproductive health. Health Care for Women International, 29:468-483.

Ilika AL (2005). Women's perception of partner violence in a rural Igbo community. African Fournal of Reproductive Health, 9:77-88.

Jespersen AF, Lalumiere ML, Seto MC (2009). Sexual abuse history among adult sex offenders and non-sex offenders: a meta-analysis. Child Abuse E Neglect, 33(3):179192.

Jewkes R (2002). Intimate partner violence: causes and prevention. The Lancet, 359 (9315):1423-1429.

Jewkes R, Morrell R (2010). Gender and sexuality: emerging perspectives from the heterosexual epidemic in South Africa and implications for HIV risk and prevention. Fournal of the International AIDS Society, 13:6.

Jewkes R, Sen P, Garcia-Moreno C (2002). Sexual violence. In: Krug EG et al., eds. World report on violence and health, pp. 149-181. Geneva, World Health Organization.

Jewkes $\mathrm{R}$ et al. (1999). He must give me money he mustn't beat me. Violence against women in three South African Provinces. Medical Research Council Technical Report, Medical Research Council, Pretoria.

Jewkes R et al. (2001). Relationship dynamics and teenage pregnancy in South Africa. Social Science and Medicine, 52 (5):733-744.

Jewkes R et al. (2006). Rape perpetration by young, rural South African men: prevalence, patterns and risk factors. Social Science and Medicine, 63(11):2949-2961.

Jewkes R et al. (2008). Impact of stepping stones on incidence of HIV and HSV-2 and sexual behaviour in rural South Africa: cluster randomised controlled trial. British Medical Fournal, 337: 383-387.

Jewkes R et al. (2009) Understanding men's health and use of violence: interface of rape and HIV in South Africa. Medical Research Council Technical Report, Medical Research Council, Pretoria.

Jeyaseelan L et al. (2004). World studies of abuse in the family environment - risk factors for physical intimate partner violence. International Fournal of Injury Control and Safety Promotion, 11(2):117-124.

Johnson KB, Das MB (2009). Spousal violence in Bangladesh as reported by men: prevalence and risk factors. Fournal of Interpersonal Violence, 24(6):977-995.

Kabeer N (2001). Conflicts over credit: Re-evaluating the empowerment potential of loans to women in rural Bangladesh. World Development, 29(1):63-84.

Katz J (2006). The Macho paradox: why some men hurt women and how all men can help. Napierville (IL), Sourcebooks. 
Kim J et al. (2009). Assessing the incremental effects of combining economic and health interventions: the IMAGE study in South Africa. Bulletin of the World Health Organization, 87(11):824-832.

Kitzmann KM et al. (2003). Child witnesses to domestic violence: a meta-analytic review. Fournal of Consultative Clinical Psychology, 71(2):339-352.

Knox KL et al. (2003). Risk of suicide and related adverse outcomes after exposure to a suicide prevention programme in the US Air Force: cohort study. British Medical Fournal, 327:1376-1381.

Koenig MA, Saifuddin A, Mian Bazle H, and Khorshed Alam Mozumder ABM (2003) Women's status and domestic violence in rural Bangladesh: individual- and community-level effects. Demography, 40(2):269-288.

Koenig MA et al. (2004). Coercive sex in rural Uganda: prevalence and associated risk factors. Social Science and Medicine, 58(4):787-798.

Koenig MA et al. (2006). Individual and contextual determinants of domestic violence in north India. American fournal of Public Health, 96(1):132-138.

Krug EG et al. (2002). Eds. World report on violence and health. Geneva, World Health Organization.

Lankester T (1992). Setting up community health programmes: a practical manual for use in developing countries. London, Macmillan Press.

Laranjeira R, Hinkly D (2002). Evaluation of alcohol outlet density and its relation with violence. Revista de Saúde Pública, 36(4):455-461.

Last JM (2001). A dictionary of epidemiology, 4th Edition, International Epidemiological Association. New York, Oxford University Press.

Levinson D (1989). Family violence in cross-cultural perspective. Thousand Oaks (CA), Sage.

Liu M, Chan C (1999). Enduring violence and staying in marriage. Stories of battered women in rural China. Violence Against Women, 5:1469-1492.

Lösel F, Beelmann A. (2003). Effects of child skills training in preventing antisocial behaviour: a systematic review of randomized evaluations. Annals of the American Academy of Political and Social Science, 587:84-109.

Maman S et al. (2000). The intersection of HIV and violence: directions for future research and interventions. Social Science and Medicine, 50(4):459-478.

Mangioloi R (2009). The impact of child sexual abuse on health: a systematic review of reviews. Clinical Psychology Review, 29(7):647-657.

Markowitz S (2000). The price of alcohol, wife abuse, and husband abuse. Southern Economic fournal, 67:279-303.

Marshall AD, Panuzio J, Taft CT (2005). Intimate partner violence among military veterans and active duty servicemen. Clinical Psychology Review, 25(7):862-876.

Martin EK, Taft CT, Resick PA (2007). A review of marital rape. Aggression and Violent Behavior, 12(3):329-347.

McGuigan WM, Pratt CC (2001). The Predictive impact of domestic violence on three types of child maltreatment. Child Abuse $\mathcal{G}$ Neglect, 25:869-883. 
Meltzer H et al. (2003). Persistence, onset, risk factors and outcomes of childhood mental disorders. Office for National Statistics. HMSO, London.

Mercy JA et al. (2002). Youth violence. In: Krug EG et al., eds. World report on violence and health, pp. 23-56. Geneva, World Health Organization.

Mikton C, Butchart A (2009). Child maltreatment prevention: a systematic review of reviews. Bulletin of the World Health Organization, 87(5):353-361.

Mirrlees-Black C (1999). Domestic violence: findings from a new British Crime Survey self-completion questionnaire. Home Office Research Study 191. London, Home Office. Available at: www.homeoffice.gov.uk/rds/pdfs/hors191.pdf

Mitra A, Singh P (2007). Human capital attainment and gender empowerment: the Kerala paradox. Social Science Quarterly, 88:1227-1242.

Morrison A, Ellsberg M, Bott S (2007). Addressing gender-based violence: a critical review of interventions. The World Bank Observer, 22(1):25-51.

Morrison S et al. (2004). An evidence-based review of sexual assault preventive intervention programs. Department of Justice. Available at: www.ncjrs.gov/pdffiles1/nij/ grants/207262.pdf

National Collaborating Centre for Mental Health (2007). Antenatal and postnatal mental health. NICE Clinical Guideline no 45. NICE, London.

Olds DL, Sadler L, Kitzman H (2007). Programs for parents of infants and toddlers: recent evidence from randomized trials. Fournal of Child Psychology and Psychiatry, 48:355-391.

Paine K et al. (2002). Before we were sleeping, now we are awake: preliminary evaluation of the Stepping Stones sexual health programme in The Gambia. African Fournal of AIDS Research, 1(1):39-40.

Palmer CA (1999). Rapid appraisal of needs in reproductive health care in southern Sudan: qualitative study. British Medical Fournal, 319:743-748.

Petersen I, Bhana A, McKay M (2005). Sexual violence and youth in South Africa: the need for community based prevention interventions. Child Abuse \& Neglect, 29:12331248 .

Philpart et al. (2009). Prevalence and risk factors of gender-based violence committed by male college students in Awassa, Ethiopia. Violence and Victims, 24(1):122-136.

Plichta SB, Falik M (2001). Prevalence of violence and its implications for women's health. Women's Health Issues, 11:244-258.

doi:10.1016/S1049-3867(01)00085-8 PMID:11336864

Rahman A (1999). Women and microcredit in rural Bangladesh: anthropological study of the rhetoric and realities of Grameen Bank lending. Boulder (CO), Westview Press.

Ramiro LS, Hassan F, Peedicayil A (2004). Risk markers of severe psychological violence against women: a WorldSAFE multi-country study. International fournal of Injury Control and Safety Promotion, 11(2):131-137.

Reza A et al. (2009). Sexual violence and its health consequences for female children in Swaziland: a cluster survey study. The Lancet, 373(9679):1966-1972.

Rhyne E (2001). Mainstreaming microfinance: how lending to the poor began, grew, and came of age in Bolivia. Green Haven (CT), Kumarian Press. 
Romans S et al. (2007). Who is most at risk for intimate partner violence? A Canadian population-based study. Fournal of Interpersonal Violence, 22:1495-1514.

Room R et al. (2003). Alcohol in developing societies: a public health approach. Helsinki and Geneva, Finnish Foundation for Alcohol Studies and World Health Organization.

Russo NF, Pirlott A (2006). Gender-based violence: concepts, methods, and findings. Annals of the New York Academy of Science, 1087:178-205.

Schewe PA (2007). Interventions to prevent sexual violence. In: Doll L et al., eds. Handbook of injury and violence prevention, pp.183-201. New York (NY), Springer.

Schopper D, Lormand J-D, Waxweiler R (2006). Developing policies to prevent injuries and violence: guidelines for policy-makers and planners. Geneva, World Health Organization. Available at: www.who.int/violence_injury_prevention/publications/39919_oms_ br_2.pdf

Schuler SR et al. (1996). Credit programs, patriarchy and men's violence against women in rural Bangladesh. Social Science and Medicine, 43(12):1729-1742.

Schwartz JP et al. (2006). Unhealthy parenting and potential mediators as contributing factors to future intimate violence: a review of the literature. Trauma Violence $\mathbb{E}$ Abuse, 7(3):206-221.

Sheehan D (2008). Alcohol, health and wider social impact. SE Regional Public Health Group Information Series. Department of Health, England.

Shipway L (2004). Domestic violence: a handbook for health professionals. London, Routledge.

Silverman JG, Raj A, Clements K (2004). Dating violence and associated sexual risk and pregnancy among adolescent girls in the United States. Pediatrics, 114(2):e220-e225.

Silverman JG et al. (2009). Maternal experiences of intimate partner violence and child morbidity in Bangladesh: evidence from a national Bangladeshi sample. Archives of Pediatrics E Adolescent Medicine, 163(8):768-770.

Skowron EA, Reinemann DHS (2005). Psychological interventions for child maltreatment: A meta-analysis. Psychotherapy: Theory, Research, Practice, and Training, 42:52-71.

Slap GB et al. (2003). Sexual behaviour of adolescents in Nigeria: cross sectional survey of secondary school students. British Medical fournal, 326(7379):15.

Smith JD et al. (2004). The effectiveness of whole-school antibullying programs: a synthesis of evaluation research. School Psychology Review, 33:548-561.

Smith PH, White JW, Holland LJ (2003). A longitudinal perspective on dating violence among adolescent and college-age women. American fournal of Public Health, 93(7):1104-1109.

Smith Fawzi MC et al. (2005). Factors associated with forced sex among women accessing health services in rural Haiti: implications for the prevention of HIV infection and other sexually transmitted diseases. Social Science and Medicine, 60:679-689.

Smithey M, Straus MA (2004). Primary prevention of intimate partner violence. In Kury H, Obergfell-Fuchs J, eds. Crime prevention - new approaches, pp. 239-276. Mainz, Weisser Ring Gemeinnutzige Verlags-GmbH. 
Söchting I, Fairbrother N, Koch WJ (2004). Sexual assault of women: Prevention efforts and risk factors. Violence Against Women, 10(1):73-93.

Solórzano I, Abaunza H, Molina C (2000). Evaluación de impacto de la campaña contra las mujeres un desastre que los hombres si podemos evitar [Impact evaluation of the campaign violence against women: a disaster we can prevent as men]. Managua, CANTERA.

Stith SM et al. (2004). Intimate partner physical abuse perpetration and victimization risk factors: a meta-analytic review. Aggression and Violent Behavior, 10(1):65-98.

Straus MA (1999). The controversy over domestic violence by women: a methodological, theoretical, and sociology of science analysis. In Arriaga X, Oskamp S, eds. Violence in intimate relationships, pp. 17-44. Thousand Oaks (CA), Sage.

Straus MA (2009). Gender symmetry in partner violence: the evidence and the implications for primary prevention and treatment. In Lutzker JR, Whitaker DJ, eds. Prevention of partner violence. Washington DC, American Psychological Association.

Stuart GL et al. (2003). Reductions in marital violence following treatment for alcohol dependence. Fournal of Interpersonal Violence, 18:1113-1131.

Swart LA et al. (2002). Violence in adolescents' romantic relationships: findings from a survey amongst school-going youth in a South African community. Fournal of Adolescence, 25(4):385-395.

Taft CT et al. (2009). Intimate partner violence against African American women: an examination of the socio-cultural context. Aggression and Violent Behavior, 14:50-58.

Tang CS, Lai BP (2008). A review of empirical literature on the prevalence and risk markers of male-on-female intimate partner violence in contemporary China, 19872006. Aggression and Violent Behavior, 13(1):10-28.

Testa M (2004). The role of substance use in male-to-female physical and sexual violence: a brief review and recommendations for future research. Fournal of Interpersonal Violence, 19(12):1494-1505.

Tjaden P, Thoennes N (2006). Extent, nature, and consequences of rape victimization: findings from the National Violence Against Women Survey. Washington DC, US Department of Justice. Available at: www.ojp.usdoj.gov/nij/pubs-sum/210346.htm

Usdin S et al. (2005). Achieving social change on gender-based violence: a report on the impact evaluation of Soul City's fourth series. Social Science and Medicine, 61(11):24342445.

Uthman OA, Lawoko S, Moradi T (2009). Factors associated with attitudes towards intimate partner violence against women: a comparative analysis of 17 sub-Saharan countries. BMC International Health and Human Rights, 9:14.

Vest JR et al. (2002). Multistate analysis of factors associated with intimate partner violence. American Fournal of Preventive Medicine, 22(3):156-164.

Vos $\mathrm{T}$ et al. (2006). Measuring the impact of intimate partner violence on the health of women in Victoria, Australia. Bulletin of the World Health Organization, 84(9):739744.

Vung ND, Krantz G (2009). Childhood experiences of interparental violence as a risk factor for intimate partner violence: a population-based study from northern Vietnam. Fournal of Epidemiology and Community Health, 63:708-714. 
Walby S (2004). The cost of domestic violence. Women and Equality Unit, DTI. London. Available at: www.lancs.ac.uk/fass/sociology/papers/walby-costdomesticviolence. pdf

Welbourn A (2009). Stepping Stones - list of surveys and reports to 2006 and some quotes from Stepping Stones users around the world. Some brief notes prepared for the UNAIDS pre-Think Tank Meeting on Evaluation Strategies for Prevention Interventions, Geneva. Available at: www.steppingstonesfeedback.org/resources/22/Welbourn_ Quotes_UNAIDS_Presentation_2009.pdf

Welsh P (1997). Hacia una masculinidad sin violencia en las relaciones de pareja [Towards masculinity without partner violence]. Managua, CANTERA.

Whitaker DJ et al. (2006). A critical review of interventions for the primary prevention of perpetration of partner violence. Aggression and Violent Behavior, 11:151-166.

Whitaker DJ, Baker CK, Arias I (2007). Interventions to prevent intimate partner violence. In: Doll L et al., eds. Handbook of injury and violence prevention, pp.203-223. New York (NY), Springer.

Winslow CEA (1920). The untilled fields of public health. Science, 51(1306):23-33.

WHO-ISPCAN (2006). Preventing child maltreatment: a guide to taking action and generating evidence. Available at: www.who.int/violence_injury_prevention/violence/activities/child_maltreatment/en/index.html

WHO (2001). Putting women first: ethical and safety recommendations for research on domestic violence against women. Geneva, World Health Organization. Available at: www.who.int/gender/violence/en/womenfirtseng.pdf

WHO/UNAIDS (2010). Addressing violence against women and HIV/AIDS: What works? Geneva, World Health Organization. Available at www.who.int.reproductivehealth/topics/violence.

Williams JR et al. (2008). Female perpetration of violence in heterosexual intimate relationships: adolescence though adulthood. Trauma Violence \& Abuse, 9(4):227-249.

Wolfe DA et al. (2003). The effects of children's exposure to domestic violence: a metaanalysis and critique. Clinical Child and Family Psychology Review, 6(3):171-187.

Wolfe DA et al. (2003). Dating violence prevention with at-risk youth: a controlled outcome evaluation. Fournal of Consulting and Clinical Psychology, 71(2):279-291.

Wolfe DA et al. (2009). A school-based program to prevent adolescent dating violence: a cluster randomized trial. Archives of Paediatrics $\mathcal{E}$ Adolescent Medicine, 163(8):692699.

$\mathrm{Xu} \mathrm{X}$ et al. (2005). Prevalence of and risk factors for intimate partner violence in China. American Fournal of Public Health, 95:78-85. 


\section{Operational definitions}

For measuring the magnitude of intimate partner violence and sexual violence, it is important to have operational definitions based upon specific behaviours. This helps to avoid subjective interpretations and allows for comparability across sites. Having operational definitions is necessary both for population-based epidemiological surveys, and for monitoring cases that present to health facilities, the police or other services.

\section{Population-based surveys}

In population-based surveys of intimate partner and sexual violence, respondents are usually asked from a list of specific acts whether they have experienced any abuse. Research has shown that behaviour-specific questions - such as: have you ever been forced to have sexual intercourse against your will? - produce higher rates of positive responses than questions asking people whether they have been "abused" or "raped". They also allow for an assessment of relative severity. Follow-up questions asking how often these behaviours take place and for how long also allow researchers to better assess the frequency of the abuse. Physical acts that are more severe than slapping, pushing or throwing an object at a person are generally defined in studies as "severe violence", though some observers object to the defining of severity solely according to the act. A series of practical tools has been developed (Basile, Hertz \& Back, 2007) that helps to quantify both a victim's experience of abuse and perpetrator behaviour with standardized and validated questionnaires designed for cross-sectional surveys. Box 10 shows the operational definitions used in the WHO Multi-country study on women's health and domestic violence against women (Garcia-Moreno et al., 2005). The WHO instrument has a set of core questions that have been used in many countries in a comparable way, with some countries introducing variations according to local need. The set of core questions and variations related to domestic violence can be found at: www.who. int/gender/violence/who_multicountry_study/en/. Similar behaviour-specific questions can be developed for physical and sexual abuse by perpetrators other than intimate partners. This quantitative data should be complemented by qualitative data that can help to contextualize and better understand the violence.

\section{Service-based monitoring and ICD-10 codes}

For the purposes of surveillance and monitoring the use of services, standardized definitions for case reporting are necessary. The international standard diagnostic classification for all general epidemiological purposes and many health management purposes is the International Classification of Diseases (ICD), tenth edition (11th revision currently in progress). 
BOX 10

\section{Operational definitions used to measure physical and sexual violence, emotional abuse and controlling behaviours by an intimate partner}

\section{Physical violence by an intimate partner}

\section{Moderate violence:}

- Was slapped or had something thrown at her that could hurt her

- Was pushed or shoved or (in 2 sites) had hair pulled

\section{Severe violence:}

Was hit with fist or something else that could hurt

- Was kicked, dragged or beaten up

- Was choked or burnt on purpose

- Perpetrator threatened to use or actually used a gun, knife or other weapon against her

\section{Sexual violence by an intimate partner}

- Was physically forced to have sexual intercourse when she did not want to

- Had sexual intercourse when she did not want to because she was afraid of what partner might do

Was forced to do something sexual that she found degrading or humiliating

\section{Emotionally abusive acts by an intimate partner}

- Was insulted or made to feel bad about herself

- Was belittled or humiliated in front of other people

- Perpetrator had done things to scare or intimidate her on purpose, e.g., by the way he looked at her, by yelling or smashing things

- Perpetrator had threatened to hurt someone she cared about

\section{Controlling behaviours by an intimate partner}

- Tried to keep her from seeing friends

- Tried to restrict contact with her family of birth

- Insisted on knowing where she was at all times

- Ignored her and treated her indifferently

- Got angry if she spoke with another man

- Was often suspicious that she was unfaithful

- Expected her to ask permission before seeking health care for herself 
Most countries have issued official guidelines for coding and reporting, based on either the 9th or 10th revision of ICD. However, such guidelines for the classification of intimate partner violence and sexual violence cases might be used only in a limited number of facilities and then very selectively - the resulting coding may therefore not be reliable. In such cases, it will probably be helpful to set up a working group to improve classification and to develop an agreed set of guidelines on how to assign ICD codes to known and suspected cases of intimate partner violence and sexual violence.

The assignment of ICD codes to a case is performed only after medical professionals have provided care and have done their best to reach a definitive conclusion as to the external causes of the presenting problem. Classification of cause of death is usually based on coroner reports and inquest findings. For non-fatal cases, the classification of cause of injury is generally based on information from the files that record hospital inpatient discharges and emergency department visits.

The two main components of an ICD classification concern the nature of the presenting condition (for instance, traumatic subdural haemorrhage) and its external cause. Information on the relationship of the perpetrator to the victim is often not included in reporting making the documentation of, for example, injuries caused by an intimate partner particularly challenging.

Intimate partner violence and sexual violence can have a wide range of health consequences (Chapter 1). While it may be possible to identify certain presenting conditions that are more suggestive of intimate partner violence and sexual violence than others, it is through the allocation of an external cause - or E-Code - that an individual case is classified as known or suspected intimate partner violence or sexual violence.

ICD-10 codes for assault are X85-Y09 and include:

- YO5: Sexual assault by bodily force, includes rape (attempted), sodomy (attempted);

- Y06: Neglect and abandonment, includes by spouse or partner, by parent, by acquaintance or friend, by other specified persons, by unspecified person; and

- Y07: Other maltreatment syndromes, includes mental cruelty, physical abuse, sexual abuse, torture by: spouse or partner, by parent, by acquaintance or friend, by official authorities, by other specified persons, by unspecified person, excludes neglect and abandonment and sexual assault by bodily force.

Those assigning ICD codes and completing death certificates must be encouraged to document the relationship between the perpetrator and the victim where known. 


\section{ANNEX B \\ Prevention activities that can be used for process evaluation and potential sources of information on such activities}

\begin{tabular}{|c|c|}
\hline Activity & Potential sources of information \\
\hline \multicolumn{2}{|c|}{ ADVOCACY TO DEVELOP OR IMPROVE INTIMATE PARTNER AND SEXUAL VIOLENCE LEGISLATION } \\
\hline $\begin{array}{l}\text { - Number of letters sent } \\
\text { - Number of people contacted } \\
\text { - Public information meetings held and number of } \\
\text { attendees } \\
\text { - Press releases prepared/released }\end{array}$ & $\begin{array}{l}\text { - Files of letters } \\
\text { - Records of phone and in-person contacts } \\
\text { - Calendars } \\
\text { - Records and files }\end{array}$ \\
\hline \multicolumn{2}{|l|}{ PUBLIC INFORMATION CAMPAIGN } \\
\hline $\begin{array}{l}\text { - Messages developed and tested } \\
\text { - Subscribers/listeners/viewers when each } \\
\text { - Nessage was placed } \\
\text { - Press releases distributed/picked up by the press } \\
\text { - Interviews/talks requested } \\
\text { - People exposed to and recalling the information }\end{array}$ & $\begin{array}{l}\text { - Files and focus-group results } \\
\text { - Institution reports } \\
\text { - Institution reports } \\
\text { - Log and media searches } \\
\text { - Log } \\
\text { - Community surveys }\end{array}$ \\
\hline \multicolumn{2}{|l|}{ COALITION BUILDING } \\
\hline $\begin{array}{l}\text { - Groups/agencies/communities/people contacted } \\
\text { - Meetings held, and members participating } \\
\text { - Number/type of actions generated/implemented } \\
\text { - Interactions among members of coalition }\end{array}$ & $\begin{array}{l}\text { - Log } \\
\text { - Calendars and meeting minutes } \\
\text { - Seeting minutes } \\
\text { - Surveys and interviews }\end{array}$ \\
\hline \multicolumn{2}{|l|}{ MICROFINANCE PROGRAMME } \\
\hline $\begin{array}{l}\text { - Number of applications } \\
\text { - Number, size, location and business type of loans } \\
\text { approved } \\
\text { - Number of loans repaid }\end{array}$ & - Pre-designed data-collection forms \\
\hline \multicolumn{2}{|l|}{ CURRICULUM } \\
\hline $\begin{array}{l}\text { - Qualifications and training of staff } \\
\text { - Recruitment activities and coverage } \\
\text { - Inquiries received and how enquirers had heard } \\
\text { - Number/demographics of those enrolled, } \\
\text { - attending and dropping out } \\
\text { - Differences between non-participants, } \\
\text { - } \text { - Barticipants, drop-outs and target population } \\
\text { - Number of sessions/modules delivered } \\
\text { - Coverage of, and time allotted to, key content } \\
\text { - } \text { - Quality of delivery } \\
\text { - Participant satisfaction/recommendations for } \\
\text { - Participant recall of messages } \\
\text { - Staff satisfaction with programme and other staff, } \\
\text { and recommendations for improvement }\end{array}$ & $\begin{array}{l}\text { - Files and hiring records } \\
\text { - Observation } \\
\text { - Log and public-awareness surveys } \\
\text { - Telephone log } \\
\text { - Enrolment-application and attendance sheets } \\
\text { - Follow-up survey of drop-outs/non-participants } \\
\text { - Staff log/reports } \\
\text { - Observation } \\
\text { - Survey } \\
\text { - Observation or survey } \\
\text { - Survey or interview } \\
\text { - Survey or interview } \\
\text { - Survey or interview }\end{array}$ \\
\hline
\end{tabular}


For more information, please contact:

Department of Violence and Injury Prevention and Disability World Health Organization

Avenue Appia 20, CH-1211 Geneva 27, Switzerland

Tel +41-22-791-2064

Fax $+41-22-791-4489$

E-mail: violenceprevention@who.int

www.who.int/violence_injury_prevention

Department of Reproductive Health and Research

World Health Organization

Avenue Appia 20, CH-1211 Geneva 27, Switzerland

Tel +41-22-791-4136

Fax $+41-22-791-4171$

E-mail: reproductivehealth@who.int

www.who.int/reproductivehealth 